\title{
Re-evaluation of \\ Monitored Retrievable Storage Concepts
}

\author{
J. F. Fletcher \\ R. I. Smith
}

April 1989

Prepared for the U.S. Department of Energy under Contract DE-AC06-76RLO 1830

Pacific Northwest Laboratory

Operated for the U.S. Department of Energy by Battelle Memorial Institute 


\title{
DISCLAIMER
}

This report was prepared as an account of work sponsored by an agency of the United States Government. Neither the United States Government nor any agency thereof, nor Battelle Memorial Institute, nor any or their employees, makes any warranty, expressed or implied, or assumes any legal liability or responsibility for the accuracy, completeness, or usefulness of any information, apparatus, product, or process disclosed, or represents that its use would not infringe privately owned rights. Reference herein to any specific commercial product, process, or service by trade name, trademark, manufacturer, or otherwise does not necessarily constitute or imply its endorsement, recommendation, or favoring by the United States Government or any agency thereof, or Battelle Memorial Institute. The views and opinions of authors expressed herein do not necessarily state or reflect those of the United States Government or any agency thereof.

\author{
PACIFIC NORTHWEST LABORATORY \\ operated by \\ BATTELLE MEMORIAL INSTITUTE \\ for the \\ UNITED STATES DEPARTMENT OF ENERGY \\ under Contract DE-ACO6-76RLO 1830
}

\begin{tabular}{|c|c|}
\hline \multicolumn{2}{|c|}{ Printed in the United States of America } \\
\hline \multicolumn{2}{|c|}{ Avaitable from } \\
\hline \multicolumn{2}{|c|}{ National Technical Information Service } \\
\hline \multicolumn{2}{|c|}{ United States Department of Commerce } \\
\hline \multicolumn{2}{|c|}{5285 Port Royal Road } \\
\hline \multicolumn{2}{|c|}{ 5pringfield, Virginia 22161} \\
\hline \multicolumn{2}{|c|}{ NTIS Price Codes } \\
\hline \multicolumn{2}{|c|}{ Microfiche A01 } \\
\hline \multicolumn{2}{|c|}{ Printed Copy } \\
\hline & Price \\
\hline Pages & Codes \\
\hline $007-025$ & $\mathrm{AO2}$ \\
\hline $026-050$ & $\mathrm{A03}$ \\
\hline $051-075$ & A04 \\
\hline $076-100$ & A0S \\
\hline $101-125$ & $A 06$ \\
\hline $126-150$ & A07 \\
\hline 151-175 & A.08 \\
\hline $176-200$ & A09 \\
\hline $201-225$ & A 10 \\
\hline $226-250$ & A11 \\
\hline $251-275$ & $\mathrm{~A} \uparrow 2$ \\
\hline $276-300$ & A13 \\
\hline
\end{tabular}




\title{
RE-EVALUATION OF MONITORED RETRIEVABLE
} STORAGE CONCEPTS

\author{
J. F. Fletcher \\ R. I. Smith
}

Apri) 1989

Prepared for the U.S. Oepartment of Energy under Contract DE-ACO6-76RLO 1830

Pacific Northwest Laboratory Richland, Washington 99352 
3

1 


\section{EXECUTIVE SUMMARY}

In 1983, as a prelude to the monitored retrievable storage (MRS) faci1ity conceptual design, the Pacific Northwest Laboratory (PNL) conducted an evaluation for the U.S. Department of Energy (DOE) that examined alternative concepts for storing spent LWR fuel and high-level wastes from fuel reprocessing. The evaluation was made considering nine concepts for dry away-from-reactor storage. PNL engaged subcontractors to provide preliminary conceptual designs of an MRS facility utilizing each of the alternate concepts. These designs were based on a conceptual MRS receiving and handling building design provided by the Kaiser Engineers Hanford Company. The storage concepts were developed based on identical parameters for construction and operating schedules, operating rates, and size of the storage facility. The nine concepts evaluated were:

- Concrete storage cask

- Concrete cask-in-trench

- Metal casks (transportable and stationary)

- Field drywell

In the initial evaluation, the storage concepts were rated against seven criteria used to define the relative suitability to the waste system. The criteria selected and against which each storage concept was rated were:

- Safety and licensability

- Environmental impact

- Socioeconomic impact

- Siting requirements

Employing several teams of experts experienced in waste management technology, from PNL and elsewhere in industry, academic institutions and DOE Taboratories, and using state-of-the-art appications of Delphi techniques and hierarchical analysis, these criteria were weighted for importance to MRS storage, the concepts were rated against the criteria, and weighted composite 
rankings were developed defining the order of preference for use of the storage concepts. As a check on the validity of the numerical rankings, a "pairwise" comparison of technical attributes and of advantages and disadvantages of the concepts was performed to verify the selection against the criteria.

The results of this evaluation were reported in PNL-5176 (Triplett and Smith 1984) and in DOE/RL-84-2 (DOE 1984), with the concrete cask selected as the preferred concept and the field drywell as a backup. These two concepts were used throughout the conceptual design effort that resulted in DOE's MRS Submission to Congress in March 1987 (DOE 1987a).

With the subsequent enactment of the Nuclear Waste Policy Amendments Act (NWPAA) in December 1987, DOE determined that a review of the results of the earlier concept selection process was needed. This review was intended to update the data that formed the basis for that selection, and to determine whether recent changes in the mission, role, or anticipated construction schedule of an MRS facility might introduce changes that would affect the validity of the earlier selection.

The purpose and scope of the re-evaluation did not require a repetition of the expert-based examinations used earlier. Instead, it was based on more detailed technical review by a small group, focusing on changes that had occurred since the initial evaluation was made. Two additional storage concepts--the water pool and the horizontal modular storage vault (NUHOMS system)--were ranked along with the original nine. The original nine concepts and the added two conceptual designs were modified as appropriate for a scenario with storage capacity for 15,000 MTU of spent fuel. Costs, area requirements, and technical and historical data pertaining to MRS storage were updated for each concept.

The criteria for concept assessment were reviewed and updated. Each concept was ranked against all other concepts for its performance under each criterion. The criterion weights developed during the 1984 study were applied to the rankings under each criterion and a preference ranking of the storage concepts was computed. The sensitivity of the final preference ranking to the values of the criterion weights was also examined for a reasonable range of values for the weights. Alternative preference rankings were computed and compared, with the result that the ranking of the top concepts is 
essentially insensitive to the weights assigned to the criteria, over the range of values examined. Finally, a "pair-wise" comparison of technical attributes, advantages, and disadvantages for each concept was made to provide a check on the numerical ranking process.

This re-evaluation, reported herein, resulted in the following order of preference for selection of an MRS technology:

1. Concrete cask (sealed storage cask)

2. Field drywell

3. Open-cycle vault

4. Water pool

5. Storage-only metal cask/NUHOMS horizontal modular vault.

As a result of this re-evaluation, it was determined that any of the concepts examined could be successfully utilized for an MRS facility. However, the order of preference for concept selection listed above was derived from the evaluation. Exceptions to this order of preference could arise for some storage scenarios. As an example, it may be desirable to construct an MRS facility in a series of phases; the first phase would do little but receive and store fuel, with other handling and preparation capabilities being added later. For such an application, the transportable storage cask, despite its higher costs, would be unexcelled as a choice for storage in the first phase of operations; concrete casks or another concept would be used in later phases. 



\section{CONTENTS}

EXECUTIVE SUMMARY ..................

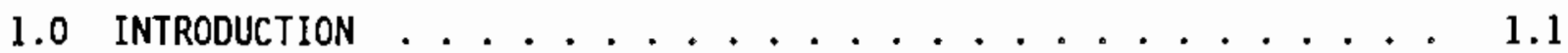

1.1 INITIAL EVALUATION OF MRS STORAGE CONCEPTS . . . . ... 1.1

1.2 NEED tO UPDATE CONCEPT EVALUATION $\ldots \ldots \ldots \ldots$

2.0 SUMMARY OF RESULTS . . . . . . . . . . . . . 2.1

3.0 METHODOLOGY OF THE EVALUATION REVIEW ........... 3.1

4.0 RESULTS OF THE MULTI-ATTRIBUTE COMPARISON . . . . . . . . . 4.1

4.1 SAFETY AND LICENSABILITY . . . . . . . . . . . . 4.1

4.1.1 Ease of Conformance with Licensing Requirements... 4.1

4.1 .2 Criticality Safety ........... 4.2

4.1 .3 Ease of Monitoring .......... 4.2

4.1 .4 Containment Integrity . . . . . . . . 4.3

4.1.5 Accident/Malfunction Recovery ........ 4.3

4.1 .6 Design Testing . . . . . . . . . . 4.4

4.1.7 Penetrability and Security ........ 4.4

4.1 .8 Accountability .............. 4.5

4.1.9 Previous Licensing Experience . . . . . . . 4.5

4.1.10 Ranking of Concepts for Safety and Licensing . . . 4.5

4.2 ENVIRONMENTAL IMPACT . . . . . . . . . . . . 4.7

4.2.1 Radioactivity Release . . . . . . . . 4.7

4.2 .2 Storage Area Size . . . . . . . . 4.8

4.2.3 Recoverability of Area . . . . . . . . 4.9

4.2.4 Ranking of Concepts for Environmental Impact . . . 4.10 
4.3 SOCIOECONOMIC IMPACT ..................... 4.10

4.3.1 Aesthetic Considerations ........... 4.11

4.3.2 Labor Force Impact . . . . . . . . . 4.11

4.3 .3 Economic Impact . . . . . . . . . . 4.1]

4.3.4 Ranking of Concepts for Socioeconomic Impact . . . 4.11

4.4 SITING REQUIREMENTS . . . . . . . . . . . 4.12

4.4 .1 Land Requirements . . . . . . . . 4.12

4.4.2 Geological Requirements........... 4.13

4.4.3 Hydrological Requirements ........... . 4.14

4.4 .4 Resource Requirements ............ 4.14

4.4.5 Ranking for Siting Requirements ......... 4.14

4.5 COST AND COST SENSITIVITY . . . . . . . . . . 4.14

4.5.1 Life-Cycle Costs ............. . 4.15

4.5 .2 Cost Sensitivity . . . . . . . . . 4.17

4.5.3 Confidence in Cost Estimate ......... 4.18

4.5.4 Concept Ranking for Cost . . . . . . . 4.18

4.6 CONCEPT MATURITY . . . . . . . . . . . . . . . 4.19

4.6.1 Concept Development ........... 4.20

4.6.2 Research and Development Requirements....... 4.21

4.6 .3 Conservatism Needed ............ 4.22

4.6 .4 Deployment Time . . . . . . . . . . . . 4.22

4.6 .5 Storage Retrievability . . . . . . . 4.26

4.6.6 Engineering Simplicity ........... 4.28

4.6.7 Concept Ranking for Maturity ......... 4.30

4.7 FLEXIBILITY . . . . . . . . . . . . . . 4.31

4.7 .1 Site Adaptability . . . . . . . . . 4.32 
4.7.2 Expandability of Throughput Rate and Capacity ... 4.32

4.7.3 Waste Form Sensitivity . . . . . . . . . 4.33

4.7 .4 Heat Load Sensitivity. . . . . . . . . . 4.34

4.7.5 Recovery of Capital Assets . . . . . . . 4.35

4.7.6 Critical Resource Consumption ........ 4.35

4.7.7 Suitability for Phased MRS Introduction . . . . 4.36

4.7.8 Suitability for Use in Long-Term Storage . . . . . 4.37

4.7.9 Concept Ranking for Flexibility ......... 4.38

5.0 COMPOSITE RANKING OF CONCEPTS . . . . . . . . . 5.1

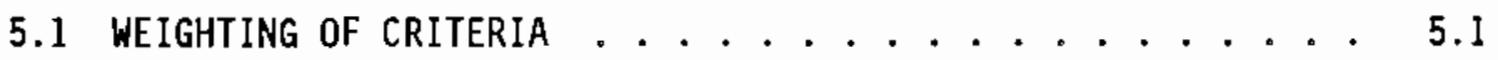

5.2 NORMALIZED CONCEPT RANKING . . . . . . . . . 5.2

5.3 SENSITIVITY OF RANKING TO CRITERION WEIGHTS . . . . . 5.3

5.3.1 Variations in Assigned Criterion Weights .... 5.3

5.3.2 Utilization of 11-Position Criterion Ranking . . . 5.3

5.3.3 Results of the Sensitivity Analyses . . . . . . 5.4

5.4 RANKING VERIFICATION ................... 5.5

5.4.1 Concrete Cask . . . . . . . . . . 5.6

5.4 .2 Field Drywett . . . . . . . . . . . 5.7

5.4 .3 0pen-Cycle Vault . . . . . . . . . . . 5.9

5.4 .4 Water Pool .............. 5.10

5.4.5 Stationary Metal Cask . . . . . . . . . . 5.11

5.4.6 NUHOMS Horizontal Modular Vault . . . . . . . . 5.13

5.4.7 Concrete Cask-in-Trench . . . . . . . . 5.14

5.4.8 Transportable Metal Cask .......... 5.15

5.4 .9 Closed-Cycle Vault . . . . . . . . . 5.16

5.4.10 Tunnel Drywel1 . . . . . . . . . . . . 5.17 
5.4.11 Tunnel-Rack Vault . . . . . . . . . 5.18

6.0 CONCLUSIONS AND RECOMMENDATIONS FOR STORAGE CONCEPTS $\ldots \ldots .6 .1$

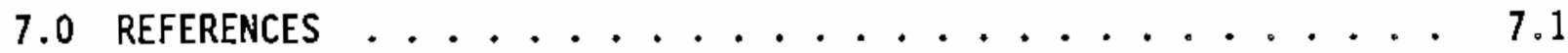

APPENDIX A - COSTS AND RELATED PARAMETERS OF STORAGE CONCEPTS . . . . A.l

APPENDIX B - DESCRIPTIONS OF CANDIDATE CONCEPTS FOR MRS . . . . B B.1

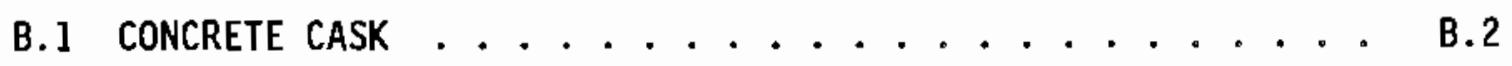

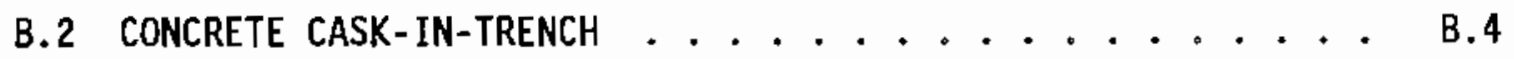

B.3 METAL STORAgE CASK . . . . . . . . . . B.5

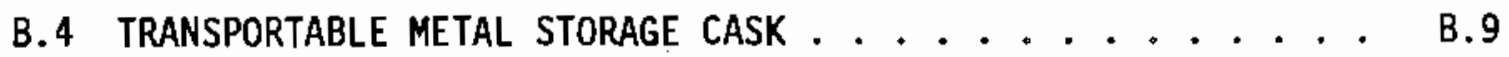

B.5 FIELD DRYWELL . . . . . . . . . . . . . B.9

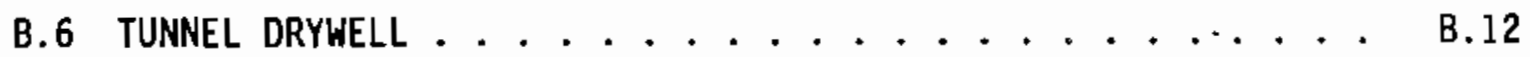

B.7 OPEN-CYCLE VAULT . . . . . . . . . . B.12

B.8 CLOSED-CYCLE VAULT . . . . . . . . . . B.15

B.9 TUNNEL-RACK VAULT . . . . . . . . . . . B.18

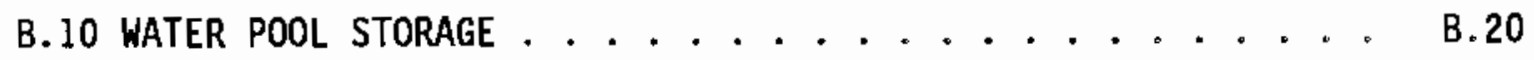

B.1I MODULAR HORIZONTAL VAULT ............ B. 21 


\section{FIGURES}

B.1 Concrete Storage Cask ..................... B.

B.2 Concrete Cask-In-Trench . . . . . . . . . . B.6

B.3 Typical Metal Storage Cask . . . . . . . . . . B.8

B.4 Field Drywell Installation .............. B.11

B.5 Tunnel Drywell . . . . . . . . . . . . B.13

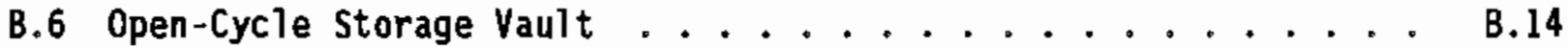

B.7 Closed-Cycle Storage Vault . . . . . . . . . . B.16

B.8 Tunnel-Rack Vault . . . . . . . . . . . . B.18

B.9 Modular Horizontal Vault ............... B.23 


\section{TABLES}

2.1 Order of Preference for Concept Selection . . . . . . . . 2.2

3.1 MRS Storage Concept Ranking Criteria and Descriptors . . . . 3.2

4.1 Concept Ranking for Safety and Licensability . . . . . . 4.6

4.2 Storage Facility Area Requirements for MRS Concepts . . . . . 4.9

4.3 Concept Ranking for Environmental Impact .......... 4.10

4.4 Concept Ranking for Socioeconomic Impact . . . . . . . . . . 4.12

4.5 Concept Ranking for Siting Requirements . . . . . . . . . 4.15

4.6 Life-Cycle Costs for Storage Concepts . . . . . . . . . 4.16

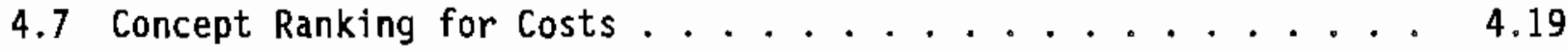

4.8a Estimated Deployment Times for Storage Concepts . . . . . . . 4.24

4.8b Estimated Deployment Times for Storage Concepts Assuming Separate Licensing of Storage Facility . . . . . . . . . 4.24

4.8c Storage Capacities Provided During Initial Construction Phase . . 4.25

4.9 Concept Ranking for Maturity ... . . . . . . . . 4.30

4.10 Concept Ranking for Flexibility. . . . . . . . . . 4.38

5.1 Assigned Weighting for Concept Evaluation Criteria . . . . . 5.2

5.2 Normalized Rankings from Multi-Attribute Evaluation . . . . . 5.3

5.3 Values of Criterion Weights Used in the Sensitivity Analyses ..................... 5.4

5.4 Results of the Sensitivity Analyses . . . . . . . . . 5.5

6.1 Order of Preference for Concept Selection . . . . . . . . . 6.3

A.l Sensitivity of Concept Rankings to Weighting of Criteria and Criterion Ranking Procedure--Original Weighting and

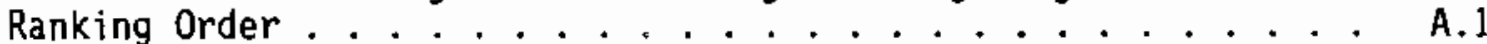

A.2 Sensitivity of Concept Rankings to Weighting of Criteria and Criterion Ranking Procedure--Equal Weighting, Original Ranking Order 
A.3 Sensitivity of Concept Rankings to Weighting of Criteria and Criterion Ranking Procedure--Reconstructed Wejghting

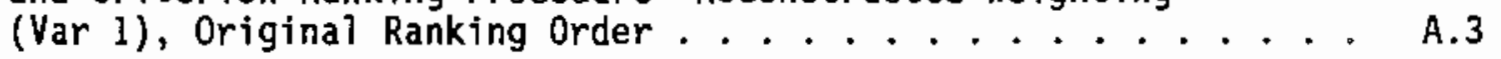

A.4 Sensitivity of Concept Rankings to Weighting of Criteria and Criterion Ranking Procedure--Reconstructed Weighting (Var 2), Original Ranking Order................. A

A.5 Sensitivity of Concept Rankings to Weighting of Criteria and Criterion Ranking Procedure--Original Weighting, Forced 11-Rank Series .................. A.5

A.6 Sensitivity of Concept Rankings to Weighting of Criteria and Criterion Ranking Procedure--Equal Weighting, Forced 11-Rank Series

A.7 Sensitivity of Concept Rankings to Weighting of Criteria and Criterion Ranking Procedure--Reconstructed Weighting (Var 1), Forced 11-Rank Series . . . . . . . . . . . .

A.8 Sensitivity of Concept Rankings to Weighting of Criteria and Criterion Ranking Procedure--Reconstructed Weighting (Var 2), Forced 11-Rank Series ..............

A.9 Comparisons of Storage Costs and Required Storage Areas . . . . A.9

A.10 MRS Storage Deployment Times . . . . . . . . . . . . A.10

A.11 Cost/Area Estimate for Concrete Cask Option . . . . . . . . . . A.11

A.12 Cost/Area Estimate for Concrete Cask-in-Trench Option . . . . . A.13

A.13 Cost/Area Estimate for Field Orywell Option (Original

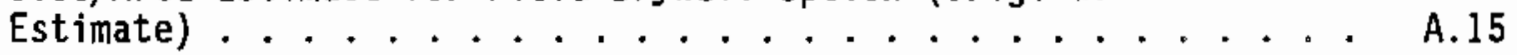

A.14 Cost/Area Estimate for Field Drywe11 Option (from MRS Conceptuat Design) ............... A.17

A.15 Cost/Area Estimate for Tunnel Drywell Option . . . . . . . . A.19

A.16 Cost/Area Estimate for Storage-Only Metal Cask Option . . . . . A.21

A.17 Cost/Area Estimate for Transportable Metal Cask Option . . . . . A.23

A. 18 Cost/Area Estimate for Dpen-Cycle Vault Option . . . . . . . . A.25

A. 19 Cost/Area Estimate for Closed-Cycle Vault Option . . . . . . . A.27

A.20 Cost/Area Estimate for Tunnel-Rack Vault Option . . . . . . . . A.29

A.21 Cost/Area Estimate for Modular Horizontal Vault Option . . . . A.31 
A.22 Cost/Area Estimate for Water Poot Option ......... A.33

B.l Characteristics of Typical Metal Storage Casks for Spent Fuet ................... B.7 


\subsection{INTRODUCTION}

In 1983, the Pacific Northwest Laboratory (PNL) performed an evaluation of monitoried retrievable storage (MRS) concepts for the U.S. Department of Energy (DOE). The evaluation examined alternative concepts for storage of spent LWR fuel and high-level radioactive wastes from fuel reprocessing. The results of that evaluation were reported in PNL-5176 (Triplett and Smith 1984). The storage concepts selected during the PNL-5176 evaluation were used throughout the conceptual design effort that resulted in DOE's MRS Submission to Congress in March 1987 (DOE 1987a).

With the subsequent enactment of the Nuclear Waste Policy Amendments Act (NWPAA) in December 1987, a review of the earlier concept selection was considered to be needed. This review was intended to update the data that formed the basis for that selection, and to determine whether recent changes in the mission, role, or permissible construction period of an MRS facility might introduce changes that would affect the validity of the earlier selection.

\subsection{INITIAL EVALUATION OF MRS STORAGE CONCEPTS}

The initial evaluation was made considering eight concepts for dry, away-from-reactor storage. A ninth concept was in effect synthesized by considering one of the eight concepts (metal casks) for storage only and for both storage and transportation of the spent fuet.

PNL engaged several subcontractors to provide preliminary conceptua] designs of an MRS facility utilizing each of the alternate concepts. As a first step, the Kaiser Engineers Hanford Company was engaged to provide a conceptual MRS receiving and handling building (Kaiser 1984). The storage concepts were developed based on Kaiser's design and on identical parameters for construction and operating schedules, operating rates, and size of the storage facility. The subcontractors and the concepts they evaluated were:

- Boeing Engineering Company

- Concrete storage casks (BEC 1983a)

- Open-cycle vauit (BEC 1983b) 
- Concrete cask-in-trench (BEC 1983c)

- GA Technologies

- Closed-cycle vault (Washington and Ganley 1984)

- Tunnel rack vault (Morrisette and Ganley 1984)

- Westinghouse Electric Corporation, Waste Technology Services Division

- Metal casks (storage only) (WEC 1983a)

- Transportable metal casks (WEC 1983b)

- Open-field drywells (WEC 1983c)

- Tunnel drywells (WEC 1983d)

The concepts, after normalization, were ranked with respect to seven different criteria relating to their feasibility for use as storage facilities. The criteria considered were:

- Safety and licensabitity

- Environmental impact

- Socioeconomic impact

- Siting requirements

The ranking was performed by a committee of experts drawn from different disciplines related to waste management from within PNL. This ranking was based on data developed by the concept evaluation subcontractors and from other available information. Discriminating factors were developed to define each of these criteria, and the storage concepts were evaluated and numerically graded for their conformance with each factor. These grades were accumulated into rankings for each of the criteria. Criterion rankings developed by each committee member were statistically combined into a single set of rankings for each concept.

Weighting, or relative importance, of each criterion was established by a second, independent committee of experts through a modified Delphi approach wherein individual matrices of importance of the criteria to the waste management system were constructed. Each committee member assigned a weight to each of the criteria based on his developed matrix. The weights for the 
criteria developed by each committee member were then statistically combined into a single set of weights using the so-called Analytic Hierarchy Process (Saaty 1980).

The rankings by criterion for each concept were multiplied by the appropriate weighting factor for each criterion and the products summed to provide a composite rank, which was then transposed into an ordinal ranking of the concepts. Sensitivity analyses were applied to the ranking to assess its applicability. Finally, a detailed "pairwise" comparison of each concept against each of the others was carried out to verify the order of ranking.

Based on the results of the study, the concrete cask concept was selected by DOE as the preferred technology for MRS conceptual design, and the field drywell was selected as the backup concept. The field drywe 11 was also taken through the conceptual design phase.

\subsection{NEED TO UPDATE CONCEPT EVALUATION}

In order to provide the best possible data to the DOE, the prior evaluation was reviewed and restated in terms of today's level of knowledge.

Several factors were involved in the decision to perform this review. These included:

- Additional information has been developed since the original evaluation, through efforts in DOE programs and those of utilities and utility groups.

- Additional storage concepts have been developed, and some are being adopted, for at-reactor storage. Comparison of these concepts with those considered previously will add to the depth of information made available to the DOE, and will insure that potential storage candidates are not overlooked in the review.

- Recent changes in the OCRWM program resulting from enactment of the NWPAA may make modification of MRS implementation activities desirable to minimize time required until the initiation of spent fuel acceptance. One such modification is the "phased" introduction of MRS, providing early storage capability prior to fullfeature operation of the facility. The compatibility of the storage concepts to such mission variants is an important item of additional information which the present review attempts to provide. 
.

.

. 1

$\cdot$

$\because$ 


\subsection{SUMMARY OF RESULTS}

The initial evaluation process for selection of monitored retrievable storage (MRS) concepts, performed in late 1983 by Triplett and Smith (1984), resulted in selection of the concrete cask and field drywell, respectively, as the primary and backup concepts to be developed in the conceptual design effort.

Recently, the enactment of the Nuclear Waste Policy Amendments Act (NWPAA) by Congress, and its signing into 1 aw by the President, has mandated significant changes in the federal waste management system. Meeting these changes may involve significant changes in the time and method of MRS deve1opment and of the role MRS may play in the future. For example, one possible scenario would involve rapid, phased development of an initial MRS facility to allow early acceptance of fuel from utilities, with subsequent addition of the capability for preparing fuel for emplacement in the repository.

To ascertain the effects of such changes on MRS needs, and to investigate storage concepts most compatible with changed deployment timing and possible new functions for MRS, the storage concept selection process was repeated, following the course of the prior analysis but with a view to the changes that might evolve. Like the prior analysis, this evaluation centered on a multi-attribute analysis technique considering a range of characteristics required of a nuclear waste storage facility. As before, the multiattribute analysis was backed up by extensive comparisons of the characteristics of each of the storage concepts considered.

The evaluation resulted in selection of the concrete cask concept as the preferred storage technology for development, reinforcing the choice made earlier. Additionally, the field drywell was selected for recommendation as backup methodology; it is recommended that its development be carried along with that of the concrete cask until the point where definitive design of the system is started.

Each of the eleven storage concepts evaluated in this study was indicated to be suitable for use in an MRS system. However, the concrete cask and field drywell were indicated by the evaluation to be the most suited and 
cost-effective over the range of attributes examined. The other concepts were judged to have lower applicability in one or more of those attributes. Some promising concepts had insufficient development or operating history to assure timely construction and reliable operation; others would be difficult to expand rapidly if storage needs increased; still other had features that could restrict the availability of sites. The overall preference ratings of the concepts considered are summarized in Table 2.1.

Details of the normalization of concept rankings from which this order of preference was derived are given in Appendix $A$ and summarized in Table 5.2. The normalized rankings show that the top concepts in Table 2.1, the concrete cask, field drywe11, open-cycle vault, water pool, stationary metal cask, and NUHOMS horizontal vault, were very close in the composite rankings.

One of the proposed MRS functions to be examined is the "tailoring" of repository containers that vary little in the heat generation rates of the contained fue1. The ability for random retrieval of fuel--common to all the first five concepts in Table 2.1--may be important for the adequacy of this tailoring. All of these concepts allow ready access to individual assemblies or canisters of fuel (as canistered consolidated rods or as canistered or

TABLE 2.1. Order of Preference for Concept Selection

\begin{tabular}{|c|c|}
\hline $\begin{array}{l}\text { Order of } \\
\text { Preference }\end{array}$ & Concept \\
\hline 1 & Concrete Cask \\
\hline 2 & Field Drywell \\
\hline 3 & Open-Cycle Vault \\
\hline 4 & Water Pool \\
\hline $\left.\begin{array}{l}5 \\
5\end{array}\right\}$ tie & $\begin{array}{l}\text { Stationary (storage only) Metal Cask } \\
\text { NUHOMS Horizontal Vault }\end{array}$ \\
\hline 7 & Concrete Cask-in-Trench \\
\hline 8 & Transportab]e Metal Cask \\
\hline 9 & Closed-Cycle Vault \\
\hline 10 & Tunnel Drywe11 \\
\hline 11 & Tunnel-Rack Vault \\
\hline
\end{tabular}


bare integral assemblies) with relatively little effort. Combined with lag storage capability in the reference receiving and handling (R\&H) building design, adequate flexibility for age-tailoring should be available with any of the first five concepts. Other concepts (except the transportable metal cask) entail progressively greater difficulties in rapid, repetitive retrieval of specific canisters or assemblies.

If further analysis were to show that greater precision in the tailoring were needed, involving intensive retrieval and substitution of fuel, the open-cycle vault might be preferred. It allows rapid, random selection of any canister in storage, and is capable of being "close-coupled" with the R\&H building so that transit time between the storage location and the R\&H packaging areas can be minimized. A simple system of overhead cranes or transfer carts may suffice for fuel movements in such a system.

On the other hand, a decision to store spent fuel as integral assemblies, with any consolidation and canistering performed at the time of shipment, might favor storage in a water pool. Pool storage would permit the same random selection of fuel as the open-cycle vault, on an assembly-byassembly basis. Retrieval from a pool would likely be slower than from a vault, but if it were performed at the head end of a disassembly operation a slower retrieval rate might be acceptable. Contamination resulting from storage of bare fuel assemblies could also be easier to control with use of a pool. Pool storage would be less favored, however, if the period of storage were extended considerably; the higher operating costs for a pool would disfavor pool storage under these conditions. Dry storage of fue 1 is important to meeting the Nuclear Waste Policy Act (NWPA) direction that requires capability for "continuous monitoring, management and maintenance of...spent fue 1 and waste for the foreseeable future."

Overa11, the greatest flexibility for use of storage at the MRS facility, in view of the uncertainty both of timing and of role of MRS, is achieved with use of the preferred concept, the concrete cask, or its alternate, the field drywell. 


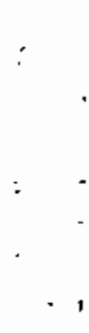

. . 


\subsection{METHODOLOGY OF THE EVALUATION REVIEW}

The methodology of the present review of monitored retrievable storage (MRS) concepts followed that of the original evaluation (Triplett and Smith 1984) in simplified form. The same list of criteria was used, and the criteria were again subdivided into descriptors, which were compared against the current state of knowledge of characteristics of the storage alternatives. A listing of the criteria used in the ranking of concepts, and their descriptors, is given in Table 3.1. As is shown in the table, descriptors were added to the criterion of flexibility to include the suitability of a concept in supporting phased construction of an MRS facitity, and its suitability for long-term storage.

The original evaluation followed a ful1, rigorous multi-attribute approach involving a team of experts selected from various disciplines within the Pacific Northwest Laboratory (PNL); the procedure used is described in Triplett and Smith (1984). The present re-evaluation involved primarily updating of information and consideration of two additional concepts. Repetition of the initial evaluation in its entirety was not required for this incremental adjustment, and the scope of the re-evaluation did not permit the use of a team of experts such as was employed in the initial evaluation. Therefore, a simpler method was adopted for re-evaluation of the concepts. This method primarily used the authors' engineering judgment, and coordination of judgment of others familiar with waste management requirements, on the impact of the new information on the relative merits of the concepts for use in an MRS facility.

Four specific MRS design attributes were examined in the re-evaluation, to conform to the requirements of the MRS System Studies Task C (Storage Concepts for the MRS Facility). These included:

- the ability to be integrated with at-reactor storage

- the ability to support a repository emplacenent strategy based on heattailoring of the waste packages

- the ability to be integrated with a waste packaging facility

- the adaptability for phased MRS development. 
IABLE 3.1. MRS Storage Concept Ranking Criteria and Descriptors

\section{Safety/Licensability}

Ease of Conformance with

Licensing Requirements

Criticality Safety

Ease of Monitoring

Containment Integrity

Accident/Malfunction Recoverability

Design Testing

Penetrability and Security

Accountability

Previous Licensing Experience

Environmental Impact

Radioactivity Release

Storage Area Size

Recoverability of Area

Socioeconomic Impact

Aesthetic Considerations

Labor Force Impact

Economic Impact

Siting Requirements

Land Requirements

Geological Requirements

Hydrological Requirements

Resource Requirements
Cost

Life-Cycle Costs

Cost Sensitivity

Cost Estimating Confidence

Concept Maturity

Concept Development

R\&D Requirements

Conservatism Needed

Deployment Time

Storage Retrievability

Engineering Simplicity

Flexibility

Site Adaptability

Expandability of Throughput Rate and Capacity

Sensitivity to Waste Form

Sensitivity to Heat Load

Recoverability of Capital Assets

Critical Resource Consumption and Recovery

Suitability for Phased Deployment*

Suitability for Long-Term Storage*

NOTE: Descriptors marked $\left(^{*}\right)$ were added to the initial items listed in Triplett and Smith (1984). 
The first three of these attributes were implicitly contained in the descriptors included in the initial evaluation, particularly in the Concept Maturity and Flexibility criteria. Only the fourth attribute, that of adaptability for phased MRS development, was explicitly added to the list of descriptors. An additional descriptor, that of suitability for long-term storage, was aiso added to "cover bases" in the event a future need for such evaluation should develop.

Following the rankings of the concepts for each of the criteria, an overall ranking of concepts was made by applying the weighting factors described in Triplett and Smith (1984). Each criterion was assigned a fractional weighting factor (adopted from the initial evaluation), and rankings for each concept for a given criterion were multiplied by the weighting factor assigned to that criterion. The products for each criterion, for a given concept, were summed to provide an overall ranking, which was then normalized. The sensitivity of this preference ranking to the values of the weights assigned to each criterion was examined by varying these values over reasonable ranges and recalculating the rankings.

The final preference ranking was reviewed to assure the reasonableness of that ranking by performing a pair-wise comparison of all pairs of concepts. Each pair was compared for each criterion and its descriptions, and included consideration of specific advantages and disadvantages for each concept.

In order to update the evaluation, the database for each storage concept in the original evaluation was modified as appropriate to reflect current status of system maturity, selection for use, costs, etc. Two new alternatives were added to the comparison: water storage pools and horizontal modular vaults (the latter is marketed as the NUHOMS system). The water pool represents an old, established storage technology that has raised interest recently as a potential storage candidate, and the NUHOMS system has been chosen by two U.S. utilities for at-reactor storage of spent fue1. In view of the lack of data on these concepts from the earlier evaluation, equivalent data was gathered from current sources (NUTECH 1985) and from recent 
Battelle-Northwest evaluation projects to the extent it was available. As before, the data were normalized to comparable storage situations.

In the initial evaluation, the comparisons of costs, schedules and area requirements included a complete MRS facility, including the R\&H building and all support facilities. For the present review, the scope was limited to only the storage facility and those support functions directly affecting storage (except for licensing time requirements, which normally involve licensing of the complete facility). While there is no fundamental difference resulting from the scopes of comparison, the more direct comparison used herein demonstrates more clearly the differences among the storage facilities themselves.

Life-cycie costs and required storage areas were recalculated, for a 15,000-MTU storage system, for each of the nine original concepts and for the two added systems. Design and construction schedules also were restated for the storage-only cases; these were taken from the schedules submitted by the original evaluation subcontractors. Data for the water pool concept were taken from internal Battelle studies. NUHOMS vault system data were taken from vendor information, from a published topical report (NUTECH 1985), and from internal Battelle studies. The cost, schedule, and area data are presented in Appendix A. Additional, detailed descriptions that were developed for the initial evaluation were reviewed. Pertinent information from that study was updated, and information on the added concepts was included. These data are included in the text of appropriate sections of this report.

The review was based on a totaT MRS capacity of 15,000 MTU, to establish compatibility with the earlier evaluation. A simplified annual operating schedule was assumed, including: a) loading of the storage field at 3,000 MTU per year for five years, from 2003 through 2007, to a total of $15,000 \mathrm{MTU}$; b) storage of the fuel for 17 years, through the year 2024, with gradual reduction of the storage inventory to 9,000 MTU; and c) unloading of the storage fjeld at 3,000 MTU per year over a three-year period, from 2025 through 2027. Results based on this scenario should be valid for other scenarios centering on the 15,000 MTU storage inventory. 
The scenario used in this review involved a fundamental change in the assumed handling of transportable (dual purpose) storage casks. Usually these casks are treated as a minority constituent of the storage field, rather than as the primary storage vehicle. A transportable storage cask received from a reactor would be transported directly to the storage field without opening; after the storage period it would be shipped directly to the repository. No opening of the cask, or handling of the contained fuel, would be performed.

In the present review, the MRS facility is viewed as the primary facility for consolidating spent fuel into canisters ready for subsequent loading into emplacement containers. In considering the transportable storage cask concept, spent fuel received at MRS in any cask (transportable storage cask or dedicated shipping cask) is removed and prepared for the repository. Following preparation, all fuel to be stored is loaded into transportable casks and placed in the storage field. At the end of the storage period, the casks are shipped directly to the repository. Thus, this concept offers system benefits in avoidance of the waste handling and cask reloading costs and of purchase of MRS-to-repository shipping casks. However, the saving from avoidance of purchasing the MRS-to-repository shipping casks benefits the transportation system rather than MRS itself, and was not counted as a savings in storage costs. Only the cost savings resulting from avoidance of waste handling and cask reloading in the direct shipping of storage casks to the repository was claimed as an MRS benefit. 
4

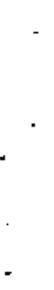

$+$

-

$\because$

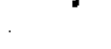

. 


\subsection{RESULTS OF THE MULTI - ATTRIBUTE COMPARISON}

The results of the review of multi-attribute comparisons of the monitored retrievable storage (MRS) concepts are given in this section. These results are discussed primarily as differences from those reached in the earlier evaluation (Triplett and Smith 1984). The earlier evaluation was judged to remain valid with the exception of the noted differences. The rationale for changes made in the ranking of concepts is discussed in this section and in Section 5 .

\subsection{SAFETY AND LICENSABILITY}

In conformance with nuclear standards, the criterion of safety is paramount in any selection of operating equipment. Assurance of licensability, derived from safety of the equipment, is important in minimizing delays in the licensing process that might otherwise seriously delay deployment of an MRS facility, whose worth to the system hinges on its early availability.

\subsubsection{Ease of Conformance with Licensing Requirements}

The original nine concepts were ranked for this factor in the initial evaluation on the basis of 1) system complexity; 2) availability of data from testing, demonstration or operational experience; 3 ) effects of equipment failure on safety of operation; 4) methods and effectiveness of ventilation and cooling systems; 5) susceptibility to disabling accidents; 6) available margins of safety in operations; and 7) protection of operating staff against radiation exposure. The conclusions of the reference evaluation as to the safety and licensability remains valid, with the following changes:

- Both the concrete storage cask and the field drywell concepts have undergone conceptual design evaluation in the MRS program to date. Both concepts appear licensable with some additional data confirmation. One topical report has been submitted to NRC, and docketed, for a concrete cask design (NUPAC 1987).

- Metal casks have been licensed for at-reactor storage of spent fuel at Virginia Power Surry site, thus demonstrating conformance with licensing requirements. However, no casks have as yet been licensed in the U.S. for shipment after a period of storage. A 
significant question as yet unanswered is the requirement for recertification of a cask for shipment after a significant period in storage, and how this requirement can be satisfied for a loaded and sealed cask.

- A topical report has been submitted to NRC by the Foster-WheeTer Corporation, and docketed, for an open-cycle vault (FW 1987), sized for at-reactor storage applications but similar in configuration to the one (BEC 1983b) included in this review and the initial evaluation. Both the Foster-Wheeler and Boeing concepts are directly derived from a vault concept developed in Britain by the British General Electric Company (GEC).

- Both the added concepts (water pools and modular horizontal vaults) have been 1 icensed for storage under 10 CFR 72. The pool at the Morris, Illinois, Fuel Storage Facility was licensed for away-fromreactor storage in 1982 (NRC 1982); before that time a11 pools were 1 icensed under 10 CFR 50 . The NUHOMS horizontal modular vault system was licensed for storage at the Carolina Power and Light Company's H. B. Robinson site in 1987, and licensing of this concept for the Oconee site of Duke Power was recently granted.

\subsubsection{Criticality Safety}

The previous evaluation indicated that all the concepts then considered can be designed and built to minimize the potential for occurrence of a criticality event, but that differences existed in the ease of assuring criticality safety over a wide range of events, including natural phenomena such as tornados or flooding. Since all the concepts are capable of being critically safe, the earlier concept ranking was based on the relative ease of attaining assured safety from critical events. No change in this basis was noted for the concepts previously covered. For the added concepts, criticality can be precluded in pools by appropriate design of the storage racks for the material being stored. For the NUHOMS concept, administrative procedures, supporting calculations, and use of added poison material when necessary are used to assure non-criticality. Allowance for burnup credit, not considered in the earlier evaluation, would not affect the relative ranking of the storage concepts.

\subsubsection{Ease of Monitoring}

The initial evaluation was based on the ability to detect and locate leaking canisters to permit retrieval for repair or encapsulation, and for ease of accountability of fuel in storage. That evaluation remains valid for 
the covered concepts. The NUHOMS system is amenable to monitoring of the individual storage canisters, each of which contains several spent fuel canisters. Pool storage is not well adapted to identification of leakage from individual fuel assemblies or canisters, but the visibility of all assemblies (or canisters) in storage in a pool enhances the ease of accountability.

\subsubsection{Containment Integrity}

This factor considers the ability of the storage concepts to protect against physical damage during handling operations or during storage that might result in radioactive releases, and the ability to contain such releases as might occur. All concepts were deemed to be licensable from this aspect, but to vary in the ease of demonstrating licensability. Surface storage devices were judged more susceptible to damage than the below-surface concepts or those where storage or handling operations are confined within protective buildings. The evaluation previously performed remains valid. of the added systems, the pool has been demonstrated to afford low probability of radioactive releases and ready recoverability from radiation release. In the NUHOMS system, field handling of the heavy (12-ton) storage canisters in loading and unloading the vault modules may make the system more susceptible to radionuclide releases in the storage field, where containment of any release would be difficult. However, overall probabilities of such releases appear low.

\subsubsection{Accident/Malfunction Recovery}

The ability to recover from accidents or malfunctions is important in assessing the safety and operability of a storage system. Simplicity of both the fuel transport and storage systems was paramount in judging recoverability; complexity can result in both greater chances of component failure and difficulty in recovery. Results of the initial evaluation appear valid except that, with appropriate design, the open-cycle vault concept should be equivalent to drywell systems in recoverability from accidents and malfunctions. Pools have been shown to be amenable to recovery from fajlure situations. The fuel handling in a pool is simple and manually controlled; furthermore, although a poot is "active" and requires continual operation of 
the cooling and cleanup systems, the large inventory of water provides inertia that provides ample time'for repairs and recovery. For the NUHOMS system, as discussed above, recovery after transfer operation accidents may be more difficult because of the heavy weights being handled and the open-air environment.

\subsubsection{Design Testing}

Continued testing of metal casks under the CSFM program has verified their feasibility for storage, as has the licensing of metal-cask storage at the Surry plant. Prior test programs for concrete casks and drywells have been supplemented by the design evaluations made during the MRS conceptual design effort. Demonstration testing of concrete casks in storage use is scheduled to begin soon at the Idaho National Engineering Laboratory (INEL). As was pointed out in Triplett and Smith (1984), the open-cycle vault has been used for storage at INEL and in Britain. Pools have been used extensively for storage; the first NUHOMS system has been 1 icensed and constructed, and is awaiting its first loading with fuel. Licensing was recently granted for a second NUHOMS installation. Pools are considered an established technology, whereas the NUHOMS horizontal module concept is less well established; no operating experience has been achieved to date, although loading is scheduled for the fall of 1988 at the H. B. Robinson plant. No major differences were found in the overall ratings of concepts considered in the prior evaluation.

\subsubsection{Penetrability and Security}

Performance as regards this factor was considered in the initial evaluation to be dependent on size of the storage area and distribution of storage modules within that area, ease of visual surveillance of the area, and the presence of additional penetration barriers within the security fence, such as massive buildings or tunnel structures. No changes were noted from the prior evaluation; all concepts can be made adequately secure. Costs of security systems should be directly proportional to the length of the security perimeter required for the area, and thus to the size of the area itself. 


\subsubsection{Accountability}

The pool concept permits constant visual affirmation of the spent fue 1 inventory; the NUHOMS concept uses sealed canisters which require precise documentation of their contents, but which make it very difficult to remove fuel or otherwise perturb the inventories. The conclusions of the prior evaluation were that direct visual examination (including TV sensors) of the stored fuel may be impossible and (except for the tunnel-rack vault) would not be feasible, but that documentation of contents of each canister and of its placement in storage, augmented by monitoring of closures on the individual storage units, could satisfactority provide the needed accountability. The open-cycle vault was judged to be among the most amenable to visual inspection; drywe11, cask, and closed-cycle vault concepts (and the NUHOMS concept) are more difficult to cover by the closed-circuit TV scanner technique; the above-ground storage units reduce visibitity within the field. The pool affords complete visibility of each fuel assembly or canister.

\subsubsection{Previous Licensing Experience}

At the time the initial evaluation was performed, none of the concepts then considered had been 1 icensed in the U.S. The accumulated experience with concrete casks, vaults, and drywells in the U.S. was noted, however, as was the licensing of metal casks in Europe and of open-cycle vaults in Britain. Additions to licensing experience since the initial evaluation include: 1) licensing of metal casks for at-reactor storage at Virginia Power's Surry plant, and of the NUHOMS modular vault system at Carolina Power and Light Company's H. B. Robinson plant, and 2) recent licensing of the NUHOMS system for the Oconee plant of Duke Power. The Morris pool was licensed in 1982 for storage under 10 CFR 72.

\subsubsection{Ranking of Concepts for Safety and Licensing}

Ranking of concepts for this criterion were listed in the earlier evaluation (Triplett and Smith 1984). Changes from that evaluation include: 
- The pool storage concept is assigned a ranking of 1 , and joins other concepts with this ranking.

- The open-cycle vault is elevated in ranking from 3 to 1 ; proper design can make this concept essentially equal to the field drywell in safety and licensability.

- The NUHOMS concept is assigned a ranking of 1 . This concept has been 1 icensed for at-reactor storage applications. Its potential applicability to MRS is discussed under the criterion of maturity.

- Two concepts were lowered in rating. The transportable storage cask was reduced from a rating of 1 to 2 , based on currently outstanding questions relating to recertification of a cask for transport service following an extensive period of use in storing spent fuel. The tunnel drywell concept was reduced from 2 to 3 in ranking, based on a complete lack of any licensing action on this concept.

The revised ranking of the storage concepts as to safety and licensability is shown in Table 4.1.

TABLE 4.1. Concept Ranking for Safety and Licensability

\begin{tabular}{|c|c|c|}
\hline Concept & $\begin{array}{l}\text { Original } \\
\text { Group } \\
\end{array}$ & $\begin{array}{l}\text { Re-Evaluated } \\
\text { Group }\end{array}$ \\
\hline Concrete Cask & 1 & 1 \\
\hline Field Drywell & 1 & 1 \\
\hline Stationary Metal Cask & 1 & 1 \\
\hline Transportable Metal Cask & 1 & 2 \\
\hline Open-Cycle Vault & 3 & 1 \\
\hline Closed-Cycle Vault & 4 & 4 \\
\hline Concrete Cask-in-Trench & 1 & 1 \\
\hline Tunne1 Drywe11 & 2 & 3 \\
\hline Tunnel-Rack Vault & 5 & 5 \\
\hline Water Pool & $\cdots$ & 1 \\
\hline NUHOMS Horizontal Vault & $\cdots$ & 1 \\
\hline
\end{tabular}




\subsection{ENVIRONMENTAL IMPACT}

For the environmental impact criterion, there are no changes in the evaluation previously performed as regards potential radioactivity release. Facility area requirements have been modified to reflect only the areas (with security perimeter) required for storage of the spent fuet. Comparisons of the water pool and the NUHOMS horizontal vault system are added.

\subsubsection{Radioactivity Release}

The potential for release of radioactivity to the biosphere depends on 1) likelihood of damaging fuel canisters in handling procedures used in loading or unloading the fuel; 2) capability of recovering released contaminants (recovery from release much more difficult outside than within the R\&H building); 3) potential of penetrating a canister (through physical force or corrosion) while in storage; and 4) pathways to the environment (via cooling air streams, groundwater, etc.). Most of the concepts rated high in their ability to prevent or restrict releases of radioactivity. However, the tunnel-rack was rated somewhat lower, since it provides no barrier to release other than the fuel canister itself, and the natural-draft cooling system provides a pathway for release outside the tunnels.

The prior evaluation remains unchanged for the concepts covered. of the added concepts, the NUHOMS system relies primarily on the outer storage canister to preclude release of radioactive species. The version licensed has no provisions for air sampling during storage, although monitors can be provided for canister-by-canister sampling if required. Water pools have been recognized as safe storage facilities by NRC in its Waste Confidence Decision rulemaking (49 FR 171). However, pools are notably inadequate for identifying an individual leaking assembly (or canister). They rely on radwaste systems for maintaining water purity. Minor gaseous leaks are normaliy not treated; for larger leaks, the leaking assemblies are commonly placed in canisters.

The safety of pools for storing spent fuel generally relates to cont inued storage of fuel in the pools, generally as assemblies. After the fuel has been removed from the pool and kept under inert-atmosphere conditions for some time, as when fuel is shipped to the MRS and then disassembled and 
consolidated into canisters, cladding temperatures stabilize at considerably higher temperatures than those of the pool. Reinsertion into the pool after such an interval, either as integral assemblies or in canisters, may result in quenching of the fuel cladding and may induce thermal shock to the point of damage to some rods. This could result in radiation releases into the pools (for integral assemblies). Instances involving introduction of heated fuel into pools have consistently resulted in spallation of crud from the cladding surfaces, and in several cases have resulted in fission gas releases, apparently through re-opening of pinholes in the cladding. Although sealed consolidation canisters would prevent escape of the releases from the fuel, the potential presence of large quantities of canistered, failed fuel rods or of loosened crud within the canisters may affect the acceptability of this fuel for geologic disposal without more than the normal treatment. Facilities could be added to provide a cooling period for the fuel before it is immersed in the pool; this would require an additional han$\mathrm{d}$ ling step, added time in handling, and added costs. Additional data are needed on the potential effects of quenching and on their avoidance.

The "underground" concepts--fjeld and tunnel drywells, and the tunnelrack vault--have potential pathways for radioactivity releases via groundwater pathways. However, this factor can be accommodated by proper siting in the case of field drywells (maintaining the wells above the water table), and by normal monitoring of both field and tunnel drywells to verify maintenance of seated drywell liners. The tunnel-rack vault may be more susceptible to possible releases of this type; if the tunnel extends below the water table at any place, or intersects pathways for water descending to the water table, sophisticated drainage systems may be needed to assure that the water does not contact potentially contaminated air.

\subsubsection{Storage Area Size}

Sizes of the required storage areas for each concept, including the security perimeter with capacity for storing 15,000 MTU of consolidated spent fuel with associated non-fuel assembly hardware, are shown in Table A.2, Appendix A. They are sumnarized below in Table 4.2. 
TABLE 4.2. Storage Facility Area Requirements for MRS Concepts

\begin{tabular}{lll}
\multicolumn{1}{c}{ Concept } & & \begin{tabular}{c} 
Storage Area \\
$(15,000$ MTU) \\
\cline { 3 - 3 } Acres
\end{tabular} \\
\cline { 1 - 1 } Metal Storage Cask & 45 \\
Concrete Cask & 47 \\
Concrete Cask-in-Trench & & 147 \\
Field Drywe11 & $92-295$ (see text) \\
Tunnel Drywe11 & 380 (underground) \\
Open-cycle Vault & 17 \\
Closed-cycle Vault & 47 \\
Tunnel Rack Vault & 20 (underground) \\
Transportable Meta7 Cask & 45 \\
NUHOMS Horizonta] Vault & 58 \\
Water Pool & 9
\end{tabular}

The variation indicated for area requirements for field drywells is of particular interest. The smaller area (92 acres) was calculated by the subcontractor performing in the initial evaluation. The higher value (295 acres) is that estimated by the MRS architect-engineer (Parsons 1985); it is for a site with large-scale leveling requirements and more requirements for rock drilling in the placement of drywells, and utilizes more conservative estimates of heat dissipation at the site selected, as compared to the generic site of the first subcontractor. The subcontractor's 92-acre field was used for this re-evaluation as well as for the prior evaluation. These differences represent the variation in area requirements and area-dependent costs that can result in an area-intensive concept such as the field drywell.

\subsubsection{Recoverability of Area}

The ability to recover a storage area during decommissioning of a facility, and to release it for other purposes, was found to vary considerably among the concepts initially evaluated. The surface-cask facilities (metal and concrete casks) rated highest in recoverability No changes in the conclusions reached in the prior evaluation were made in this re-evaluation. As before, the tunnel-rack vault and the tunnel drywell concepts entail the 
production and handling of massive quantities of excavation spoils. The cask-in-trench concept also produces large quantities of these spoils, but they are mainly backfilled around the casks.

\subsubsection{Ranking of Concepts for Environmental Impact}

No changes were made in the rankings from the prior evaluation. The horizontal module concept was added into Group 1. Water pools were assigned to Group 2, primarily because of the concern over thermal stress when introducing fuel at elevated temperatures into the water. The resulting grouping is given in Table 4.3 .

TABLE 4.3. Concept Ranking for Environmental Impact

\begin{tabular}{lccc}
\multicolumn{1}{c}{ Concept } & $\begin{array}{c}\text { Original } \\
\text { Group }\end{array}$ & & $\begin{array}{c}\text { Re-Evaluated } \\
\text { Group }\end{array}$ \\
\cline { 1 - 1 } Concrete Cask & & 1 & 1 \\
Field Drywel] & & 1 & 1 \\
Stationary Metal Cask & & 1 & 1 \\
Transportable Metal Cask & 1 & 1 \\
Open-Cycle Vault & & 1 & 1 \\
Closed-Cycle Vault & & 1 & 1 \\
Concrete Cask-in-Trench & 2 & 2 \\
Tunne1 Drywel1 & & & 3 \\
Tunne]-Rack Vault & & 4 & 4 \\
Water Pool & -- & 2 \\
NUHOMS Horizontal Vault & -- & 1
\end{tabular}

\subsection{SOCIOECONOMIC IMPACT}

The socioeconomic impact criterion measures the effects on the local population and economy from building and operating an MRS facility using a given storage concept. Portions of this criterion are highly subjective, and much of the impact is site-specific; a negative impact in one area may be near-neutral or positive in another. Consequently, as is indicated later in the report, a relatively low weight was assigned to these factors in the initial evaluation, and was retained for this re-evaluation. 


\subsubsection{Aesthetic Considerations}

The thrust of the earlier analysis of this factor was that I) the presence of the large R\&H building would render less significant the differences in impressions from the storage areas; and that 2) the presence of many discrete shapes, such as casks, would have less desirable visual impact than a large building. While this conclusion may be questionable, it was accepted for the present evaluation. On this basis, the pool storage building was included with the most desirable grouping, while the NUHOMS modular vaults, involving several separate structures, were placed with the "lesser desirability" group such as casks. Ranking of the nine original concepts, in which the surface cask concepts were rated low, was not changed.

\subsubsection{Labor Force Impact}

The initial evaluation ranked concepts on this factor according to the "swings" of labor demand projected as future additions were made to the storage facilities. Facilities requiring large increments of addition were rated lower than those approaching continual expansion. Using this philosophy, the NUHOMS system was rated high while the pool was assigned a lower rating. The NUHOMS module banks are added in essentially a continuous construction program until full capacity is reached (essentially the same as for the open-cycle vault). Storage pools can be incremented in size, but usually only in fairly large increments, thus producing fairly large swings in labor. On the other hand, the operating crew of the pool is appreciably larger than those for most other concepts, thus ameliorating this "swing."

\subsubsection{Economic Impact}

As in the prior evaluation, no significant degree of discrimination was found for this factor. For the two concepts having the highest overall costs--the metal cask storage systems--the bulk of the costs were for offsite purchase of the casks.

\subsubsection{Ranking of Concepts for Socioeconomic Impact}

Minor changes were made to the earlier ranking; the concrete cask was moved to Group 1 (most desirable) from Group 2, while the transportable metal cask, because of the high purchase cost of the casks involved, was moved to 
Group 2 (the scenario in the earlier evaluation required no fuel packaging facilities with these casks; they are required for the present study). The pool and NUHOMS concepts were both placed in Group 1. The resultant grouping is shown in Table 4.4.

TABLE 4.4. Concept Ranking for Socioeconomic Impact

\begin{tabular}{lccc}
\multicolumn{1}{c}{ Concept } & $\begin{array}{c}\text { Original } \\
\text { Group }\end{array}$ & & $\begin{array}{c}\text { Re-Evaluated } \\
\text { Group }\end{array}$ \\
\cline { 1 - 1 } Concrete Cask & & 2 & 1 \\
Field Drywell & & 1 & 1 \\
Stationary Metal Cask & & 2 & 2 \\
Transportable Metal Cask & 1 & 2 \\
Open-Cycle Vault & & 1 & 1 \\
Closed-Cycle Vault & & 1 & 1 \\
Concrete Cask-in-Trench & & 2 & 2 \\
Tunnel Drywell & & 2 & 2 \\
Tunne]-Rack Vault & & 3 & 3 \\
Water Pool & -- & 1 \\
NUHOMS Horizontal Vault & -- & 1
\end{tabular}

\subsection{SITING REQUIREMENTS}

The requirements imposed on a site by the storage concept chosen for an MRS facility are a measure of the number of available sites which might be found that are satisfactory for its deployment. While many siting deficiencies can be overcome by added engineering (and cost), a concept with the least restrictive requirements for its siting will be most acceptable from both cost and environmental aspects.

\subsubsection{Land Requirements}

As was pointed out in the prior evaluation, the area required for storage of a given quantity of material can determine relative availability of sites in a region, although the availability of a given size plot will vary from one region to another and from one site to another. The earlier 
evaluation assigned relatively low importance to the land availability factor in the overall siting requirements criterion; that assumption was retained for the present re-evaluation.

One factor that may influence site area requirements is the need to Timit possible exposure to radiation at the site boundary to 75 mrem per year or less to the thyroid, or 25 mrem per year or less to the whole body or any other organ, as is required by 40 CFR 191 and 10 CFR 72.104. Typically, the criterion for distance from the storage area to the boundary represents a trade-off between allowance for extra separation distance and provision of additional shielding for the storage vessel or structure used. In one case, at Gorleben, West Germany, the intensity of sky shine from a field of metal storage casks forced the enclosure of the casks in a shielding structure. The radiation levels experienced were attributed to insufficient shielding in the lids of the early casks used at that site. For the present study, sufficient shielding was assumed to be provided with each concept that distance to the site boundary was governed by security considerations. Actual distance requirements may vary from one site to another, as determined by the trade-offs mentioned.

Estimated surface (and underground) area requirements were summarized for the current review in Table 4.2.

\subsubsection{Geological Requirements}

This factor considers seismic characteristics at a site and seismic behavior thermal conductivity, and chemical type of the host rock. Another factor is the depth to bedrock at a site. Shallow overburden provides ease of constructing building foundations, but increases the costs of excavation, drilling for drywells, etc. Excessive depth to bedrock, on the other hand, can increase costs of building foundations and may detract from seismic safety. Thermal conductivity of the rock affects the required storage area size for concepts relying on heat dissipation through the rock structure; and rock chemistry, combined with hydrological conditions, can affect corrosion of drywell liners or other storage features. 
No changes were made to the original ranking of concepts. Both added concepts, the pool and the NUHOMS modular vault system, were placed in the highest category, with the other surface storage concepts.

\subsubsection{Hydrological Requirements}

Groundwater can affect storage systems which it contacts by promoting corrosion of structures or containment of the systems, or more directly by flooding portions of the storage area. As before, surface concepts were rated highest from a hydrologic standpoint. No changes were made in the original ratings. Both the NUHOMS system (an above-ground concept) and the pool were rated in the highest category. Although the structural shell of a pool may be in contact with groundwater, pools at reactor sites have generally operated well. with no discernible effect from groundwater-induced corrosion.

\subsubsection{Resource Reguirements}

For this factor the pool and the NUHOMS system were both placed at second-Tevel category. Pools require large amounts of stainless steel for lining of the pool itself, and for storage racks. The NUHOMS concept uses large quantities of lead in the end shields for the storage canisters. Metal casks, as noted in the initial evaluation, use large amounts of lead and stainless steel in some designs. As was noted earlier, the discrimination among concepts on resource requirements is not significant; no unusually large amounts of scarce or strategic resources are used.

\subsubsection{Ranking for Siting Requirements}

Only minor changes were made in the prior ranking. With the new concepts added, the ranking order is as 1 isted in Table 4.5. The order of ranking in this table shows the greater sensitivity of the concepts interfacing below-ground strata to heat-dissipation capacity and possible corrosive action.

\subsection{COST AND COST SENSITIVITY}

As might be expected for a system like the MRS, which is basically environmentally benevolent and has low sensitivity to siting regions or characteristics, cost factors involved in the storage concepts take on 
TABLE 4.5. Concept Ranking for Siting Requirements

\begin{tabular}{|c|c|c|}
\hline Concept & $\begin{array}{l}\text { Original } \\
\text { Group }\end{array}$ & $\begin{array}{l}\text { Re-Evaluated } \\
\text { Group } \\
\end{array}$ \\
\hline Concrete Cask & 2 & 1 \\
\hline Field Drywell & 5 & 4 \\
\hline Stationary Metal Cask & 1 & 1 \\
\hline Transportable Metal Cask & 1 & 1 \\
\hline Open-Cycle Vault & 1 & 1 \\
\hline Closed-Cycle Vault & 3 & 2 \\
\hline Concrete Cask-in-Trench & 5 & 4 \\
\hline Tunnel Drywe11 & 6 & 5 \\
\hline Tunnel-Rack Vault & 4 & 3 \\
\hline Water Pool & -- & 1 \\
\hline NUHOMS Horizontal Vault & -- & I \\
\hline
\end{tabular}

considerable significance. Added to this significance is DOE's mandate from the Nuclear Waste Policy Act (NWPA) to use Waste Fund money in as costeffective a manner as possible. In like manner, confidence that a cost estimate will be accurate, and the sensitivity of costs to changes in size or throughput of a facility, are important. These factors--life-cycle costs, cost sensitivity, and cost-estimating confidence--were considered in the initial evaluation and are re-cast herein.

\subsubsection{Life-Cycle Costs}

The 7 ife-cycle costs of concepts in the initial evaluation were given in undiscounted, 1983 dollars. Al1 costs were reviewed, re-cast by eliminating those MRS costs not directly associated with the storage facility, and recalculated in view of current knowledge, including data from later studies and results of recent research and demonstration projects where appropriate. Costs for the pool and the NUHOMS system were included. In the course of the recalculation, all costs were updated to mid-1988 dollars. As in the original study, undiscounted dollars were used for the ranking. Life-cycle costs for the concepts, under these conditions, are given in Table 4.6. 
IABLE 4.6. Life-Cycle Costs for Storage Concepts(a)

\begin{tabular}{lc}
\multicolumn{1}{c}{ Concept } & $\begin{array}{c}\text { Life-Cycle Costs } \\
\text { (s million) }\end{array}$ \\
\hline Field Drywell & 141 \\
Concrete Cask & 189 \\
Water Pool & 227 \\
Tunnel-Rack Vault & 326 \\
Open-Cycle Vault & 344 \\
NUHOMS Horizontal Vault & 509 \\
Concrete Cask-in-Trench & 625 \\
Closed-Cycle Vault & 668 \\
Tunnel Drywell & 821 \\
Stationary Metal Cask & 1709 \\
Transportable Storage Cask & 2330 \\
& \\
\hline (a) Costs shown are given for 15,000 MTU spent fue] \\
$\quad$ storage facilities at an MRS site in undiscounted \\
$\quad$ mid-1988 dollars.
\end{tabular}

All concepts were assumed to be utilized for storage in the same context, except that transportable storage casks were assumed to be shipped directly to the repository from the storage field. This use of the casks is estimated to save approximately $\$ 30$ million by avoiding trans-Toading of the fuel into dedicated shipping casks. Additional savings to the transportation system of about $\$ 70$ million would accrue from the avoidance of capital costs of dedicated MRS-to-repository shipping casks. The Tatter savings, however, were not considered as savings to MRS, and hence were not included (even if they had been fully allowed the ranking of this concept would not have changed). The projected savings are included in the cost estimates of Table 4.6.

Costs of the metal casks were taken from DOE estimates of recent cask designs currently under consideration (DOE 1987b). For either the storageonly or transportable metal cask concepts, it was estimated that 1187 casks would be required in the scenario assumed, for storage of the 15,000-MTU fue 1 and the associated assembly hardware. Since all casks are purchased from 
vendors, normally quantity discounts would be assumed with this high a usage. However, it was assumed that no casks could be purchased until NRC has granted a license for the MRS facility. All casks must be purchased and delivered during a 24 -month construction period and the ensuing 4.5 years of the first five years of operation (all casks are filled at the end of the five-year period). Therefore, the casks must be produced at a minimum rate of about 185 per year, or nearly two orders of magnitude above current industry capability. During approximately the same time period the entire fleet of dedicated transport casks must be procured from and manufactured by the same industry. Furthermore, no storage casks would be required after the MRS storage field was filled. Under these conditions, costs charged per cask may represent a premium rather than a discount; therefore, no discount was assumed for cask costs. However, a reduction of $\$ 500,000$ (out of $\$ 1.75$ mi11ion total) per cask was assumed for transportable storage casks, representing a possible reduction in the costs of cask certification.

other scenarios involving less intensive use of metal casks may encounter more favorable costs than projected above. One such scenario is that of the three-phase MRS, whose first phase would involve transportable storage casks, filled at the reactor sites, with little required at MRS but cask pads and equipment for unloading incoming casks from their carriers and transporting them to the pads. Later, after the full MRS handling and packaging capabilities were in place, the fuel in these casks would be unloaded, processed through the MRS facility, and either returned to a (final-phase) storage field or shipped to the repository. In such a scenario, use of the casks in only the early-phase acceptance would require fewer casks, would place less burden on the manufacturers, and could result in some discounting of the cask purchase price.

\subsubsection{Cost Sensitivity}

This factor examines the ability of a storage facility to adapt to 1) increase or decrease in the rate at which material is received and stored, or 2) increase (once or repeatedly) in the storage capacity of a facility above that originally provided, with minimal increase (or, hopefuliy, with a decrease) in the unit costs of storage. 
In the initial evaluation, the drywell and turnel-rack vault concepts were found to be least sensitive to waste form and to storage capacity. No change in that ranking was made in this review. Of the added concepts, the NUHOMS system is assigned a mid-range ranking. The individual banks of horizontal storage vaults are sequentially constructed as needed; expansion should therefore be accorded an essentially constant unit cost. Storage pools, however, involve considerable effort to increment, and any expansions are probably best done in large increments. No pool has as yet been expanded in storage area; however, provisions for future additions were made in the construction of the Morris spent fuel storage facility, which was initially bujlt as the receiving pool for a planned fuel reprocessing plant. The initial excavation for the pool was extended far enough to accommodate the thenplanned addition, then backfilled to the size needed for the present pool; this was done to avoid future stress on the pool walls caused by excavations for future construction work. Also, a transfer channel and gate were installed at the "outer" end of the pool to provide fuel transfer between the planned pool sections.

Because of the perceived difficulties in operations of this type, the pool was given a low rating in cost sensitivity.

\subsubsection{Confidence in Cost Estimate}

This factor weighs the base of construction and operations experience for the various storage concepts as a measure of the confidence that a given cost estimate will be realized in actual cost experience. No changes were made in the original ranking. The water pool, with its wealth of history, was ranked in the top category on this account. The first NUHOMS system constructed, for Carolina Power and Light Company, was completed for about $\$ 60 / \mathrm{kg}$. Since this is the first unit completed, the system was assigned a third-Tevel category. Additional construction experience could well improve this rating.

\subsubsection{Concept Ranking for Cost}

Ranking of the candidate concepts for the cost criterion is shown in Table 4.7 . 
TABLE 4.7. Concept Ranking for Costs

\begin{tabular}{lccc}
\multicolumn{1}{c}{ Concept } & $\begin{array}{c}\text { Original } \\
\text { Group }\end{array}$ & & $\begin{array}{c}\text { Re-Evaluated } \\
\text { Group }\end{array}$ \\
\cline { 1 - 1 } Concrete Cask & & & 1 \\
Field Drywell & 1 & & 1 \\
Stationary Metal Cask & 5 & & 5 \\
Transportable Metal Cask & 4 & & 6 \\
Open-Cycle Vault & 3 & & 2 \\
Closed-Cycle Vault & 4 & & 5 \\
Concrete Cask-in-Trench & 6 & 5 \\
Tunnel Drywell & 4 & \\
Tunnel-Rack Vault & 3 & \\
Water Pool & -- & & 4 \\
NUHOMS Horizontal Vault & -- & 3
\end{tabular}

\subsection{CONCEPT MATURITY}

A concept that is well-developed, has been demonstrated, and has had prior usage will have a minimum of unknown factors affecting the cost and schedule of deployment. Such a concept would require little research and development to verify design, and would have a high likelihood of operating at design rates without extended learning periods. Since a major benefit of MRS may be its compatibility with rapid deployment to provide early start of acceptance of spent fuel from the utilities, the criterion of maturity has considerable weight in concept selection. A mature storage concept can be deployed in less time, and with greater certainty of meeting operational objectives, than can less-developed concepts.

The overall maturity of the concepts was based on analysis of the following factors:

- state of concept development

- research and development requirements

- need for conservatism in design and construction

- time required for deployment 
- retrievability from storage

- engineering simplicity.

As for other criteria, the initial evaluation was reviewed, modified if appropriate, and analyses for the pool and NUHOMS concepts were added. A ranking of concepts for maturity was made based on a composite of the factors above.

\subsubsection{Concept Development}

The concepts initially reviewed ranged from those having well-developed designs and demonstration facilities, and in some cases extensive histories of successful operation, to those which have not progressed beyond the conceptual design phase and which require extensive, complex remote handling systems.

of the concepts initially evaluated, the field drywell, concrete cask, and open cycle vault have been used extensively in storage operations in the U.S., Canada, and the United Kingdom. Concrete casks have been used extensively in Canada and at the E-MAD facility at the Nevada Test Site. Tunnel drywells have been extensively tested in the Climax mine at the Nevada Test Site, and more recently in test facitities for the former Basalt Waste Isolation Project. The concrete cask-in-trench is configured similarly to a drywe11, giving confidence as to its operability. Metal casks have been used as the mainstay of radioactive materials transportation for over 40 years; they are also used extensively in Europe for spent fue] storage. In the U.S., metal casks have not been used operationally for long-term storage, but testing is under way, and the storage facility at Virginia Power's Surry site has been in operation since 1987. The extensive past history of this concept gives high confidence that its long-term reliability and operability will meet expectations.

On the other hand, the closed-cycle vault and the tunnel-rack vault have been neither built nor operated. The closed-cycle vault uses developed technology, but no testing of the system--and particularly of the use of 
heat-pipe cooling--has been performed for spent fuel storage. The tunnelrack vault exists as a design only. It makes use of complex placement-andretrieval systems based on remote operations. Similar operations have been developed for use in warehousing operations, but evidence of reliable operation in high-radiation fields, and demonstration of procedures for maintenance and recovery from failure under those conditions, is lacking.

of the added concepts, the water pool is highly developed; pools have been used for spent fuel storage since the earliest reactor operations in the 1940 s, and are universally used in today's power reactors. On the other hand, the NUHOMS modular horizontal vault concept is new; it has only recently been licensed by NRC, and the first commercial application is still under construction, with loading scheduled to begin in the fall of 1988. Thus, it has not been "proved out" in operation. Its maturity would rank below that of open-cycle vaults, but above the closed-cycle vault and tunnelrack vault concepts.

\subsubsection{Research and Development Requirements}

An important measure of the maturity of a concept is the amount of research and development effort required prior to construction and operation. For the various storage concepts involved, the R\&D effort can range from routine testing for design optimization to complex programs to develop untested systems.

The water pool concept is by far the most developed of the storage methods considered; little if any R\&D effort would be needed for normal storage operations. Concrete and metal casks are undergoing testing under the Commercial Spent Fuel Management (CSFM) Program, at the Idaho National Engineering Laboratory and at several reactor sites and the Morris storage facility; as noted above, metal casks are in service at the Surry storage yard. Sufficient data should be available from these activities to minimize additional R\&D needs associated with use of these concepts at MRS. For the transportable storage cask, however, development of an appropriate method for instrumented inspection of cask body integrity would be needed for recertification without need for emptying a loaded cask. 
Some benchmark data are available for drywells, but additional on-site tests may be needed at some locations to assure sufficient heat dissipation capability. Further studies on long-range corrosion characteristics of drywells in various soils would be desirable.

Open-cycle vaults and NUHOMS horizontal vaults operate on we11-understood principles with their natural-draft cooling arrangements. However, verification testing involving prototypes or models may be desirable to "prove out" the operability of specific designs. The heat pipe cooling system of closed-cycle vaults would need additional development of similar nature. Although heat pipes have been used in a variety of applications, the design principles involved are not yet mature.

The tunnel-rack vault concept appears to require more R\&D effort for successful deployment than any of the other concepts evaluated. The complex remote-handling systems involved in storage of fuel in the tunnels and its subsequent retrieval are based on similar systems developed for warehousing operations, but the high radiation environment and remote operation requirements require substantial development of this system. In addition, the natural-draft cooling system would require demonstration, and modification if needed, to assure that it could function adequately while confining radioactivity releases.

\subsubsection{Conservatism Needed}

The degree to which conservative estimates and design features must be included in a concept to assure operability is dependent on the state of development, and thus is directly related to the factors discussed in the last two subsections. The ranking of concepts for conservatism requirements thus follows directly from the rankings for the factors of development status and $R \& D$ requirements.

\subsubsection{Deployment Time}

The required deployment time for a storage concept can heavily influence both planning processes for an MRS facility and the merits of the facility in the waste management system. This is particularly true for a "phased" MRS facility, in which a storage facility with minimal fuel handling capabilities 
would be deployed initially to advance the date when it could begin receiving spent fuel, with the full MRS facility coming into service later.

In the earlier evaluation, deployment of the complete MRS facility was considered; thus the deployment period required for the receiving and handling facility would mask shorter deployment periods for some storage facilities. Benefits from short-deployment storage systems were thus limited. For this study, the analysis was repeated for the storage facility itself, together with any interconnections with an MRS facility but excluding the non-storage portions of that facility. This procedure gives a better indication of those concepts with short deployment times, which might best be used in a phased MRS deployment.

The estimated deployment times (excluding times for facility siting) are shown in Table 4.8. The estimated times in the initial evaluation included schedules for design and construction, but did not include time requirements for licensing actions by NRC. For this re-evaluation, estimates of licensing time were added to provide more complete estimates of time requirements for deployment.

The estimated total times are shown in the table for three cases:

- Deployment of a full MRS facility utilizing the storage concept (Table 4.8a);

- Designing and licensing a full MRS concept, but advance construction of the storage field (Table 4.8a);

- Designing, licensing and construction of a storage field only, in advance of the remainder of the MRS facility (Table 4.8b).

The table is based on an ultimate storage capacity of 15,000 MTU for each concept. The capacity supplied at the time fuel acceptance begins is indicated in Table 4.8c; the balance of the storage capacity is assumed to be added over the first five years of operation, during the time when additional fuel is assumed to be placed in storage.

Time estimates for design and construction in the table (4.8a and 4.8b), for the previously evaluated concepts, were taken from overall schedules furnished by the evaluation subcontractors. The schedules for the water pool and NUHOMS concepts were derived from other Battelle analyses. 
TABLE 4.8a. Estimated Deployment Times for Storage Concepts

(Time for Facility siting Excluded)

concept

Deployment Time (months)/Total Facility

\begin{tabular}{l} 
Fjeld Drymll \\
Tunnel Dryell \\
Concrete Cask \\
Concrete Cosk-in-Trench \\
Stationary Metal Cask \\
Transportable Metal Cask \\
NuHCis Horizontal Veult \\
Open-Cycle Vault \\
Closed-Cycle Vault \\
Woter Pool \\
Tunnel-Rack Veult \\
\hline
\end{tabular}
Design $^{(a)}$ Licensing $^{(a)}$ Construction ${ }^{(b)}$ Totel

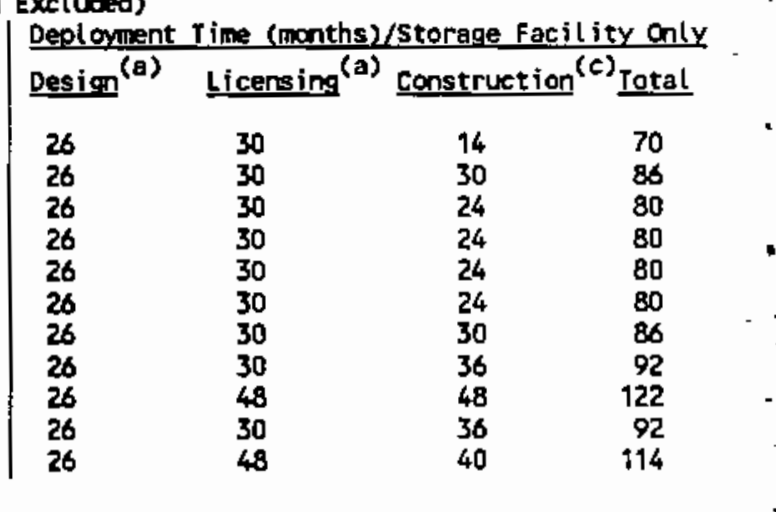

(a) Absumes design and licensing of full MrS facility.

(b) From ias proposel - initial construction phase only (from granting of license until fuel acceptance starts).

(c) From cantractors' estimates - initial construetion phase for storage field only (from granting of license until fuel acceptance starts).

TABLE 4.8b. Estimated Deployment Times for Storage Concepts Assuming Separate Licensing of Storage Facility

\begin{tabular}{|c|c|c|c|c|}
\hline \multirow[b]{2}{*}{ Concept } & \multicolumn{4}{|c|}{$\begin{array}{l}\text { (Time for Facility Siting Excluded) } \\
\text { Deployment Time (months)/Storage Facjlity only }\end{array}$} \\
\hline & Design $(a)$ & Licensing (b) & Construction (c) & Iotal \\
\hline $\begin{array}{l}\text { Field Drywe 1l } \\
\text { Tunnel Drywel1 } \\
\text { Concrete Cask } \\
\text { Concrete Cask-in-Trench } \\
\text { Stationary Metal Cask } \\
\text { Transportable Metal Cask } \\
\text { NUHOMS Horizonta] Vault } \\
\text { Open-Cycle Vault } \\
\text { Closed-Cycle Vault } \\
\text { Water Pool } \\
\text { Tunnel-Rack Vault }\end{array}$ & $\begin{array}{l}14 \\
18 \\
12 \\
12 \\
14 \\
14 \\
16 \\
24 \\
14 \\
24 \\
22\end{array}$ & $\begin{array}{l}30 \\
30 \\
24 \\
30 \\
24 \\
30 \\
24 \\
24 \\
48 \\
24 \\
48\end{array}$ & $\begin{array}{l}14 \\
30 \\
24 \\
24 \\
24 \\
24 \\
30 \\
36 \\
48 \\
36 \\
40\end{array}$ & $\begin{array}{r}58 \\
78 \\
60 \\
66 \\
62 \\
68 \\
70 \\
84 \\
110 \\
84 \\
110\end{array}$ \\
\hline
\end{tabular}

(a) Completion of license application design for storage facilities only (estimate based on contractors' estimates).

(b) Assumes separate licensing action on storage facility prior to licensing of balance of MRS.

(c) From contractors' estimates: Initial construction phase for storage field only (from granting of license until fuel acceptance starts). See Table $4.8 \mathrm{c}$. 
TABLE 4.8c. Storage Capacities Provided During Initial Construction Phase (total storage capacity 15,000 MTU)

\section{Concept}

Field Drywell

Tunnel Drywe 1

Concrete Cask

Concrete Cask-in-Trench

Stationary Metal Cask

Transportable Metal Cask

NUHOMS Horizontal Vault

Open-Cycle Vault

closed-Cycle Vault

Water Pool

Tunnel-Rack Vault
Initial

Capacity, MTU

$$
\begin{array}{r}
0 \\
3,000 \\
1,500 \\
3,000 \\
4,500 \\
4,500 \\
3,000 \\
3,000 \\
5,700 \\
15,000 \\
15,000
\end{array}
$$

Based on experience gained in the MRS conceptual design, licensing times for a full MRS facility that utilizes concepts with prior licensing histories or substantial prior use are estimated at 30 months (1 imited by the MRS licensing period); for the less proven concepts, a 48-month period is assumed to be required.

For the third case, involving advance licensing of the storage concept and necessary support facilities prior to licensing of the full MRS facility, those concepts that have previously been licensed at reactors (metal casks, NUHOMS horizontal vault, and the water pool) or have received approval of a topical report (open-cycle vault) were assumed to require 24 months for licensing (at-reactor licenses for some concepts have been granted in as little as 18 months; added time allowance was made for the larger size of the MRS storage field and the likely greater interest paid by interveners to MRS). Other concepts were assumed to require 30 months for licensing, except for two advanced concepts. These, the closed-cycle vault and the tunnel-rack vault, were assigned 48-month licensing periods.

Task H of DOE's MRS System Studies addresses the questions of NRC licensing; the assumptions made above are subject to change depending on the outcome of that task, but are believed to be appropriate for use in the ranking of the concepts. 
The time required for siting an MRS facility is indeterminate at present; it will depend in part upon the selection process, and on siting guidelines now under development. However, the site selection must be made before the deployment steps in Table $4.8 \mathrm{a}$ and b can proceed; thus, the deployment times shown in the table must be preceded by an adequate time for siting the facility (although for a concept with sufficient flexibility as to site conditions the site selection could perhaps overlap into the early design period).

Preliminary conceptual design of the storage facility is assumed to be performed during the period of siting of the facility.

A different factor may affect the timely deployment of a storage field employing metal casks. As was previousiy mentioned, the storage of 15,000 MTU of consolidated spent fuel, together with its associated assembly hardware, is estimated to require about 1187 casks; these casks are assumed to be filled during the first five years of facility operation. Thus, they must be procured over a period not appreciably longer than 6.5 to 7 years (Section 4.5.1).

Production of casks at the required rate would require a substantial industrial base, particularly for the casting and/or forging of the heavy cask bodies. Today's manufacturing base would require major expansion over the next decade to make the casks available in the quantities and on the schedule needed (170 to over 200 casks per year above those needed for transportation). Further, after the repository begins operation, there would be no "aftermarket" for additional storage casks. The uncertainties of major industrial expansion to meet a short-term demand lead to corresponding uncertainty as to meeting the "up front" demand for storage in casks. This led to the assumption of an extended lead time of 24 months for procurement of the first casks (about 356 casks would be supplied initially).

\subsubsection{Storage Retrievability}

The MRS storage facility is intended to store spent fuel only until the time it can be received at the repository. For the scenario used in this evaluation, the maximum storage time would be that of the projected operating life of MRS - about 25 years. A11 fuel placed in storage must be retrieved 
within that time period, with minimum effort. From time to time, early retrieval of specific fuel canisters may be required--for example, for blending with other canisters to provide "heat-tailored" loads for disposal containers, or to repair a canister that has shown indications of radioactivity Teakage.

The drywe11, water pool, and the open-cycle vault concepts provide rapid and random access to any canister in storage, with relatively simple operations involved in the retrieval. Metal and concrete casks offer similar ready access; however, a cask must be transferred to the R\&H building port, opened, and the desired spent fuel canisters removed. The cask, if canisters are left inside, must then be returned to storage. (a) closed-cycle vaults and NUHOMS horizontal vaults use special storage canisters, each of which may contain several spent fuel canisters. The storage canisters must be removed from the vault and transferred to the R\&H building (using shielded carriers) where the storage canisters are opened and the fuel canisters extracted. If only one (or a few) canisters are desired, the remainder must be re-sealed in the storage canister and returned to the vault. (a) In addition to the extra effort involved, some added opportunity for transfer accidents would be introduced.

The cask-in-trench concept requires excavation of the cask before its return to the $\mathrm{R} \& \mathrm{H}$ building, again adding to the required effort.

The tunnel-rack vault concept is fundamentally different in its operation. Fuel is normally stored in and retrieved from storage in a first-in, last-out process; each rack is removed from its storage rail in the reverse order of its placement. Thus, retrieval of any spent fuel canister other than one in the last rack stored requires extensive shuffling of the racks to empty rail positions, removal of the desired rack, then replacement of the

(a) To a limited extent, "extra" fuel canisters, left in a cask or storage canister after removal of selected canisters for heat tailoring purposes, may be stored in the in-building MRS lag storage facility instead of being returned to the storage field. 
displaced racks. Such a procedure, carried out by remote control, would be time-consuming and costly; it also could introduce hazards of fuel canister damage or of equipment breakdown.

\subsubsection{Enqineering Simplicity}

Simplicity in engineered systems generally equates to ease and reliability of operation and to lower operational costs. The reliability factor applies both to handling requirements during storage and retrieval operations and to periods of unattended storage. Thus, there are considerable incentives toward use of simple systems for storage.

Metal and concrete casks are the simplest of the concepts investigated. All handling of radioactive materials during storage or retrieval is performed within the R\&H building. The only operations outside the building involve the transport, placement and removal of sealed casks. During operation, passive cooling of the casks by the surrounding air suffices to maintain desired storage temperatures of the fuel. Drywells are similar in simplicity, depending onty on the surrounding soil to remove heat. However, this concept requires a shielded transporter for placement and removal of fuel canisters. The open-cycle vault is similar in operation to the drywell concept, but has the added complexity of a natural-draft cooling system to maintain cooling.

The heat-pipe cooling system employed in the closed-cycle vault introduces additional complexity; this concept also requires use of a shielded transporter for the storage canister.

By far the most complex of the concepts evaluated is the tunnel-rack vault. Its highly complex, remotely operated fuel transfer system may involve remote maintenance or removal of failed equipment from high-radiation areas. Its natural-draft cooling system is simple in operation, but could be complicated if confinement capability were required (large quantities of fuel would be stored in ventilated tunnel drifts in this concept, with no barriers to radioactivity escape other than the fuel canisters).

The water pool shares simplicity of storage and retrieval with the cask and drywell concepts; any canister stored can be readily retrieved, without 
restriction. On the other hand, the pool requires active cooling and radwaste treatment systems, which must be in continuous operation. This entails added operating costs. However, the large thermal capacity of the pool allows routine maintenance or repairs to the system to be carried out without additional hazard in event of malfunction or breakdown.

The NUHOMS vault and closed-cycle vault concepts use storage canisters carrying several fuel canisters each. Heavy, shielded transfer casks must be used for movements to and from the R\&H building. In addition, the sealed canisters must be opened to retrieve fuel canisters.

The NUHOMS system is currently designed for use with a reactor poot. Substantial modification may be necessary to adapt it for use with a hot cell and at MRS handling rates. Specific points are:

- The canister must be held within the transfer cask, or supported in a horizontal position, at all times during handling and storage. It has no provisions for vertical lifting, and when loaded it is questionable that the seal-weld at the top lid could support the weight of the canister plus fuel. Thus, in a hot cell fuel must be loaded/unloaded with the canister held in the transfer cask, or the cell must be provided with a horizontal entry port for loading and unloading the cask, and an adequate cradle for the canisters.

- The operations of seal-welding the top plate to the canister, and of breaking the weld seal during fuel removal, should be mechanized for use at MRS handling rates. Currently these operations are performed manually with the canister in the opened cask; dose rates at the canister top surface range from $50 \mathrm{mrem} / \mathrm{hr}$ (at the edge of the plate) upward, and dose accumulation is estimated at up to 100 mrem per canister operation (based on the application for the H. B. Robinson plant) (NUTECH 1985). At an MRS facility some 250 to 400 NUHOMS canisters per year may be filled and stored, depending on the size of shielded canisters used. An occupational dose of up to 20 man-rem per year would result for this operation alone if manual operations are adopted.

- The costs and related considerations of disposal of used, contaminated and slightly neutron-activated canisters have not been addressed for at-reactor operations, let alone for MRS. 0isposal costs for these heavy structures could be significant, and recovery of the shielding lead may be important. 


\subsubsection{Concept Ranking for Maturity}

Based on the foregoing evaluations of reliability, operational experience, simplicity, and ease (and speed) of deployment, the concepts were ranked as shown in Table 4.9. The drywell and cask concepts were ranked among the highest because of their simplicity and their long history of testing and operation. Because of their exceptionally long and favorable history in service, water pools are also ranked in this group, al though they are more complex systems. As in the initial evaluation, the two lowestranked systems--closed-cycle and tunnel-rack vault--were so ranked because they are complex systems with no developmental history.

The stationary metal storage cask is normally considered as one of the most mature of storage concepts. However, because of the questions as to the ability to procure and deploy large numbers of casks in the schedule needed (Section 4.6.4), this concept was rated a " 2 " in maturity. In the initial evaluation the metal cask was rated " 3 " for this criterion.

\section{IABLE 4.9. Concept Ranking for Maturity}

\begin{tabular}{lccc}
\multicolumn{1}{c}{ Concept } & $\begin{array}{c}\text { Original } \\
\text { Group }\end{array}$ & & $\begin{array}{c}\text { Re-Evaluated } \\
\text { Group }\end{array}$ \\
\cline { 1 - 1 } Concrete Cask & & 2 & 2 \\
Field Drywell & & 1 & 1 \\
Stationary Metal Cask & & 3 & 2 \\
Transportable Metal Cask & 4 & 4 \\
Open-Cycle Vault & & 4 & 3 \\
Closed-Cycle Vault & & 5 & 5 \\
Concrete Cask-in-Trench & 4 & 4 \\
TunneI Drywell & & 2 & 3 \\
Tunnel-Rack Vault & & 6 & 6 \\
Water Pool & -- & 1 \\
NUHOMS Horizontal Vault & -- & 4
\end{tabular}




\subsection{FLEXIBILITY}

The MRS facility, in most of the scenarios considered to date, has the role of receiving spent fuel from the utilities, preparing it for emplacement in the repository, and delivering it in that state to the repository. In addition, the MRS facility is provided to allow initiating acceptance of spent fuel from the utilities at the earliest feasible date, storing it until the repository is ready to receive fue 1 , and maintaining the storage facility as a buffer to allow fuel acceptance and shipments to the repository to be carried on independently of fue 1 receipt, providing capability for continuity of acceptance from the utilities or of shipments to the repository if disruptions should occur in either of these two activities. Delays in repository startup, or an enforced halt in emplacement following startup, for example, could quickly influence the storage capacity required of MRS. A future decision to reprocess fuel before emplacement would change the waste form and package configuration to be handled at MRS. Similarly, changes could occur in required throughput of the waste management system, affecting MRS design and operating conditions. The MRS facility should ideally be able to accommodate changes in storage capacity, acceptance rate, required length of storage, or waste form in these and other situations. In like manner, adaptability of an MRS storage concept to a variety of sites is desirable to minimize deployment times after site selection with minimum penalties in construction or operation.

Additional factors included in the flexibility criterion are those of consumption of (and recovery of) critical resources, and recovery of capital assets. The 1 ist of factors analyzed in assessing flexibility is, in summary:

- site adaptability

- expandability of throughput rate and capacity

- sensitivity to waste form

- sensitivity to heat load

- recoverability of capital assets 
- critical resource consumption and recovery

- suitability to phased deployment

- suitability for use in long-term storage.

\subsubsection{Site Adaptability}

The MRS concept selected should provide as much siting flexibility as feasible, to preserve siting options, minimize restrictions on usable sites, and minimize the amount of site-specific information required to design, license, construct and safely operate the facility. The surface cask concepts, water pool, and the surface vault concepts--open-cycle and closedcycle vaults, and the NUHOMS horizontal vault--are the most adaptable to a variety of siting conditions. None requires restrictive site conditions. Near-surface storage concepts, the field drywell and cask-in-trench, are somewhat less flexible; they should be installed with the storage units above the groundwater table, and bedrock should preferably be deep enough to minimize installation costs. Construction of earthen berms and associated drainage facilities could suffice to compensate for deficiencies in either condition, but at extra cost.

The tunnel drywe11 and tunnel-rack vault concepts are least adaptable. A mountainside is required for their construction. An alternative could be constructed using shielding and structural concrete to augment the available bedrock, with an earth overburden applied; such an approach, however, could add appreciably to the cost.

\subsubsection{Expandability of Throughput Rate and Capacity}

As previously discussed, a number of possible conditions, or modifications of the MRS role, could require increase in the storage capacity and/ or throughput capability of an MRS facility after it is in operation. Capacity additions are most easily accommodated with the field drywell or surface cask concepts, which are capable of expansion in small increments. The opencycle and closed-cycle vaults, NUHOMS, and cask-in-trench concepts require addition of capacity in larger increments; however, this is merely a continuation of the year-by-year additions which would likely be used to bring the storage facility to its rated capacity if no expansion occurred. 
The situation with water pools is similar to that of the open-cycle vaults, except that provisions for expansion must be made when the original pool is built, and more precautions are needed in preserving the integrity of the pool when adding the increments of capacity. Because of these restrictions, larger capacity increments would likely be opted for (as was previously discussed, enlargements have not as yet been made at any spent fuel pool).

The tunnel concepts--tunnel drywell and tunnel-rack vault--require substantially more effort to expand. Much larger increments of capacity would be involved, and in the tunnel-rack vault temporary shielding must be installed, or new access drifts constructed, to avoid exposure of the tunneling crews to radiation from the stored fuel. Expansion of throughput rate would probably affect the R\&H building as well as the storage facility. Within the storage facility, rate expansion would primarily affect the fue] transfer systems; additional transfer equipment (transporters, cranes, etc.) may be needed. In this respect the tunne]-rack vault may be least adaptable, if the rate capacity of its initial emplacement system is exceeded.

\subsubsection{Waste Form Sensitivity}

Currently the waste forms envisioned for storage at an MRS facility would be primarity consolidated, canistered spent fuel and its associated assembly hardware. Future changes in the waste management system could change the handling and storage requirements. A resumption of commercial spent fuel reprocessing, for example, could make HLW canisters the predominant waste form. As was noted in the initial evaluation, only minor modifications would be needed in any of the storage concepts to meet changes in waste form such as this. The same is true with the added concepts. NUHOMS would need only modifications to the basket in the storage canister; a water pool would require installation of new storage racks.

Water pools present a special case of waste form sensitivity. The packaging of spent fuel for geologic deposition is intended to assure longterm isolation of the fuel and its package from the surrounding environment. The fuel must be dry when packaged to assure this condition. Fuel that is stored as bare assemblies in water pools is subject to internal wetting of 
some rods via water entry through pinhole leaks in the cladding. Normally the handling of fuel after its removal from a reactor pool suffices to remove this water as the fuel temperature increases during shipment, hand 1 ing and pre-emplacement storage. If water pool storage is used at MRS, re-wetting of some fuel rods may occur; a separate drying step would be required prior to packaging of the fuel. Additional in-building vault storage or its equivalent would be needed to provide for the storage, and time required for handling of a batch for shipment would be increased.

\subsubsection{Heat Load Sensitivity}

Spent fuel arriving at the MRS facility is expected to range in age (time since discharge) from 5 years (the minimum age set in 10 CFR 961) to 20 years or more. There will also be a considerable range of burnup of the fuel prior to discharge. These factors will combine to result in substantial variation of the heat generation rate in the spent fuel. Spent fuel in storage must be maintained with cladding temperatures below specified limits, generally taken as $400^{\circ} \mathrm{C}$ when the fue $\mathrm{T}$ is in an inert-gas atmosphere, to preclude possible deterioration of the cladding. Criteria for the MRS conceptual design call for a maximum temperature of $375^{\circ} \mathrm{C}$ (PNL 1985) to provide an additional safety factor.

The storage concepts employing surface storage generally have low sensitivity to the heat load of the fuel. Water pools are outstanding in this respect, since they normally operate at low temperatures and have substantial heat dissipation capability. The open-cycle vault, the NUHOMS vault, and the tunnel-rack vault also have low sensitivity, since they operate with natural-draft air cooling systems in which a rise in canister temperature would tend to increase the flow of cooling air. The heat-pipe cooling of internally-circulating air in closed-cycle vaults should similarly act to minimize heat sensitivity.

Casks that depend on both conduction of heat through the cask wall and convective cooling by the surrounding air would exhibit somewhat greater sensitivity. In-ground concepts, the drywells and cask-in-trench designs, depend primarily on soil conductivity for their c00ling, and hence would be the most heat-rate-sensitive. For the cask and drywell concepts (and for 
others if needed), heat rate can be regulated by adjustment of loading: selectively loading low-heat canisters with those of higher heat rate into a cask, varying the number of canisters loaded, or varying the loading of individual canisters. Any of these adjustment methods will increase the number of storage units (casks or drywells) needed; this would increase the required storage area and the costs of storage.

\subsubsection{Recovery of Capital Assets}

The MRS, as currently conceived, has a lifetime on the order of 25 to 35 years in its service to the first repository. Presumably, the nuclear power industry will be an ongoing one. Recovery of capital equipment from the MRS for use in other such facilities, or el sewhere in the waste management system, would serve to minimize total costs from the Waste Fund. For the most part, little other than salvage values can be recovered from most of the MRS concepts included in the prior evaluation or in this review. However, metal casks if used for storage could conceivably be used in storage or transportation service elsewhere in the system after their MRS service has ended. The metal cask concepts are outstanding in this regard, but the assessment of recoverability must be tempered with the question of the usability of "ancient" casks in a future technological era--if, indeed, there is a use for casks at all after fuel acceptance and disposal become routine.

\subsubsection{Critical Resource Consumption}

Certain construction materials are classified as scarce materials, and are potentially subject to market shortages, price escalation, or possible governmental regulation of use. Chromium, vanadium, lead, and nickel are among the metals in this classification that are likely to be used in MRS construction; fuel oils or other non-renewable energy resources may also be considered as scarce materials in future years. MRS concepts tied to extensive use of such materials could be subject to future delays in the construction or subsequent expansion of the storage facilities, or to unexpected cost escalations.

As found in the prior evaluation, none of the concepts have serious limitations in this respect. However, the most intensive use of critical materials is in the metal cask concept. Metal casks were rated lower than 
the other concepts in this aspect, balancing out their potential capability for cost recovery. Of the newer concepts, water pools use stainless steel in pool linings and storage racks; the NUHOMS canisters are constructed of stainless steel with lead-and-steel end shields. In neither case is the use of scarce materials as intensive as in the metal cask concept.

\subsubsection{Suitability for Phased MRS Introduction}

The DOE Standard Contract with UtiTities (10 CFR 961) provides for acceptance of spent fuel from utilities starting in January 1998. One suggested application for MRS to meet or approach that date is the construction of an initial, simplified facility having only receiving and storage facilities for acceptance of fuel in the early years, followed by the addition of complete facilities for the consolidation and canisterization of the fuel for shipment to the repository. This approach would favor a storage concept that is modular, capable of rapid deployment, and capable of safe storage of intact spent fuel assemblies in its early years, and of consolidated and canistered fuel after the MRS reaches full capability. Scenarios for both two-phase and three-phase MRS installations are being developed.

The MRS Review Commission's report to Congress, scheduled by the NWPAA for submission in June 1989, was recently relaxed to November 1989. With a favorable report, authorization to proceed is assumed, for this evaluation, to be granted in January 1990. If a phased MRS facility is to meet the January 1998 acceptance date in 10 CFR 961, it must first be sited, then designed, constructed, and placed in operation within an eight-year period.

Estimated deployment times for the design, licensing and construction of the storage concepts were given in Table 4.8. As was previously noted, an appropriate period for siting an MRS facility must be added to the times shown on the table. However, the table indicates that the closed-cycle vault and tunnel-rack vault could not be deployed with the eight-year period assumed, even if the siting time requirement were ignored. The indicated deployment time from the table is 12 to 14 months longer than that available to meet the January 1998 date for operation. The open-cycle vault and pool concepts are indicated to have only 12 -month margins in meeting the startup date; it is questionable that additional siting time requirements could be 
accommodated within that margin. The other concepts would have wider margins for deployment, ranging from 18 to 38 months, and may more easily accommodate the large degree of uncertainty in the siting schedule. A major factor in accommodation of siting schedules would be the degree to which initial stages of design can proceed independent of site selection.

If the spent fuel received during the first phase of operations in a multi-phase MRS facility is directly stored without canisterization, contamination of the storage units in contact with the fuel would occur. This would not be of immediate concern if the only use of these storage units were for storage of this fuel until it is returned to MRS for preparation and shipment to the repository. However, if the prepared fuel is required to be returned to storage, the contaminated storage units probably could not be reused without decontamination, to prevent contamination of the spent fuel canisters. The water pool, with its radwaste system, may have some advantage it this respect; however, some decontamination of the fuel canisters would still be required prior to their shipment.

If a three-phase MRS is deployed, the transportable metal cask has unique application for the first (storage only) phase; loaded at the reactors, the casks would require little more MRS site facilities than cask pads and a transporter for moving the casks from their carriers to the casks. However, the earliest fuel to be accepted may include considerable fuel from older reactors, several of which cannot handle rail casks. Special loading techniques, or special, lighter-weight casks, may need to be considered.

\subsubsection{Suitability for Use in Long-Term Storage}

The NWPA requires that MRS design be capable of storing spent fuel "for the foreseeable future." Although the current mission of MRS involves storage over a relatively short time, future occurrences in the waste management system could result in considerable extension of storage requirements for an MRS facility, with or without concomitant expansion of storage capacity. The ability to respond to such conditions must be embedded in the design to meet the NWPA "foreseeable future" requirement.

A11 storage alternates other than the water pool entail dry storage of the fuel in an inert atmosphere, with monitoring to assure integrity of the 
storage units containing the fuel. All should be capable of long-term extension of the storage period; thus, all the dry storage options were rated equally for this factor.

Water pools, however, utilize active cooling systems and have considerably higher operating costs, even during quiescent storage when no fue] handling is performed. Furthermore, fuel storage in water may in some cases result in wetting of fuel with leaking cladding (if bare fuel is stored), or wetting the interior of canisters if leaks develop. Additional equipment and operational steps may be needed to verify integrity of the canisters, and/or to allow drying of any wetted fuel, prior to packaging for disposal. Because of the unknown factors involved, water pools were given a lower rating than the other concepts for suitability for long-term storage.

\subsubsection{Concept Ranking for Flexibility}

The ranking of concepts for flexibility in the initial evaluation was used without change in the current review, except for downgrading of the closed-cycle vault because of its inability to meet schedules for a phased MRS facility. Rankings for the water pool and NUHOMS concepts were added. The resultant ranking is shown in Table 4.10.

TABLE 4.10. Concept Ranking for Flexibility

\begin{tabular}{|c|c|c|}
\hline Concept & $\begin{array}{l}\text { Original } \\
\text { Group } \\
\end{array}$ & $\begin{array}{l}\text { Re-Evaluated } \\
\text { Group } \\
\end{array}$ \\
\hline Concrete Cask & 1 & 1 \\
\hline Field Drywell & 1 & 1 \\
\hline Stationary Metal Cask & 1 & 1 \\
\hline Transportable Metal Cask & 1 & 1 \\
\hline Open-Cycle vault & 1 & 1 \\
\hline Closed-Cycle Vault & 1 & 2 \\
\hline Concrete Cask-in-Trench & 1 & 1 \\
\hline Tunne1 Drywell & 2 & 4 \\
\hline Tunnel-Rack Vault & 2 & 4 \\
\hline Water Pool & $\cdots$ & 3 \\
\hline NUHOMS Horizontal Vault & $\cdots$ & 1 \\
\hline
\end{tabular}


The concepts in Group 1 were found to have high performance ratings in the evaluation; the NUHOMS horizontal vault concept was added to this group. All were rated high on the factors included in the flexibility criterion; differences among these concepts were minor in comparison with those in lower-rated groups.

The water pool was given a Group 3 rating, based largely on its lesser adaptability to expansion of storage capacity, its apparent inability to meet schedules for phased-MRS introduction, and the uncertainties involved in its use for long-term storage. The tunnel facilities--tunnel drywell and tunnelrack vault--were assigned the lowest rating (4) because of their topographica] restrictions. 
เ 


\subsection{COMPOSITE RANKING OF CONCEPTS}

In the initial concept evaluation of monitored retrievable storage (MRS) alternatives, the procedures following the criteria-based ranking involved committee response evaluation, statistical data reduction, hierarchical analysis, and pairwise comparisons of concepts to evolve a set of weightings for the seven evaluation criteria and an ordered set of numerical rankings involving a minimum of subjective input. The complete process was not repeated in this re-evaluation. First, the criteria weightings derived in the initial evaluation were accepted, since no factors were discovered in the review which necessarily affect them. These weightings were combined with the rankings, or groupings, assigned to the concepts for each criterion, as described in Section 4, and normalized numerical rankings were derived from them. The sensitivity of the preference ranking to different values of the criterion weights was examined over a reasonable range of values for the weights. As a final step, pair-wise comparisons of the concepts were made based on updates of the detailed descriptions of concepts from the prior evaluation. Similar descriptive data for the water pool and NUHOMS concepts were added to the original base for these comparisons. The final result, while less rigorously derived than that for the initial evaluation, follows from consideration of the same factors. It is believed to be unlikely that the repetition of the prior evaluation in its full rigor would introduce sufficient change to displace the two leading contenders, or to modify appreciably the ranking arrived at herein.

The factor of flexibility could be of more importance at the current time than is indicated by its weighting, because of the uncertainties involved in the siting schedule and in the final functions assigned to MRS. However, inspection of the sensitivity analyses in Section 5.3 shows that the ranking of the top five concepts would be little affected if different weight were assigned to this criterion.

\subsection{WEIGHTING OF CRITERIA}

Criteria weightings were derived in the initial evaluation, using an analytical technique described in the report of that evaluation (Triplett and 
Smith 1984). Those weightings were accepted for use in this review, and are shown in Table 5.1. The addition of several new descriptors under the Flexibility criterion was judged to have no impact on the appropriate weight for that criterion. Therefore, the weightings developed in the initial study were accepted.

TABLE 5.1. Assigned Weights for Concept Evaluation Criteria (Triplett and Smith 1984)

\begin{tabular}{lc}
\multicolumn{1}{c}{ Criterion } & Weight \\
\hline Safety and Licensability & 0.43 \\
Environmental Impact & 0.11 \\
Socioeconomic Impact & 0.05 \\
Siting Requirements & 0.09 \\
Cost & 0.10 \\
Concept Maturity & 0.12 \\
Flexibility & $\underline{0.10}$ \\
Total & 1.00
\end{tabular}

\subsection{NORMALIZED CONCEPT RANKING}

The overall ranking of the concepts was obtained by 1) for each concept, multiplying the ranking assigned under each evaluation criterion by the weight assigned that criterion in Table 5.1, and 2) summing the resulting products for each criterion. This base composite ranking is shown in column 1 of Table 5.2. The composite ranking was then normalized to the lowest number (highest ranking) obtained, and finally ordinal rankings were assigned in order of the normalized composite; these final rankings are given in the last column of Table 5.2. Oetailed calculations in the ranking procedure are shown in Appendix A, Table A.1.

Note that the storage-only metal cask and the NUHOMS vault concept, with a composite ranking difference of only 0.01 , were given a tie for fifth ordinal rank. 
TABLE_5.2. Normalized Rankings from Multi-Attribute Evaluation

\begin{tabular}{|c|c|c|c|}
\hline Concept & $\begin{array}{c}\text { Base } \\
\text { Composite } \\
\text { Ranking }\end{array}$ & $\begin{array}{c}\text { Normalized } \\
\text { Composite } \\
\text { Ranking } \\
\end{array}$ & $\begin{array}{l}\text { Ordinal } \\
\text { Ranking }\end{array}$ \\
\hline $\begin{array}{l}\text { Concrete Cask } \\
\text { Field Drywel1 } \\
\text { Stationary Meta1 Cask } \\
\text { Transportable Metal Cask } \\
\text { Open-Cycle Vault } \\
\text { Closed-Cycle Vault } \\
\text { Concrete Cask-in-Trench } \\
\text { Tunnel Drywell } \\
\text { Tunnel-Rack Vault } \\
\text { Water Pool } \\
\text { NUHOMS Horizontal Vault }\end{array}$ & $\begin{array}{l}1.12 \\
1.27 \\
1.57 \\
2.34 \\
1.34 \\
3.16 \\
2.19 \\
3.33 \\
4.53 \\
1.41 \\
1.56\end{array}$ & $\begin{array}{l}1.00 \\
1.13 \\
1.40 \\
2.09 \\
1.20 \\
2.82 \\
1.96 \\
2.97 \\
4.04 \\
1.26 \\
1.39\end{array}$ & $\begin{array}{r}1 \\
2 \\
5 \text { (tie) } \\
8 \\
3 \\
9 \\
7 \\
10 \\
11 \\
4 \\
5 \text { (tie) }\end{array}$ \\
\hline
\end{tabular}

\subsection{SENSITIVITY OF RANKING TO CRITERION WEIGHTS}

In any evaluation of alternatives that employs a numerical ranking and weighting methodology, critics can claim that the results are biased by the value judgements made by the evaluators in ranking the alternative concepts under a given criterion, and by the weights assigned to each criterion. The analyses presented here explore the sensitivity of the final preference ranking of the storage concepts to the values of the weights assigned to each criterion, and also explore the effect of requiring a full 11-position rank under each criterion even when several concepts are tied.

\subsubsection{Variations in Assigned Criterion Heights}

The criterion weights utilized in the base analysis were developed by an independent committee of experts, as described in Section 1.1. For this sensitivity anaiysis, three additional sets of weights were selected that cover a range of reasonable values for such weights. The values of all four sets of weights are shown in Table 5.3.

\subsubsection{Utilization of 11-Position Criterion Ranking}

In the original analysis (Triplett and Smith 1984) and in the base analysis for this re-evaluation, the rankings under a given criterion were given sequential numbers; i.e., if three concepts tied for lst place under that criterion, the next ranking concept was assigned a rank of 2 . This has the 
IABLE 5.3. Values of Criterion Weights Used in the Sensitivity Analyses

\begin{tabular}{|c|c|c|c|c|c|c|c|}
\hline $\begin{array}{l}\text { Weight } \\
\text { Set }\end{array}$ & $\begin{array}{c}\text { Safety } \\
\text { and } \\
\text { Licens- } \\
\text { ability }\end{array}$ & $\begin{array}{c}\text { Environ- } \\
\text { mental } \\
\text { Impact } \\
\end{array}$ & $\begin{array}{c}\text { Socioec- } \\
\text { onomic } \\
\text { Impact } \\
\end{array}$ & $\begin{array}{l}\text { Siting } \\
\text { Require- } \\
\text { ments }\end{array}$ & Cost & $\begin{array}{l}\text { Concept } \\
\text { Maturity }\end{array}$ & Flexibility \\
\hline $\begin{array}{l}\text { Base } \\
\text { Equal } \\
\text { Var. } 1 \\
\text { Var. } 2\end{array}$ & $\begin{array}{l}0.43 \\
0.143 \\
0.20 \\
0.10\end{array}$ & $\begin{array}{l}0.11 \\
0.143 \\
0.10 \\
0.05\end{array}$ & $\begin{array}{l}0.05 \\
0.143 \\
0.05 \\
0.05\end{array}$ & $\begin{array}{l}0.09 \\
0.143 \\
0.10 \\
0.10\end{array}$ & $\begin{array}{l}0.10 \\
0.143 \\
0.25 \\
0.30\end{array}$ & $\begin{array}{l}0.12 \\
0.143 \\
0.15 \\
0.20\end{array}$ & $\begin{array}{l}0.10 \\
0.143 \\
0.15 \\
0.20\end{array}$ \\
\hline
\end{tabular}

effect of compressing the spread under a given criterion between the top- and bottom-ranked concepts. The number of positions in the criterion rankings ranged between 1 to 3 and 1 to 6 , rather than 1 to 11 , as would reflect the number of concepts. To examine the effect this compression had on the fina] preference ranking, a sensitivity analysis was performed wherein the ranking under each criterion was required to have the equivalent of 11 positions. For example, if three concepts were tied for lst, then those three ranks were averaged, $[(1+2+3) / 3]=2$, that average rank was assigned to the three equaliy ranked concepts, and the next-ranked concept was assigned a rank of 4. If two concepts were tied for 4th, ranks 4 and 5 were averaged (4.5) and that value assigned to both concepts and the next-ranked concepts would be placed in position 6 , and so on. The resulting rankings under each criterion are shown in Table A.5 of Appendix A. Sets of concept preference rankings were computed using both the compressed and the 11-position criterion ranks, for each of the four sets of criterion weights given in Table 5.3. These detailed computations are presented in Tables A.5 through A.8 in Appendix A.

\subsubsection{Results of the Sensitivity Analyses}

The results of the analyses on the sensitivity of the final preference ranking to different sets of criterion weights and to a compressed versus full 11-position ranking under each criterion are presented in Table 5.4. By inspection of the table, it can be seen that the top concept remains the top concept throughout all of the variations. For the most part, the secondranked concept also remains the second-ranked, and similarly for the thirdranked concept. There is some switching back and forth among the concepts ranked fourth, fifth, and sixth, and among the concepts ranked seventh, 
TABLE 5.4. Results of the Sensitivity Analyses

Fina1 Preference Concept Rankings

Computed for Various Weights

(Compressed criterion rank /11-position criterion rank)

Storage Concept

Base

Equal

Variation

Variation

Concrete Cask

Field Drywe?1

Open-Cycle Vault

Water P0ol

Horizontal Modular Vault

Stationary Metal Cask

Concrete Cask-in-Trench

Transportable Metal Cask

Closed-Cycle Vautt

Tunnel Drywe11

Tunnel-Rack Vault

Weights

Weights

I Weights

2 Weights

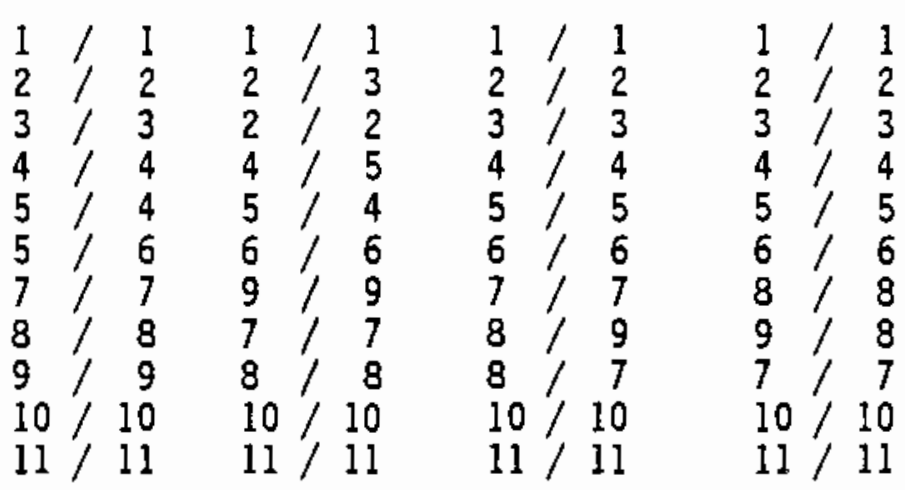

eighth, and ninth. The tenth and eleventh ranked concepts remained in those positions throughout the variations. The conclusion to be drawn from these results is that the ranking of concepts is relatively insensitive to the assigned criterion weights over a wide range of values, and is also relatively insensitive to whether one uses a full 11 -position rank or a compressed rank under each criterion in the evaluations. This result reinforces the validity of the ranking derived using the base ranking methodology and the pair-wise comparisons.

\subsection{RANKING VERIFICATION}

In a step similar to the pairwise comparisons used in the initial evaluation, a compilation of concept characteristics that was provided in a support paper for the initial anajysis was thoroughly reviewed to ascertain that the rankings given the concepts were in concordance with the earlier evaluations of the concepts, as updated, and with the characteristics of the added storage candidates. During the verification, lists of advantages and disadvantages of each concept that are listed in Triplett and Smith (1984) were used and updated to cover recent experience; similar lists were prepared for 
the added concepts. This comparison verified that the order of ranking obtained in the multi-attribute evaluation was appropriate, with one exception as shown later.

The comparative listings are given in the following subsections; the order of listing conforms to the ranking developed and reported in Table 5.2.

\subsubsection{Concrete Cask}

The concrete cask was first-ranked of the storage concepts evaluated herein. It has been studied extensively in the past, has a long history of successfut use in storage demonstrations, and provides a simple and flexible design with safety, ease of retrievability and low cost. The principal advantages of the concrete cask are:

- Its history of successfut application for demonstration storage programs, and for storage of CANDU and HTGR fuels, provides ample evidence of its safety and reliability in operation, and of its low and predictable costs of construction and operations. This extensive history also gives confidence of ease in licensing.

- The concrete cask was selected in 1975 by the National Academy of Sciences (NAS 1975) as the recommended storage concept for the Retrievable Surface Storage Facility (RSSF), for temporary storage of commercial reprocessing wastes prior to their disposition in a repository. It was also selected by DOE as the reference storage concept for the MRS facitity (DOE 1984).

- The concrete cask is the second least expensive storage concept considered. It is slightly more expensive than the field drywell. However, the cost of cask storage is relatively insensitive to site conditions. Unfavorable soil conditions at a site, for example, can increase the cost of a drywell system to near-equality with those of one using concrete casks.

- The cask concept is highly adaptable to incremental expansion; additions of as little as one cask can be readily made. Also, casks are assumed to be manufactured at an on-site (or near-site) concrete batch plant; they can be produced in the number needed, with minimal concern over delays in delivery of the units.

- All handling of fuel or fuel canisters is performed within the R\&H building, where any radioactive releases that may result from hand ing accidents can easily be controlled or contained. In contrast, several alternative concepts involve extensive handling in the storage yard, in movable transfer casks or similar mechanisms, where releases, should they occur, would be difficult to control. 
- The ready transportability of the casks and the ease of construction of the surface pads on which they are mounted make them insensitive to site characteristics which may affect the size, shape or continuity of the storage field. Also, as was noted in the initial evaluation (Triplett and Smith 1984), casks may be perceived as less permanent than other concepts.

- The casks are constructed on-site as needed; cask availability would be independent of outside suppliers.

The principal disadvantages of the concrete cask concept are:

- A field of concrete storage casks is highly visible; the cask design selected for the MRS Program is approximately 6.7 meters in height and 3.7 meters in diameter. Approximately 1200 casks would be required to contain the projected 15,000 MTU inventory of spent fuel with associated disassembly hardware. In this study, a storage area of 47 acres was estimated to be required; the more conservative estimate of the MRS A-E was 90 acres. Such a field would present a significant visual impact in either case, and masking or blending in of this impact would be difficult. Construction of a berm around the storage field would help in this regard.

- The cask manufacturing facilities (located on or near the MRS site because of the awkwardness of offsite transportation of the casks) would add to the site complexity and need for services. The cost of the manufacturing plant is amortized in the cost of the casks, however, independent of its location.

- The "forest" of casks in a field would impede visibility of all but the outermost casks. Comparatively more emphasis would need to be placed on instrumented surveillance systems to counter entry into a field and resulting exposure to the residual radiation field.

\subsubsection{Field Orywell}

The field drywell is second-ranked of the concepts studied in this evaluation. In addition to its low cost, it has the advantage of extensive operational experience and use in demonstrations, is simple to construct, and is non-obtrusive. It was the lowest-cost of all concepts evaluated, although the costs are subject to considerable variation with changes in site conditions. The principal advantages of the field drywell are:

- This concept has been used in storing HTGR spent fuel from Peach Bottoml since 1971, and for Fermi-1 since 1975 (Anderson and Meyer 1980). It a]so has an extensive history of testing and demonstration at Hanford, the Idaho Nuclear Engineering Laboratory, the Nevada Test Site, and el sewhere in the DOE waste management program. A large amount of experimental data has been gathered from these activities, resulting in 
a high level of confidence that behavior of the drywells and their costs of construction and operation can be accurately predicted. The experience gained al so lends confidence that a drywell system could be designed, licensed and constructed in a timely and predictable manner.

- The drywell provides a high degree of flexibility, and readily adapts to changing storage capacity requirements. As little as one drywell at a time may be added if desired; this can be equivalent to 0.3 to 1 metric ton of fuel. The drywell field also permits random and rapid access to any canister desired for retrieval.

- The field drywell, under favorable conditions, is the least expensive of all storage concepts considered. Its cost also tends to be insensitive to the type of fuel stored. Variations in well diameter and spacing can be made to acconmodate essentially any waste type.

- This concept has much smaller visual impact than do others (on the other hand, surface area requirements for a drywell field are considerably greater than for any other concept studied except the related tunnel drywell or concrete cask-in-trench). Leakage of one canister would not contaminate other canisters in storage in adjacent drywe1ls; facility operations would not be disrupted by such an incident, and recovery would be eased by the relative isolation of each canister.

- The field drywell concept provides for ready identification and location of a leaking fuel canister. Each drywell is individually monitored through sampling of the inert gas space around the canister, and groundwater beneath the storage field is monitored to guard against transport of any radionuclides from the vicinity of the drywells if they should somehow escape from the canister and drywell structure without detection by the gas monitoring system.

- The low construction cost and simplicity of the drywell concept result in correspondingly low decommissioning costs (Appendix A). The indicated decommissioning costs for this concept are lower than for any other concept except the water pool.

The principal disadvantages of the field drywell concept follow. They result mainly from the below-surface storage used in a drywell concept and in the effects of various site characteristics on drywell cost and performance.

- Sites requiring extensive leveling of the field, or extensive rock drilling for placing the drywell liners, could increase capital costs considerably.

- The surface area requirement for the field drywell concept is the largest of the concepts considered except the closely-related tunnel drywell concept or the cask-jn-trench concept. 
- The underground location of spent fuel in drywells may lend an air of permanence to the storage field; in addition, some may view drywe 11 storage as presenting a hazard of soil contamination.

- Low conductivity of the soil could increase the already large surface area requirements for the drywell field significantly. Similarly, excess soil moisture could result in problems of corrosion of the drywell structure. Use of cathodic protection from corrosion, or construction of earthen berms for placing the drywell field, could alleviate problems associated with ground water and possibly could provide higher-conductivity pathways for heat dissipation.

- Handling of the spent fuel canisters in placing them in drywells takes place in an open field; any radiation releases resulting from handling accidents would be difficult to confine.

\subsubsection{Qpen-Cycle Vault}

The open-cycle vault concept has been employed extensively in Britain for storage of Magnox fuel. It is similar to the drywell in some of its operational aspects, but features a storage facility enclosed in a protective building she17. The principal advantages of this storage concept are:

- Its modular structure allows considerable flexibility of expansion as capacity requirements increase. Like drywells, the canisters are placed one to a storage position and can be readily accessed for retrieval. However, unlike field drywells, the storage additions are made by adding segments to the vault structure; for a typical design, the unit of increase is approximately 300 storage units.

- Vaults at the Idaho Nationa] Engineering Laboratory in Idaho and at Wyfla in the United Kingdom have provided a significant base of operating experience.

- A vault features storage within an engineered surface facility that is essentially independent of site features. It is moderate in its land requirements.

- The enclosed structure of a vault makes unauthorized access to the stored material more difficult than in open storage arrays.

- The life-cycle cost of a vault structure is relatively insensitive to the type of material stored. For this evaluation (Table 4.6), the lifecycle cost of an open-cycle vault installation is estimated to be about $85 \%$ above that for a concrete cask system, or about 2.4 times that for a drywell installation.

- A topical report on the open-cycle vault concept has been filed with NRC by Foster-Wheeler (FW-1987) as a first step toward licensing of the concept. 
The principal disadvantages of the open-cycle vault concept are:

- The concept has less accumulated experience and more operationa] complexity than either the concrete cask or the drywell concepts, and its licensability is less assured than those two concepts.

- The large vault structure may be perceived as more permanent than the concrete cask or drywell concepts, and therefore less desirable in the eyes of the local public.

\subsubsection{Water Pool}

The water pool is the most developed of all the concepts studied. It has been used for spent fuel storage since the earliest days of nuclear reactor operation, and is universally used at LWRs today. The principal advantages of the water pool for MRS are:

- Licensability of the water pool is essentially assured. All U.S. LWR power reactors utilize pools, all of which have been licensed under NRC regulations 10 CFR 50; the pool at the Morris spent fuel storage facility has been licensed under 10 CFR 50 , and subsequent Ty under 10 CFR 72 (NRC 1982), as an away-from-reactor storage facility.

- NRC, in the Federal Register publication 49 FR 171, has expressed its confidence in pool storage of spent fuel for up to 30 years following fina] shutdown of the reactor where it was irradiated.

- The water pool affords ready accessibility of any canister of spent fuel (or assembly, if uncanistered fuel is stored) with little effort. Each canister is stored in an individual rack position within the pool.

- The life-cycle costs for a pool were found to be midway between those for drywells and those for the open-cycle vault.

- The large inventory of water in the pool provides thermal inertia, which would preserve cooling action for considerable lengths of time if the active cooling system should fail. It also provides radiation shielding, and tends to provide some cushioning of the fuel against impact from falling objects.

The principal disadvantages of the water pool concept are:

- The pool is an "active" storage system. Its cooling and radioactive waste treatment systems must be kept in constant operation, involving consumption of electric energy, periodic replacement of ion-exchange resins, and utilization of multi-shift crews for operations and maintenance. This requires considerably larger 
operating costs than storage concepts using passive cooling. These costs could mount rapidly during protracted storage periods should they occur.

- The pool is not readily amenable to incremental expansion. While expansions could be achieved, no pool has as yet been expanded in physical dimensions. Pool expansion may require pre-planning (including advance excavation of the expanded pool base) before the initial pool is constructed. The limitations on expandability could result in inefficient utilization of a large pool, or lack of storage capacity due to delays in expansion of a small one, should spent fue] storage requirements change substantially.

- Depending on the age and quantity of fuel present, pools will probably operate in a water temperature range of $30^{\circ} \mathrm{C}$ to $40^{\circ} \mathrm{C}$. Fuel that has been out of pool for transportation or packaging operations will typically be at temperatures of $300^{\circ} \mathrm{C}$ to $350^{\circ} \mathrm{C}$. The extent to which thermal shock may degrade the fuel cladding when it is introduced into the pool is not well known. Large-scale spalling of crud from the fuel cladding has been observed under similar conditions, together with development of hairline cracks in cladding which may have had incipient cracking before immersion. The effects of immersing a canister full of consolidated fuel under similar conditions, and the effects of crud spallation and cracking of the cladding on suitability of a canister for further storage and geological emplacement, need to be assessed.

- Wetting of stored fuel may occur when bare assemblies are stored, through water penetration of pinhole leaks in the cladding. Similarly, if leaks develop in fuel canisters, inleakage of water may result. Since the fuel in storage cannot conveniently be monitored for either occurrence, post-storage testing is needed to assure integrity, and additional drying steps (and resealing of canisters) must be added prior to packaging for emplacement.

\subsubsection{Stationary Metal Cask}

The stationary (storage-only) metal cask builds upon many years' extensive experience in transportation of spent fuel and other radioactive materials, and provides assurance of safety, reliability and flexibility in operations. This concept is licensed for at-reactor storage and is in use at Virginia Power's Surry plant. Its main drawback is its relatively high cost. This concept tied for fifth place in the multi-attribute evaluation. The principal advantages of the stationary metal cask are: 
- Many years of experience have been accumulated in the use of meta] casks for spent fuel transport. There is considerable experience in metal cask fabrication, and the confidence in expected construction and operations costs is high, as are the assurances of safe operation. Further, metal casks are used extensively for spent fuel storage in Europe.

- The metal cask exhibits a degree of flexibility essentially equal to that of the concrete cask and drywe11. Storage capacity can be added one cask at a time, if desired, and random access to each cask can be had in the storage field.

- No handling of storage canisters or the contained fuel takes place outside the R\&H building; radiological safety and recoverability from possible accidents are maximized.

- The above-ground location and independent placement of the metal cask makes it largely independent of site characteristics. Its land usage requirements, estimated at about 43 acres, are only marginally larger than those of the concrete cask.

- Because of its above-ground siting, it may be perceived to be less permanent than concepts featuring in-ground or underground placement, or those requiring large structures.

- The metal casks would not be subject to a high degree of contamination; presumably they could be re-used or the contained metals could be salvaged, at the end of their service. However, no credit was taken in the analys is for possible re-use or recovery. The use of an "ancient" cask in an ongoing nuclear system, some 25 to 30 years after its construction, may not be a valid assumption. Metals recovery will depend on the specific design of the cask itself, on then-existing regulations regarding re-use of materials from the nuclear industry, and on the need for storage casks in a mature waste disposa] system.

The principal disadvantages of the stationary metal cask concept are:

- The metal cask concept is expensive, due primarily to the cost of the cask itself. The calculated life-cycle costs for use of this concept, based on use of a (nominally) 125-ton cask holding about $24 \mathrm{MTU}$ of fuel and costing $\$ 900,000$ each, were $\$ 1.7$ billion, or a factor of 10 greater than was estimated for concrete casks.

- The costs for this concept are quite sensitive to the type of material being stored, to the size of individual canisters or packages, and to the heat loads of the stored material. In the scenario evaluated, about $40 \%$ of the total casks used were required for storing drums of non-fuel-bearing hardware from the fuel assemblies. 
- In the same manner as with other surface-cask concepts, the metal casks are highly visible in the storage yard, and by impeding clear view of the yard tend to be more susceptible to intrusion than are some other concepts.

\subsubsection{NUHOMS Horizontal Modular Vault}

The NUHOMS horizontal vault concept, a comparative newcomer to the scene of spent fuel storage, ranked sixth in the multi-attribute evaluation. This concept has been licensed for use at the H. B. Robinson site of Carolina Power and Light Company, and licensing at Duke Power's Oconee site is pending. Operation at Robinson is due to commence in the spring of 1989. The principal advantages of the NUHOMS system are:

- The modular system features a natural draft cooling system in which the cooling air in each module flows directly around a stainless steel sleeve that supports the storage canister. This arrangement appears to provide adequate cooling and a reasonable margin of fuel cladding temperature.

- The thick-walled concrete storage module offers appreciable physical protection against physical damage to the storage canister it contains.

- The storage canister is equipped with shielded end pieces, which reduce occupational dose during handling operations.

The principal disadvantages of the NUHOMS horizontal modular vault concept are:

- The storage canister is large, heavy, and awkward to handle. It is designed for support from its transfer cask during fuel loading and preparation for storage; all movements into and out of the storage module are by horizontal movement. There are no provisions for vertical lifting of the canister, and it is questionable whether the seal weld at the top lid could support the loaded weight.

- Loading and unloading of the vaults requires the use of a special transfer cask which accepts a storage canister in the R\&H building, is placed in horizontal position in front of a vault module, and then slides the canister horizontally into the module by means of a hydraulic ram mounted on the transfer cask carrier. The handling steps required outside the R\&H building increase the possibility of an accident, and could complicate recovery.

- Following storage, the seal-welded storage canister must be returned to the R\&H building where it is opened; the spent fuel canisters or storage drums are removed and transferred to a shipping cask for transportation to the repository. The extra work 
involved in these steps adds to the operating costs, as does the procurement of the large, end-shielded stainless steel storage canisters.

- The NUHOMS canister is currently designed for manually loading with fuel, underwater in its transfer cask, and for manually drying, inerting, and seal-welding the canister, also within the transfer cask. These operations and the equivalent unloading operations are extremely slow for MRS application, and unless mechanized would result in unacceptable levels of occupational exposure at MRS. Considerable design change would be required for MRS application.

- Costs of disposal of the NUHOMS canisters following use have not been discussed in any application to date. The disposal operations could add considerabiy to system cost.

\subsubsection{Concrete Cask-in-Trench}

The cask-in-trench consists essentially of a concrete cask submerged in a trench and backfilled so that it essentially becomes a drywel1. The concept shares many of the attributes of both the concrete surface cask and drywell systems. This concept was ranked seventh in the multi-attribute evaluation, behind the NUHOMS system. The principal advantages of the caskin-trench concept are:

- The subsurface casks are well-protected, and much less vulnerable to physical damage from natural or man-caused event than are casks mounted on the surface.

- The visual impact of a field of buried casks would be much less than for the surface casks.

The principal disadvantages of the cask-in-trench concept are:

- The heat dissipation capability of a buried cask is considerably less than for a cask in air. Smaller, more lightly loaded casks must be used, resulting in more casks and larger storage area requirements for a given storage capacity.

- The life-cycle cost of a cask-in-trench system is substantially higher than those for surface concrete casks, field drywells, or for a pool.

- The land requirements for a cask-in-trench system are nearly ejght times greater than that for surface casks.

- Each cask must be excavated prior to its removal from storage. This considerably increases the complexity of retrieval operations. 
- Lowering of a loaded cask into a trench position, and its retrieval from that position, entail appreciably more difficult lifting operations than are required for surface casks, with increased potential for accident and damage.

\subsubsection{Transportable Metal Cask}

For the scenario against which the candidate concepts were evaluated, the transportable metal cask system placed eighth in the multi-attribute evaluation. This concept is basically similar to that of the storage-oniy (stationary) metal cask, except that the same cask is used both for storage and transportation of the fuel. The principal advantages of the transportable metal cask are:

- The transportable metal cask can conceptually be used to store fuel at reactor sites (as is being done at the Surry reactor); ship the fuel to the MRS facility without reloading; store the fuel (either as received or after consolidation and canisterization in preparation for repository emplacement) in the MRS storage yard; and again ship the fuel, without further handling, to the repository.

- Use of transportable storage casks can reduce the need for procurement of dedicated shipping casks, since the transportable casks can conceivably be used for transport service after they are emptied at the repository. This option is limited, however, since only from 20 to 50 casks of this type can be accommodated within the transport fleet (DOE 1987b), whereas some 1190 casks are estimated to be required for storage at the MRS facility.

- Reloading of spent fuel from a storage cask to a shipping cask at the end of the storage period is not required, resulting in savings in operating costs of the R\&H building during shipment.

The principal disadvantages of the transportable metal cask concept are:

- The transportable metal casks are very expensive for storage use; this concept had the highest capital costs of all those considered in the evaluation. A 125-ton cask certified and licensed for shipping was estimated to cost approximately $\$ 1.75$ million (DOE $1987 \mathrm{~b})$, as compared with $\$ 900,000$ for the same cask design fabricated for storage only. However, in this study the cost per cask was assumed to be reduced to $\$ 1.25$ million, to reflect possible savings in certification costs through high-volume use (nearly 1,200 casks would be required). Fifty sets of personnel barriers, impact 1 imiters, and associated shipping hardware, for re-use in the system, were also assumed at an additional $\$ 500,000$. Total life-cycle costs for this system approximated $\$ 2.3$ billion dollars (Appendix A), including an estimated savings of $\$ 30$ million in reduced R\&H building operations. An additional $\$ 70$ million was 
estimated in savings to the transportation system, in elimination of the need for separate MRS-to-repository shipping casks.

However, this saving was not credited to the MRS system.

- As with the storage-onty metal cask, system costs are quite sensitive to the form and characteristics of the material being stored.

- As with other cask concepts, the casks during storage are open and exposed, and have high visual impact. They are also more susceptible to intrusion than are in-ground or building-enclosed concepts.

\subsubsection{Closed-Crcle Vault}

The closed-cycle vault is similar to the open-cycle vault concept in that large, engineered surface structures are used in both systems to house the material being stored. However, the closed-cycle vault is more complex and less mature than is the open-cycle system. The closed-cycle vault ranked ninth in the multi-attribute evaluation. Its major advantages are:

- Its design and operation are relatively independent of site characteristics.

- In this concept, the canisters of spent fuel or disassembly hard. ware are sealed within special storage containers prior to placement in the vault. The container in turn is sealed into a position in the vault module. Air ducts cast into the module structure provide natural-draft convective cooling of the containers; the air in turn transfers the heat to a heat pipe, which then transfers it to the outside air. This arrangement provides total isolation of the stored material from the environment.

- Rapid, random access to all storage locations, for retrieval of specific fuel canisters or groups of canisters, is available.

- The vault structure is modular in nature, and can be expanded as the need arises by adding more pre-cast concrete modules.

- Storage increments as small as one storage module (pre-cast module with approximately nine canister storage positions) can be made when needed.

The principal disadvantages of the closed-cycle vault concept are:

- The concept lacks demonstration or operational experience; it exists only as a concept without the benefit of full design. Therefore, confidence in the prediction of heat-removal performance 
is less than for several other concepts. Considerable additiona] design development, and likely a demonstration of the concept, would be needed before licensing could be considered.

- Costs of the closed-cycle vault are higher than for any surface facility concept except metal casks.

- The use of sealed storage canisters to enclose the fuel/waste canisters introduces additional handling steps, in the application of the outer canisters and in their opening and the removal of the contents for shipment.

\subsubsection{Tunne] Drywe1l}

The tunnel drywell concept shares many of the same features as the field drywe11. The extensive operational experience with tunnel drywells at the Nevada test site, and later at the Basalt Waste Near-Surface Test Facility at Hanford, gives confidence in the operational characteristics of the concept, including heat removal capabilities. Reasonable confidence also exists in the estimated costs of construction and operation. The main advantages of the tunnel drywell concept are:

- With the drywells contained in tunnels, there is essentially no visual impact from the storage installation.

- The storage field is easily secured against intrusion.

The principal disadvantages of the tunnel drywell concept are:

- This concept requires a nearby hillside or mountain composed of capable rock for construction of the tunnel facility; this reduces the number and locations of suitable sites.

- Since the stored materials would be placed underground in the tunnels, the concept could encounter public resistance in that it would be perceived as a near-surface repository. This coutd cause delays both in finding an acceptable site and in subsequent intervention in licensing procedures.

- Construction of the tunnels causes additional interaction with the site, primarily from the spoils piles resulting from tunnel construction. Similarly, costs of recovery of the site during decommissioning would be increased due to backfilling of the tunnels.

- The construction of tunnels would lend an air of permanence to the storage facility. 
- The estimated life-cycle cost of this concept is higher than for any other concept except metal casks. Surface land requirements are minimal, but underground area requirements, at 380 acres, are higher than area requirements for any other concept.

\subsubsection{Tunnel-Rack Vault}

The tunnel-rack vault concept is an innovative one which, although moderately priced and providing secure storage, is the least mature and most complex of all the concepts considered. It would require extensive development and demonstration to assure safe, reliable and licensable operations. Consequently, this concept was ranked lowest of all those considered in the multi-attribute evaluation. The principal advantages of the tunnel-rack vault concept are:

- With all storage locations within tunnels, there is essentially no visual impact from the storage area, a feature this concept shares with the tunnel dryweil.

- The storage locations are easily secured against intrusion.

- Estimated life-cycle costs of this concept are intermediate between those of the concrete cask and water pool concepts.

- Surface land requirements for the tunnel-rack concept are minimal; they consist only of an addition to the R\&H building to provide interface with the tunnel systems, and head structures for vent shafts from the underground tunnels, used for natural-draft cooling air circulation. The tunnel system itself is estimated to cover approximately 20 acres; this is the smallest area requirement for any concept except the water pool or open-cycle vault.

The principal disadvantages of the tunnel-rack vault concept are:

- The complete lack of demonstration and operating experience leads to lower confidence in estimates of heat-removal performance and of life-cycle costs.

- The complexity of the fully automatic operating system, with fully remote operation, leads to major questions of the safety and reliability of operations. Recovery from malfunctions of equipment in the storage area could present major problems. Substantially more development and demonstration would be needed to assure licensabi]ity of the concept.

- Access to the stored canisters is slow and in sequential, last-infirst-out, order. Considerable shuffling of canisters among storage locations would be needed to retrieve selected canisters. 
- The canisters are the last barrier to prevent escape of radioactivity to the cooling air, if the fuel cladding were to fail. This air is discharged directly to the atmosphere. Containment of radioactivity if a canister were ruptured during handling, for example, would be difficult. 


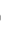




\subsection{CONCLUSIONS AND RECOMMENDATIONS FOR STORAGE CONCEPTS}

The multi-attribute evaluation performed as described in Section 4, as a review of the earlier analysis in 1983, followed by intensive comparison of characteristics as discussed in Section 5 , led to a conclusion similar to that reached in the earlier analysis (Triplett and Smith 1984): any of the eleven candidate concepts evaluated could function satisfactorily as the storage concept for an MRS facility. However, the concepts have wide variations in characteristics that affect their performance as storage facilities under differing conditions. The earlier evaluation pointed out several bases for selection of one or more candidate concepts, resulting from the concept evaluations performed at that time. The initial evaluation was made on the assumption that the MRS facility would be a backup to a repository. Later, the integral MRS facility, with functions central to the waste management system, was carried through conceptual design and a proposal for its construction was submitted to Congress (DOE 1987a). The enactment of the Nuclear Waste Policy Amendments Act (NWPAA) in 1987 introduced further changes in both the timing and the process of developing the waste management system. However, the basic requirements for an MRS concept remain as before; the changes that have occurred are relatively minor.

In this present evaluation, the multi-attribute evaluation set up a putative order of preference for selection of a concept. The effects on the rankings of assigning other reasonable values to the criterion weights were examined, and the rankings were found to be essentially insensitive to changes in the values of the weights. The subsequent examination of differences in concept characteristics, as expressed in the lists of advantages and disadvantages, and evaluation considering the five-point base for selection described below, reinforced that order of preference.

The basis for MRS concept selection, modified from that given in the earlier analysis, comprises five factors as follows:

1. While the benefits from constructing and operating an MRS facility are basic to the waste management system, additional benefit accrues from the ability to deploy an MRS facility such that operations can begin as soon as feasible. Starting the acceptance of fuel in 1998, as specified in the original NWPA, minimizes the 
requirements and costs for at-reactor storage of fuel. Thus, deploying an MRS facility by this date, or as soon as feasible thereafter, would maximize storage benefits to the waste system. Storage concepts that can be put in operation in minimum time, with few requirements for development and demonstration and with assurance of licensability and of safe, sure operation, have definite advantages over others whose development and deployment requires more time and effort. One concept in consideration is that of the phased MRS, which begins operation as a storage-on]y facility and later adds the full array of handling and preparation procedures prior to emplacement in a repository. Concepts having short deployment times and minimum need for support facilities are advantageous from this standpoint.

2. A site for MRS has not been selected. The "best," most versatile and most useful MRS facility is one that is easily adaptable to any of a large number of sites of varying characteristics. With such a concept, a major limitation on site avajlability would be removed. The storage concept serving an MRS facility is the portion most likely to be site-dependent; selecting a concept relatively free of dependencies on site removes much of the potential difficulties in site selection.

3. The storage capacity that will be required at an MRS facility is not certain at this time. Projections of storage requirements could be changed without notice if difficulties should arise in post-licensing completion of a repository, or if ongoing operations at the repository were disrupted by operating problems. Rapid increases in capacity could be required in such cases to avoid accumulation of fuel inventories at reactors to the point where operation could be affected. The capability of a storage facility to be expanded incrementally as needed is an important factor in its worth to the facility.

4. Much of the controversy about MRS has centered on the perception that an MRS facility once put in service would become a permanent facility, delaying or perhaps displacing a repository. In view of this perception and the highly political nature of opposition to MRS, it is important that an appearance of "temporary" facilities be maintained, particularly in the storage facilities. Thus, an array of storage casks looks more "temporary" than a concept requiring a substantial building, and may be more desirable for that reason.

5. The life-cycle costs of a storage concept were given low weight in the multi-attribute evaluation. Nonetheless, cost can be an important discriminator when other attributes are less than dramatically different. Also, DOE is mandated by the NWPA as well as by good practices to carry out development and operation of the waste management system in a cost-effective manner. Costs are always 
subservient to reliability and safety of operation. However, significant cost differences among the concepts are important in selecting the "right" concept.

The preference order as determined in this re-evaluation is given in Table 6.1. The two most-preferred concepts, the concrete cask and the field drywe11, were similarly ranked in the earlier selection process. The combination of low cost, adaptability, and confidence in prediction of both cost and performance entered highly into the affirmation. of this choice. of the two, the concrete cask is preferred as the most adaptable of the concepts to changing conditions in the waste management system and the most independent of potential site conditions. It is recommended that the MRS Program concentrate on development of the concrete cask as the primary storage concept, with the drywell as backup until definitive design begins.

The third-rated concept is the open-cycle vault. This concept requires a large structure to house the storage chambers, and is somewhat higher in cost than the concrete cask or drywe 11 concepts. However, it provides secure storage, is capable of close coupling to the R\&H building, and, like the two previous concepts, offers random retrievability of fuel as needed. It is also modular in design, capable of being expanded as needed, and essentially

TABLE 6.1. Order of Preference for Concept Selection

\begin{tabular}{|c|c|}
\hline $\begin{array}{l}\text { Order of } \\
\text { Preference }\end{array}$ & Concept \\
\hline 1 & Concrete Cask \\
\hline 2 & Field Drywell \\
\hline 3 & Open-Cycle Vault \\
\hline 4 & Water Pool \\
\hline $\left.\begin{array}{l}5 \\
5\end{array}\right\}$ tie & $\begin{array}{l}\text { Stationary Metal Cask } \\
\text { NUHOMS Horjzontal Vault }\end{array}$ \\
\hline 7 & Concrete Cask-in-Trench \\
\hline 8 & Transportable Meta1 Cask \\
\hline 9 & Closed-Cycle Vault \\
\hline 10 & Tunnel Drywe11 \\
\hline 11 & Tunnel-Rack Vault \\
\hline
\end{tabular}


independent of site characteristics. Although the open-cycle vault has not been licensed in the U.S., its extensive past experience suggests that 1 icensing would not be difficult. However, it appears to be less conducive than the concrete cask and drywell concepts to the fast-track, phased-introduction mode that may well be designated for MRS deployment, and less suited for rapid, short-response increases in storage capacity that the MRS facility may be subject to accommodating. The vault structure is more complicated than that of a cask field. Design of the vault must include seismic and wind resistance of the building shell as well as integrity of the fuel-handling portions of the structure (this is true of all concepts enclosed in building structures). Construction of the vault likewise takes longer than for concrete casks, and larger increments of addition may be required commensurate with the longer construction time required. Casks, on the other hand, may be built rapidiy in as much quantity as needed, matched to the demand for their use.

The water pool concept, although well-developed and with lower lifecycle costs than the open-cycle vault, appears to adapt poorly to a need for incremental expansion. Questions relating to possible thermal stress when hot fuel assemblies or fuel canisters are re-introduced into a water poot, and to wetting of fuel over long periods, also need investigation. Furthermore, the pool entails high operating costs; life-cycle costs would increase disproportionately if the period of storage were to be extended significantly.

The NUHOMS concept, although it has been licensed for at-reactor storage, was ranked Tow because of its higher cost and because of the complex loading/unloading procedures required in the storage yard. Such procedures may be less desirable with a 3,000 MTU-per-year rate than with the much lower handling rates at a reactor site.

Both the metal cask concepts were given low preference ratings principally because of their higher costs. Other concepts could perform as we11 for much less. However, for storage of smaller quantities of fuel, the disadvantages of metal casks are less important. In particular, transportable 
storage casks could serve well for the first phase of a three-phase MRS facility, with an alternate concept used for later phases.

Tunnel drywells and the concrete cask-in-trench concept have substantially higher costs, and do not add appreciably to the safety or reliability of operation afforded by the preferred concepts. The concrete cask-in-trench concept is awkward in retrieval operations, and the tunnel drywell concept would severely restrict the available sites.

Neither the closed-cycle vault nor the tunnel-rack vault has any developmental history, and it is doubtful that they could be developed in time for use in the MRS Program. In particular, the tunnel-rack vault concept is highly complicated and would require a major development effort.

Thus, although all the storage concepts considered could provide suitable storage for an MRS facility, the concrete cask and the field drywell, in that order, have the combination of attributes that offer low-cost, reliable operation, flexibility to different site characteristics and to changes in system requirements, and ease of licensing that make them the preferred concepts for further development as MRS technologies. 



\subsection{REFERENCES}

Nuclear Waste Policy Act (NWPA) of 1982. Public Law 97-425.

Nuclear Waste Policy Amendments Act (NWPAA) of 1987. Public Law 100-203.

49 FR 171. 1984. U.S. Nuclear Regulatory Commission, "Waste Confidence Decision." Federal Register.

Anderson, P. A., and H. S. Meyer. 1980. Dry Storage of Spent Nuclear Fuel. NUREG/CR-1223, U.S. Nuclear Regulatory Commission. Report by Exxon NucTear Idaho Company, Inc., Idaho Falls, Idaho.

Boeing Engineering Company (BEC). 1983a. Monitored Retrievable Storage Conceptual System Study: Concrete Storage Casks. BEC-MRS-3302, Seattle, Washington.

Boeing Engineering Company (BEC). 1983b. Monitored Retrievable Storage Conceptual System Study: Open Cycle Vault. BEC-MRS-3304, Seattle, Washington.

Boeing Engineering Company (BEC). 1983c. Monitored Retrievable Storage Conceptual System Study: Cask-In-Trench. BEC-MRS-3303, Seatt7e, Washington.

Davis, J. M. 1977. "Demonstration of a Surface Storage System for Spent Fuel or Waste." Paper presented at the 70th Annual Meeting of AIChE, New York, November 11, 1977. ARH-SA-302, Atlantic Richfield Hanford Co., Richland, Washington.

F-W Energy Applications, Inc. (F-W). 1987. Topical Report for the Foster Wheeler Modular Vault Dry Store (M.V.D.S.) for Irradiated Nuclear Fuel. Docket No. M-46, Livingston, New Jersey.

Kaiser Engineers Hanford Company (Kaiser). 1984. Monitored Retrievable Storage Conceptual System Study: Dry Receiving and Handling System. KEH R-83-96, Richland, Washington.

Morrisette, R. P., and J. T. Ganley. 1984. Tunnel-Rack Monitored Retrievable Storage Facility. GA-Al7323, GA Technologies, Inc., San Diego, California.

National Research Council, National Academy of Sciences (NAS). 1975. Interim Storage of Solidified Radioactive Wastes. Panel on Engineered Storage, Committee on Radioactive Waste Management, Washington, D.C.

Nuclear Packaging, Inc. (NUPAC). 1987. Topical Safety Analysis Report for NUPAC CP-9 Concrete Storage Cask. TP-08, Rev 9, Docket No. M-44, Vo7s. 1-2. Prepared for U.S. Nuclear Regulatory Commission, Nuclear Packaging, Inc., Federal Way, Washington. 
NUTECH Engineers, Inc. (NUTECH). 1985. Topical Report for the NUTECH Horizontal Modular Storage System for Irradiated Nuclear Fuel. NUH-001, Rev. 1, Docket No. M-39. Prepared for U.S. Nuclear Regulatory Commission, NUTECH Engineers, Inc., San Jose, California.

Pacific Northwest Laboratory (PNL). 1985. Functional Design Criteria for an Integral Monitored Retrievable Storage (MRS) Facility. PNL-5673, Richland, Washington.

Ralph M. Parsons Company (Parsons). 1985. Integral Monitored Retrievable Storage (MRS) Conceptual Design Report. MRS-11, Pasadena, Cal ifornia.

Saaty, T. L. 1980. The Analytic Hierarchy Process. McGraw-Hill, New York.

Triplett, M. B., and R. I. Smith. 1984. Evaluation of Concepts for Monitored Retrievabie Storage of Spent Fuel and High-Level Radioactive Waste. PNL-5176, Pacific Northwest Laboratory, Richland, Washington.

U.S. Department of Energy (DOE). 1984. Selection of Concepts for Monitored Retrievable Storage of Spent Nuclear Fuel and High-Level Radioactive Wastes. DOE/RL-84-2, Richland Operations Office, Richland, Washington.

U.S. Department of Energy (DOE). 1987a. Monitored Retrievable Storage Submission to Congress. DOE/RW-0035/1-Rev.1, 3 Volumes, Washington, D.C.

U.S. Department of Energy (DOE). 1987b. Additional Information on Monitored Retrievable Storage. DOE/RW-0166, Washington, D.C.

U.S. Nuclear Regulatory Commission (NRC) 1981. Safety Evaluation Report Related to the Renewal of Materials License SNM-1265 for the Receipt, Storage, and Transfer of Spent Fuel Pursuant to 10 CFR 72: Morris Operation, General Electric Comoany, Docket Nos. 70-1308 and 72-1. NUREG-0709, Washington, D.C.

U.S. Nuclear Regulatory Commission (NRC). 1982. Materials License No. SNM-2500 Docket Nos. 70-1308 and 72-1, for Morris Operation Facility. General Electric Co., Grundy County, Illinois.

Washington, J. A., and J. T. Ganley. 1984. Closed-Cycle Vault Monitored Retrievable Storage Facility. GA-A17322, GA Technologies, Inc., San Diego, California.

Westinghouse Electric Company (WEC). 1983a. Monitored Retrievable Storage Conceptual System Study: Metal Storage Casks. WTSD-TME-010, Waste Technology Services Division, Pittsburgh, Pennsylvania.

Westinghouse Electric Company (WEC). 1983b. Monitored Retrievable Storage Conceptual System Study: Transportable Storage Casks. WTSD-TME-013, Waste Technology Services Division, Pittsburgh, Pennsylvania. 
Westinghouse Electric Company (WEC). 1983c. Monitored Retrievable Storage Conceptual System Study: Open Field Drywells. WTSD-TME-011, Waste Technology Services Division, Pittsburgh, Pennsylvania.

Westinghouse Electric Company (WEC). 1983d. Monitored Retrievable Storage Conceptual System Study: Tunnel Drywells. WTSD-TME-012, Waste Technology Services Division, Pittsburgh, Pennsylvania. 

APPENDIX A

COSTS AND RELATED PARAMETERS OF STORAGE CONCEPTS 
TABLE A.1. Sensitivity of Concept Rankings to Heighting of Criteria and Criterion Ranking Procedure--Original Weighting and Ranking Order

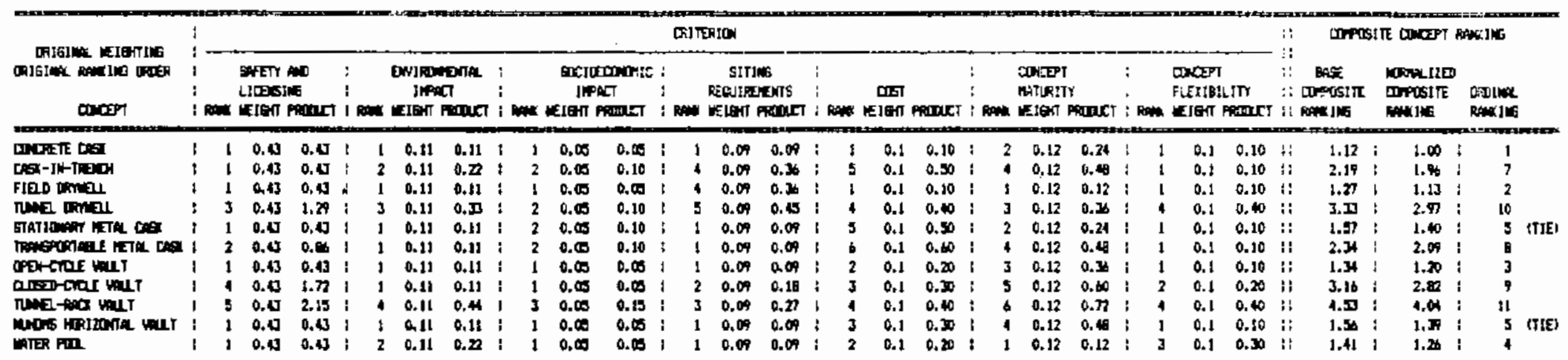


TABLE A.2. Sensitivity of Concept Rankings to Weighting of Criteria and Criterion Ranking Procedure--Equal Weighting, Original Ranking Order

\begin{tabular}{|c|c|c|c|c|c|c|c|c|c|c|c|c|c|c|c|c|c|c|c|c|c|c|c|c|c|c|c|c|c|}
\hline \multirow{2}{*}{ 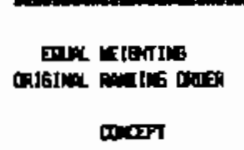 } & \multirow{2}{*}{$a_{1}$} & \multicolumn{23}{|c|}{ GIIIRIOA } & \multicolumn{5}{|c|}{ 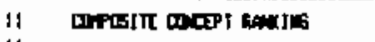 } \\
\hline & & 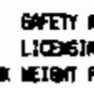 & Ther & & & time & mank & i & 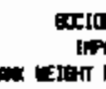 & 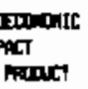 & & 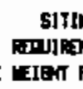 & troms & ! & & $\begin{array}{c}\cos 1 \\
\cos 10+1\end{array}$ & $\max$ & & 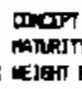 & $\begin{aligned} \pi \\
\text { rexanct }\end{aligned}$ & $\vdots$ & & 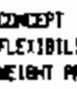 & thist & & 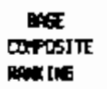 & 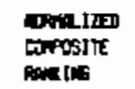 & Potim & \\
\hline 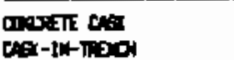 & 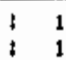 & $\begin{array}{ll}1 & 0.140 \\
1 & 0.143\end{array}$ & $\begin{array}{l}0.100 \\
0.140\end{array}$ & $\vdots$ & $\begin{array}{l}1 \\
2\end{array}$ & $\begin{array}{l}0.16 \mathrm{~J} \\
0.10 \mathrm{~J}\end{array}$ & $\begin{array}{l}0,103 \\
0,20\end{array}$ & i & $\begin{array}{ll}1 & 0.140 \\
2 & 0.140\end{array}$ & $\begin{array}{l}0.143 \\
0.256\end{array}$ & 1 & $\begin{array}{l}0.10 \mathrm{~N} \\
0.1 \mathrm{~N}\end{array}$ & $\begin{array}{l}0.10 \\
0.571\end{array}$ & $t$ & $\begin{array}{l}10 \\
50\end{array}$ & $\begin{array}{l}0.110 \\
0.101\end{array}$ & $\begin{array}{l}0.110 \\
0.714\end{array}$ & : & $\begin{array}{l}0.143 \\
0.100\end{array}$ & $\begin{array}{l}0.74 \\
0.91\end{array}$ & : & $\begin{array}{ll}1 & 0 \\
1 & 0\end{array}$ & $\begin{array}{l}0.160 \\
0.143\end{array}$ & $\begin{array}{l}0.14 \mathrm{~J} \\
0.1 \mathrm{~N}\end{array}$ & $: !$ & $\begin{array}{l}1.114 \\
2.714\end{array}$ & $\begin{array}{ll}1.000 \\
2.18\end{array}$ & $!$ & 1 \\
\hline in onal & & 10.10 & 0,10 & $i$ & & 0.10 & 0.100 & ; & 10.140 & 0.143 & $i$ & 0.10 & 0.071 & i & & 0.103 & Q.10 & $i$ & 0.143 & 0.103 & $\vdots$ & 10 & 0.10 & 0.10 & i: & $1.4 \%$ & 1.0 & $\vdots$ & \\
\hline & $i$ & 0,143 & 0.47 & $i$ & 3 & 0.143 & 0.47 & $i$ & 20.143 & 0.286 & & 0.143 & 0.74 & i & & 0.143 & 0.511 & $i$ & 0.10 & 0.429 & $i$ & +0 & 0.143 & 0.57 & it & 3. & & $\theta$ & \\
\hline TIower in & i & 10.143 & $0.10 \mathrm{~J}$ & 1 & & 0.10 & 0.100 & $:$ & 20.16 & $0.2 \mathrm{sin}$ & $i$ & 0.143 & 0.140 & i & 50 & 0.103 & 0.74 & i & 0.10 & $0.2 \%$ & $i$ & 10 & 0.143 & 0.143 & ii & 1.007 & [... & 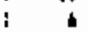 & 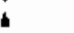 \\
\hline HORTAEF & & 20.10 & 0.20 & ; & & $0.10 \mathrm{~J}$ & 0.10 & $\mathbf{i}$ & 20.1 & $0.2 \mathrm{n}$ & i & 0.143 & 0.140 & $i$ & 6 & 0.10 & 0.67 & $i$ & 0.143 & 0.571 & i & 10 & 0.143 & 0.143 & 1! & 2.4 & 13 & & $?$ \\
\hline & 1 & 0.10 & $0.14 \mathrm{~J}$ & i & 1 & 0,143 & 0.10 & $i$ & $: 0.14 \mathrm{~J}$ & 0.103 & i & $0.10 \mathrm{~J}$ & 0.140 & : & 2 & 0.100 & $0.2 n$ & i & 0.143 & 0.49 & i & 10 & 0.143 & 0.143 & $: 1$ & 1.427 & 1.25 & & 2 \\
\hline & $i$ & 40.10 & 0.571 & : & & 0.10 & 0,163 & & $0.1 \mathrm{~J}$ & 0.100 & i & $0.10 \mathrm{~J}$ & $0.2 \mathrm{wn}$ & $i$ & 3 & 0.100 & $0 . \sqrt{10}$ & $i$ & 0.143 & 0.714 & i & $=0$ & 0.147 & 0.286 & $\because:$ & 2. & 2.2 & & 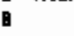 \\
\hline$-\infty x$ & ; & 50.10 & 0.714 & : & & 0.10 & 0.571 & : & ] 0.140 & 0.429 & $t$ & 0.140 & $0.47 \pi$ & : & & 0.100 & 0.51 & $i$ & 0.143 & 0.67 & $i$ & & 0.143 & 0.571 & : & 4.103 & 3.63 & 11 & 1 \\
\hline & i & 10.100 & $0.10]$ & : & & 0.103 & 0.10 & ; & $1 \quad 0.143$ & 0.143 & $i$ & $0.10 \mathrm{~J}$ & 0.143 & : & & $0.10]$ & 0.47 & & 0.10 & 0.57 & & & 0.140 & $0.1 \mathrm{~J}$ & ii & 1.714 & 1.50 & 5 & 5 \\
\hline & $i$ & $\begin{array}{lll}1 & 0.143\end{array}$ & $0.18 \mathrm{~J}$ & i & i & 0.140 & $0.2 \%$ & ; & 10.143 & 0.143 & i & $0.14]$ & 0.143 & i & 20 & $0.14 \mathrm{~J}$ & 0.20 & i & $0.10 \mathrm{~J}$ & 0.143 & $i$ & J 0 & 0.143 & 0,120 & i; & 1.571 & 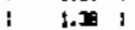 & 4 & 4 \\
\hline
\end{tabular}


IABLE A.3. Sensitivity of Concept Rankings to Weighting of Criteria and Criterion Ranking Procedure--Reconstructed Weighting (Var 1), Original Ranking Order

\begin{tabular}{|c|c|c|c|c|c|c|c|c|c|c|c|c|c|c|c|c|c|c|c|c|c|c|c|c|c|c|c|}
\hline \multirow{2}{*}{ 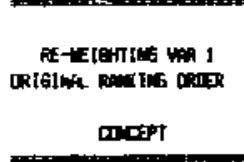 } & \multirow{2}{*}{; } & \multicolumn{21}{|c|}{ LRITERTOW } & \multirow{2}{*}{$\begin{array}{cc}: \\
\vdots \\
\vdots \\
\vdots \\
\vdots \\
: a n\end{array}$} & \multicolumn{4}{|c|}{ 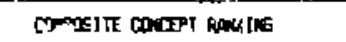 } \\
\hline & & & $\begin{array}{l}\text { SWTT } \\
\text { LICBSIE } \\
\text { LEIET }\end{array}$ & דמשת & : & Enjere & 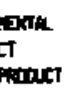 & $\begin{array}{l}\vdots \\
\vdots \\
\vdots\end{array}$ & $\underset{110}{\operatorname{man}}$ & 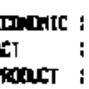 & & $\begin{array}{l}\text { SIIJ日 } \\
\text { REDities } \\
\text { CIET ? }\end{array}$ & ens & $\vdots$ & 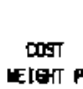 & monar & $\begin{array}{l}\vdots \\
\vdots \\
1\end{array}$ & 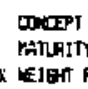 & & $\vdots$ & $\begin{array}{r}\text { CNCSPT } \\
\text { FIXIBIL } \\
- \text { MEIET P }\end{array}$ & $\begin{array}{l}\text { LTTY } \\
\text { Prowat }\end{array}$ & & 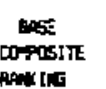 & 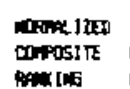 & 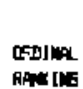 & \\
\hline $\operatorname{mox}=11 \cos x$ & ; & 1 & 0.2 & 0.20 & 1 & 0.1 & 0.10 & i & $0 . \infty$ & $0.00 ;$ & i & 0.1 & 0,10 & $:$ & 0.25 & 0.2 & ; & 0.15 & 0.30 & $:$ & 0.15 & 0.15 & :: & $1.15 \mathrm{i}$ & $1 . \infty$ & 1 & \\
\hline $3 x-12-\operatorname{tracos}$ & 1 & 1 & 0.2 & 0.20 & 1 & 0.1 & 0.20 & i & 0.00 & $0.10 \mathrm{i}$ & $i$ & 0.1 & 0,40 & i & 0.2 & $1 . \overline{0}$ & : & 0.15 & 0.60 & $:$ & 0.15 & 0.15 & i: & 2.90 & 2.5 & 7 & \\
\hline a o ond & $i$ & $i$ & 0.2 & 0.20 & 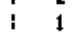 & 0.1 & 0.10 & $\vdots$ & 0.0 & 0.00 & $i$ & 0.1 & 0.40 & $i$ & 0.8 & 0.0 & $i$ & 0.15 & 0.15 & $i$ & 0.15 & 0.15 & $\because:$ & 1.30 & 1.131 & 2 & \\
\hline 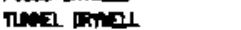 & $i$ & 3 & 0.2 & 0.00 & i & 0.1 & 0.50 & $i$ & 0.0 & $0.10 \mathrm{i}$ & i & 0.1 & 0.50 & $i$ & $0.2 \pi$ & 1.00 & $i$ & 0.15 & 0.45 & $i$ & 0.15 & 0.60 & $\because:$ & 3.5 & 3.09 & 10 & \\
\hline ATILOMT ETR Cos & ; & 1 & 0.2 & 0.20 & $i$ & 0.1 & 0.10 & $\vdots$ & 0.05 & 0.10 & $:$ & 0.1 & 0.10 & $i$ & 0.5 & 1.0 & $i$ & 0.15 & 0.30 & $i$ & 0.15 & 0.15 & i: & 2.20 & & b & \\
\hline TREOTOTI & & 2 & 0.2 & 0.40 & $i$ & 0.1 & 0.10 & $i$ & 0.0 & 0.10 & $i$ & 0.1 & 0.10 & $i$ & 0.8 & 1.50 & ; & 0.15 & 0.60 & $i$ & 0.15 & 0.15 & i) & 2.95 & $2.5 !$ & B & \\
\hline PFi- & 1 & 1 & $a .2$ & 0.20 & i & 0.1 & 0.10 & : & 0.0 & 0,05 & i & 0.1 & 0.10 & $i$ & 0.25 & 0.50 & $t$ & 0.15 & 0.0 & $i$ & 0.15 & 0.15 & $\because:$ & 1.25 & $1.35:$ & 3 & \\
\hline a defan-c & $i$ & 4. & 0.2 & 0,00 & 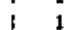 & 0.1 & 0.10 & $i$ & $0, \infty$ & 0.05 & 2 & 0.1 & 0.20 & i & 0.20 & 0.5 & : & 0.15 & 0.7 & $i$ & 0.15 & 0.30 & $\because$ & 2.55 & $2.5 i$ & B & (TIE) \\
\hline & $i$ & 3 & 0.2 & $1 . \infty$ & : & 0.1 & 0.40 & $i$ & 0,00 & 0.15 & 3 & 0.1 & 0.30 & $i$ & 0.8 & 1.00 & : & 0.15 & $0 . \%$ & i & 0.15 & 0.60 & ii & 4.55 & 3. & 11 & \\
\hline ValT & ; & j & 0.2 & 0.20 & ; & 0.1 & 0.10 & $i$ & $0 . \bar{\sigma}$ & 0.00 & 1 & 0.1 & 0.10 & 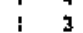 & 0.8 & $0 . \pi$ & $i$ & 0.55 & 0.60 & 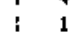 & 0.15 & 0.15 & it & 1.95 & 1.70 & 5 & \\
\hline min & $i$ & $i$ & 0.2 & 0.20 & 2 & 0.1 & 0.20 & $i$ & 0.0 & $0 . \infty \div$ & : & 0.1 & 0.10 & $z$ & 0.2 & 0.50 & $i$ & 10.15 & 0.19 & $i$ & 0.15 & 0.45 & $\because$ & $1.65 ;$ & $1.4:$ & 4 & \\
\hline
\end{tabular}


TABLE A.4. Sensitivity of Concept Rankings to Weighting of Criteria and Criterion Ranking Procedure--Reconstructed Weighting ( $\operatorname{Var} 2$ ), Original Ranking Order

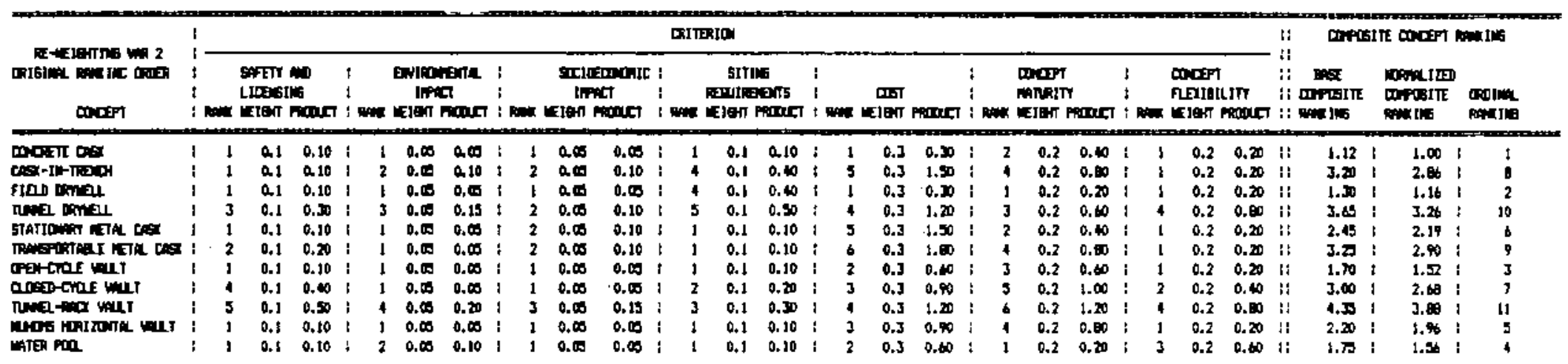


IABLE A.5. Sensitivity of Concept Rankings to Weighting of Criteria and Criterion Ranking Procedure--0riginal Weighting, Forced 11-Rank Series (ties averaged)

\begin{tabular}{|c|c|c|c|c|c|c|c|c|c|c|c|c|c|c|c|c|c|c|c|c|c|c|c|c|c|c|}
\hline \multirow{2}{*}{ 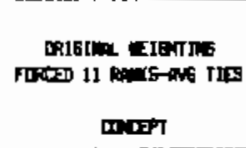 } & \multirow{2}{*}{$i$} & \multicolumn{20}{|c|}{ Lxiterion } & \multirow{2}{*}{$\begin{array}{c}n \\
\vdots \\
\vdots \\
\vdots \\
\vdots \\
i \\
i\end{array}$} & \multicolumn{4}{|c|}{ COPOSITE DOCEPT RAKING } \\
\hline & & 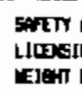 & Finer & & 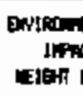 & $\begin{array}{l}\text { orat } \\
\text { c7 } \\
\text { naner }\end{array}$ & $\begin{array}{l}\vdots \\
\vdots \\
i \\
i \max \end{array}$ & 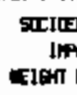 & & & 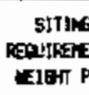 & Dits & : & 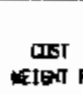 & (1) & & 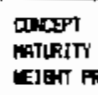 & & & 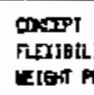 & & & 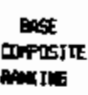 & 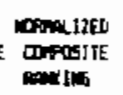 & $\operatorname{mandinat}$ & \\
\hline 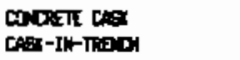 & $\begin{array}{l}1400 \\
1 \\
1\end{array}$ & $\begin{array}{l}0.40 \\
0.47\end{array}$ & $\begin{array}{l}1 . \pi \\
1.72\end{array}$ & $\begin{array}{l}4.000 \\
: 8.00\end{array}$ & $\begin{array}{ll}0 & 0.11 \\
0 & 0.11\end{array}$ & $\begin{array}{l}0.44 \\
0.74\end{array}$ & $\begin{array}{l}3.30 \\
18.50\end{array}$ & $\begin{array}{l}0.00 \\
0.00\end{array}$ & $\begin{array}{l}0.18 \\
0.47\end{array}$ & $\begin{array}{l}3.50 \\
7.50\end{array}$ & $\begin{array}{l}0.09 \\
0.09\end{array}$ & $\begin{array}{l}0.58 \\
0.03\end{array}$ & $\begin{array}{ll}1 & 1.50 \\
+ & 9.50\end{array}$ & $\begin{array}{l}0.1 \\
0.1\end{array}$ & $\begin{array}{l}0.15 \\
0.95\end{array}$ & $\begin{array}{l}3.50 \\
8.00\end{array}$ & $\begin{array}{l}0.12 \\
0.12\end{array}$ & $\begin{array}{l}0.4 \\
0.7\end{array}$ & $\begin{array}{l}4.00 \\
4 . \infty\end{array}$ & $\begin{array}{l}0.1 \\
0.1\end{array}$ & $\begin{array}{l}0.40 \\
0.40\end{array}$ & $\begin{array}{l}\$ \vdots \\
\vdots\end{array}$ & $\begin{array}{l}2.62 \\
6.20\end{array}$ & $\begin{array}{l}1.00 \\
1.3\end{array}$ & $i$ & \\
\hline a d anal & $i 4.00$ & 0.4 & $1 . \pi$ & 1400 & 0.11 & 0.4 & ; 3.50 & 0.0 & $0.1 \mathrm{~s}$ & 9,50 & 0.09 & 0.86 & i 1.50 & 0.1 & 0.15 & 1.50 & 0.12 & 0.18 & $4 . \infty$ & 0.1 & 0.40 & $: 4$ & 3.92 & 1.60 & 2 & \\
\hline ס & 19.00 & $0.4 \mathrm{~J}$ & 3.87 & $\$ 10,00$ & 0.11 & 1.10 & ; B.30 & $0 . \infty$ & 0.43 & $: 11.00$ & 0.09 & 0.9 & 7.50 & 0.1 & 0.75 & 5.50 & 0.12 & $0 .+\infty$ & ; 10,50 & 0.1 & 1.6 & II & e. & 2.4 & 10 & \\
\hline & 5.00 & 0.43 & $1 . \pi$ & 4.00 & 0.11 & 0.4 & B.20 & 0.00 & 0.47 & 3.5 & 0.09 & o. & $: 9.50$ & 0.1 & & 3.50 & o. & 0.42 & 4.0 & 0.1 & & & 4. & & & \\
\hline & $9 . \infty 0$ & 0.4 & 3.4 & 14.00 & 0.21 & 0.4 & B. 50 & 0,00 & 0.47 & 250 & 0.09 & $0 . \pi$ & $: 11.00$ & 0.1 & 4.10 & $8 . \infty$ & 0.12 & 0.96 & 4.00 & 0.1 & 0,40 & it & 7.08 & 1.2 & $\theta$ & \\
\hline Ex- & 1.400 & 0.4 & L. $n$ & $: 4.00$ & 0.11 & 0.4 & 3.50 & 0, & 0.18 & 3.50 & 0.09 & 0.52 & i 3.2 & 0.1 & $\mathbf{D}$ & \begin{tabular}{|l|l|l|}
5.50 \\
\end{tabular} & 0.12 & $0 . \$$ & 4. & 0.1 & 0.40 & :! & 4.06 & 1.12 & 3 & \\
\hline & 10.00 & 0.4 & 4.50 & 14.00 & 0.11 & 0.4 & 3.30 & 0.0 & 0.18 . & 7,00 & 0.09 & $0.6 \mathrm{~J}$ & 2.50 & 0.1 & 0.5 & ; 10.00 & 0.12 & 1.20 & i 8.0 & 0.1 & 0.20 & it & 0.10 & 2.24 & ; & \\
\hline & 131.00 & 0.4 & 4.7 & $: 11.00$ & 0.11 & t. 21 & 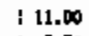 & 0.00 & 0.5 & 8.00 & 0.09 & $0 . \pi$ & 17.50 & 0.1 & $0 . \pi$ & : 11,00 & 0.12 & 1.2 & : 10. & 0.1 & & & $10 . \Omega$ & 2. & 11 & \\
\hline & $: 4.00$ & 0.43 & $1 . n$ & $: 4, \infty$ & 0.11 & 0.4 & 3.50 & 0.100 & 0.18 & 3.50 & 0.08 & 0.3 & | 5.50 & 0. & & $8 . \infty$ & & & & & & 14 & & $2 \mathrm{~b}$ & 4 & \\
\hline ter & 14.00 & 0.47 & 1.72 & 18.50 & 0.0 .11 & 0.9 & 3.50 & $0 . \infty$ & 0.18 & 3.50 & 0.09 & 0.2 & $: 3.50$ & 0.1 & 0.5 & 1.50 & 0.12 & 0.18 & 9.10 & 0.1 & 0.90 & H & $4 . \mp$ & $1.2 \mathrm{~b}$ & 4 & (IIE) \\
\hline
\end{tabular}


TABLE A.6. Sensitivity of Concept Rankings to Weighting of Criteria and Criterion Ranking Procedure--Equal Weighting, Forced 11-Rank Series (ties averaged)

\begin{tabular}{|c|c|c|c|c|c|c|c|c|c|c|c|c|c|c|c|c|c|c|c|c|c|c|c|c|c|}
\hline \multirow{2}{*}{ 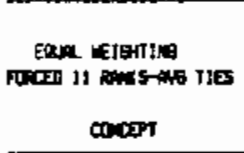 } & \multirow{2}{*}{ 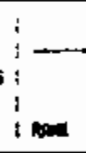 } & \multicolumn{20}{|c|}{ GIIERIN } & \multirow{2}{*}{ 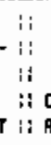 } & \multicolumn{3}{|c|}{ 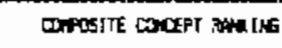 } \\
\hline & & 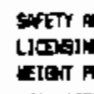 & & $:$ & 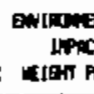 & & $i_{\sin }$ & 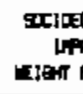 & & & 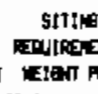 & & & $\underset{\text { DIST }}{\text { ताS }}$ & oner & : & 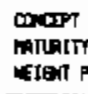 & & & $\begin{array}{l}\text { COCFPT } \\
\text { FEXI9tL } \\
\text { LEtent P }\end{array}$ & & & 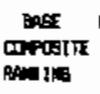 & 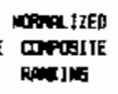 & molimk \\
\hline 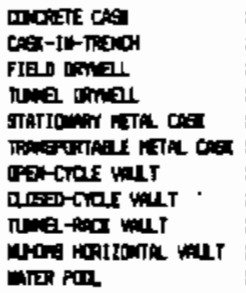 & $\begin{array}{l}4.00 \\
4.00 \\
4.00 \\
4.00 \\
4.00 \\
0.00 \\
4.00 \\
1000 \\
1 \\
1.00 \\
4.00 \\
4.00\end{array}$ & 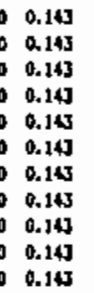 & $\begin{array}{l}0.57 \\
0.57 \\
0.57 \\
1.77 \\
0.57 \\
1.14 \\
0.57 \\
1.47 \\
1.9 \\
0.97 \\
0.57\end{array}$ & $\begin{array}{l}4.00 \\
1.50 \\
4.00 \\
10.0 \\
4.00 \\
4.00 \\
4.00 \\
4.00 \\
11.0 \\
4.00 \\
0.50\end{array}$ & $\begin{array}{ll}0 & 0.140 \\
0 & 0.10 \\
0 & 0.10 \\
0 & 0.10 \\
0 & 0.10 \\
0 & 0.110 \\
0 & 0.10 \\
0 & 0.10 \\
0 & 0.10 \\
0 & 0.10 \\
0 & 0.10 \\
0 & 0.10 \\
0 & 0.10\end{array}$ & $\begin{array}{l}0.57 \\
1.21 \\
0.7 \\
1.40 \\
0.9 \\
0.97 \\
0.97 \\
0.97 \\
1.9 \\
0.9 \\
1.21\end{array}$ & $\begin{array}{l}3.50 \\
8.50 \\
3.50 \\
8.50 \\
8.50 \\
8.50 \\
3.50 \\
3.50 \\
31.00 \\
3.50 \\
3.50\end{array}$ & $\begin{array}{l}0.14] \\
0.143 \\
0 \\
0.143 \\
0.143 \\
0.143 \\
0.143 \\
0.143 \\
0.143 \\
0.143 \\
0.143 \\
0.143 \\
0.143\end{array}$ & $\begin{array}{l}0.50 \\
1.21 \\
0.50 \\
1.21 \\
1.21 \\
1.21 \\
0.50 \\
0.50 \\
1.57 \\
0.50 \\
0.50\end{array}$ & $\begin{array}{r}7.00 \\
9.50 \\
9.50 \\
1.50 \\
11.00 \\
1.00 \\
3.00 \\
1.00 \\
7.00 \\
0.00 \\
3.00 \\
3.00\end{array}$ & $\begin{array}{ll}0 & 0.143 \\
0 & 0.140 \\
0 & 0.113 \\
0 & 0.143 \\
0 & 0.143 \\
0 & 0.143 \\
0 & 0.143 \\
0 & 0.143 \\
0 & 0.143 \\
0 & 0.143 \\
0 & 0.143\end{array}$ & $\begin{array}{l}0.43 \\
1.43 \\
1.3 \\
1.97 \\
0.43 \\
0.43 \\
0.43 \\
1.00 \\
1.14 \\
0.43 \\
0.63\end{array}$ & $\begin{array}{l}1.50 \\
7.50 \\
1.50 \\
7.50 \\
7.50 \\
11.00 \\
3.50 \\
5.50 \\
7.50 \\
5.50 \\
3.50\end{array}$ & $\begin{array}{l}0.143 \\
0.143 \\
0.143 \\
0.143 \\
0.143 \\
0.143 \\
0.143 \\
0.143 \\
0.143 \\
0.143 \\
0.143 \\
0.143\end{array}$ & $\begin{array}{l}0.21 \\
1.3 \\
0.21 \\
1.07 \\
1.36 \\
1.57 \\
0.50 \\
0.74 \\
1.07 \\
0.74 \\
0.50\end{array}$ & $\begin{array}{l}3.50 \\
8.00 \\
1.50 \\
5.50 \\
1.50 \\
0.00 \\
0.50 \\
10.00 \\
1.00 \\
0.00 \\
1.50\end{array}$ & $\begin{array}{l}0.143 \\
0.143 \\
0.143 \\
0.143 \\
0.143 \\
0.143 \\
0.143 \\
0.143 \\
0.143 \\
0.143 \\
0.143\end{array}$ & $\begin{array}{l}0.50 \\
1.14 \\
0.21 \\
0.74 \\
0.50 \\
1.14 \\
0.74 \\
1.43 \\
1.97 \\
1.14 \\
0.21\end{array}$ & $\begin{array}{r}4.00 \\
4.00 \\
4.00 \\
10.50 \\
4.00 \\
4.00 \\
4.00 \\
0.00 \\
10.00 \\
4.00 \\
9.00\end{array}$ & $\begin{array}{l}0.143 \\
0.143 \\
0.143 \\
0.143 \\
0.143 \\
0.143 \\
0.143 \\
0.143 \\
0.143 \\
0.143 \\
0.143\end{array}$ & $\begin{array}{l}0.57 \\
0.57 \\
0.97 \\
1.50 \\
0.57 \\
0.57 \\
0.97 \\
1.14 \\
1.50 \\
0.57 \\
1.29\end{array}$ & 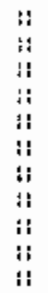 & 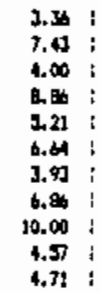 & $\begin{array}{l:}1.00 \\
2.21 \\
1.29 \\
2.64 \\
1.50 \\
1.70 \\
1.17 \\
2.04 \\
2.90 \\
1.16 \\
1.40\end{array}$ & $\begin{array}{c}1 \\
9 \\
3 \\
10 \\
8 \\
7 \\
2 \\
8 \\
11 \\
4 \\
5\end{array}$ \\
\hline
\end{tabular}


TABLE A.7. Sensitivity of Concept Rankings to Weighting of Criteria and Criterion Ranking Procedure--Reconstructed Weighting (Var 1), Forced 11-Rank Series (ties averaged)

\begin{tabular}{|c|c|c|c|c|c|c|c|c|c|c|c|c|c|c|c|c|c|c|c|c|c|c|c|c|c|}
\hline \multirow{2}{*}{ 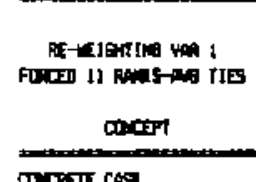 } & \multicolumn{21}{|c|}{ QITTRIOA } & & \multicolumn{3}{|c|}{ COPOSITE GACPT RAUING } \\
\hline & $i_{\operatorname{man}}$ & \multicolumn{2}{|c|}{ 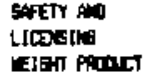 } & (1) & \multicolumn{2}{|c|}{ 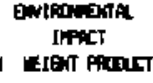 } & and & \multicolumn{2}{|c|}{ 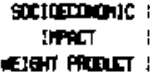 } & \multirow{2}{*}{ ant } & \multicolumn{2}{|c|}{ 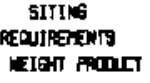 } & $\begin{array}{l}1 \\
1 \\
1\end{array}$ & प्रा & & in & \multicolumn{2}{|c|}{ 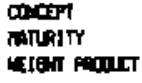 } & $\int_{1}^{1}$ & \multicolumn{2}{|c|}{ 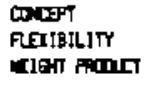 } & & 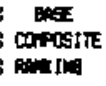 & 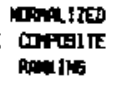 & 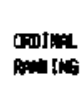 \\
\hline & $\begin{array}{l}4,00 \\
\end{array}$ & $\begin{array}{l}0.2 \\
0.2\end{array}$ & 0.0 & 1400 & 0.1 & 0.40 & 3.50 & 0.00 & 0.18 & & 0.1 & 0.30 & 1.50 & 0.27 & 0.3 & 3.50 & 0.15 & 0.3 & 1,00 & 0.8 & 0.40 & :! & 2.90 & 1,00 & 1 \\
\hline ald omelt & $\begin{array}{r}4.00 \\
: \quad .00\end{array}$ & $\begin{array}{l}0.2 \\
0.2\end{array}$ & $\begin{array}{l}0.80 \\
0.90\end{array}$ & $\begin{array}{ll} & 0.50 \\
4 & 4.00\end{array}$ & $\begin{array}{l}.1 \\
0.1\end{array}$ & $\begin{array}{l}0.40 \\
0.40\end{array}$ & $\begin{array}{ll}1 & 0.50 \\
1 & 3.50\end{array}$ & $\begin{array}{l}0.09 \\
0.05\end{array}$ & $\begin{array}{l}0.13 \\
0.16\end{array}$ & $\begin{array}{r}\quad 9.50 \\
: \quad 9.50\end{array}$ & & $\begin{array}{l}0.95 \\
0.58\end{array}$ & & $\begin{array}{l}0.29 \\
0.28\end{array}$ & $\begin{array}{l}\text { 2.표 } \\
0 . \text { 표 }\end{array}$ & $\begin{array}{l}: 9.00 \\
1.50\end{array}$ & $\begin{array}{l}0.15 \\
0.15\end{array}$ & $\begin{array}{l}1.20 \\
0.27\end{array}$ & & .1 & $\begin{array}{l}0.40 \\
0.40\end{array}$ & $\begin{array}{l}14 \\
i:\end{array}$ & $\begin{array}{l}7, \infty \\
3.1\end{array}$ & $\begin{array}{l}2.35 \\
: .12\end{array}$ & 7 \\
\hline & 9.00 & 0.2 & 1,80 & 10.0 & 0.1 & $1, \infty$ & 8.50 & 0.00 & 0,45 & $: 11 . \infty$ & 1 & 1.10 & $: 7.50$ & 0.27 & 1.8 & $\mathbf{5 . 5 0}$ & 0.15 & 0.85 & & & 1.00 & & & & 10 \\
\hline 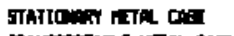 & 4.00 & 0.2 & $0 . \oplus 0$ & 14.00 & 0.1 & 0.40 & 8.50 & 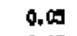 & 0.43 & 3.00 & 0.1 & 0.70 & 19,50 & 0.2 & $2 \pi$ & 3.50 & 0. & ass & & 4 & 0.40 & & 1 & t. & 6 \\
\hline & 18.00 & 0.2 & 1.80 & $1+\infty, 0$ & 0.1 & 0.40 & 8.50 & 0.00 & 0.0 & 3.00 & 0.1 & 0.30 & $: 11 . \infty$ & 0.2 & $2 . \pi$ & $\mathbf{8 . \infty}$ & 5 & 1.20 & 4. & & 0.6 & & 7.68 & & 9 \\
\hline & 14,00 & 0. & 0.80 & 4,00 & 0.1 & 0.40 & 3. & 0. & 0.1 & 3. & & 0.7 & ; J. & 0.2 & 0.8 & ; 3.50 & 0.15 & 0.03 & & & 0.40 & & & & 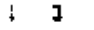 \\
\hline & $: 10.00$ & 0.2 & 2.00 & $: 4.00$ & 0.1 & 0.40 & i 3.50 & 0.05 & 0.18 & 17.00 & 0.1 & 0.70 & 5.50 & 0.2 & 1.38 & $: 10.00$ & 0.15 & 1.50 & B. 00 & .1 & 0,0 & & & & \\
\hline & 111.00 & 0.2 & 2.20 & 111.0 & 0.1 & 1.10 & $: 11, \infty$ & & & & & & 7.50 & 0. & l. & & & & & & & & & & \\
\hline & $14 . \infty$ & 0.2 & 0.80 & $4, \infty$ & 0.1 & 0.40 & 3.50 & 0.05 & 0.18 & 3.0 & 0. & 0.30 & 2.50 & 0. & 1.39 & 18.00 & & & & & & & & & 5 \\
\hline & $14 . \infty 0$ & 0.2 & $0 . \infty 0$ & : 250 & 0.1 & 0.国 & i 3.50 & 0.50 & 0.18 & $J . \infty$ & 0.1 & 0.5 & 750 & 0.2 & & 1.50 & 0.15 & 0.2 & 9.00 & 0.1 & $0 . \$ 0$ & & 4.13 & $1.39:$ & * \\
\hline
\end{tabular}


TABLE A.8. Sensitivity of Concept Rankings to Weighting of Criteria and Criterion Ranking Procedure--Reconstructed Weighting (Var 2), Forced 11-Rank Series (ties averaged)

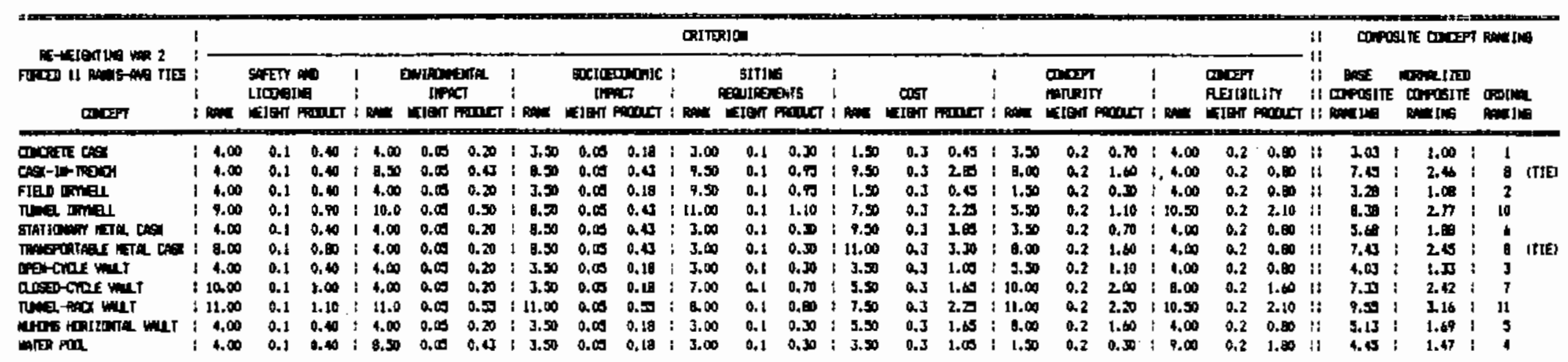


TABLE A.9. Comparisons of Storage Costs and Required Storage Areas

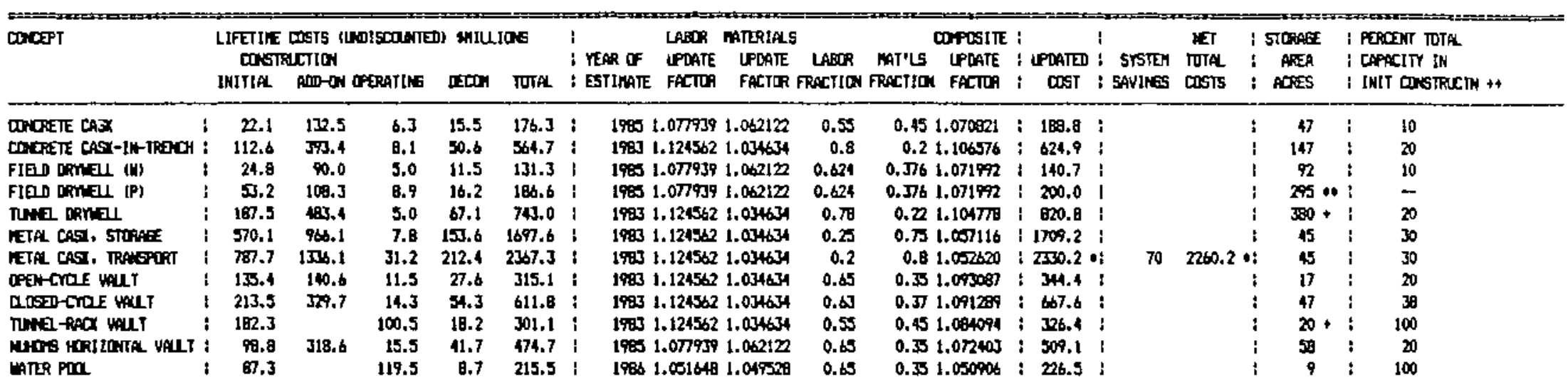

NIJES:

- Lse of transportable metal cusks results in offsetting syste savings of aprox. \$100 nillion 200 willion in aroidance of foel transfer to shipping cast

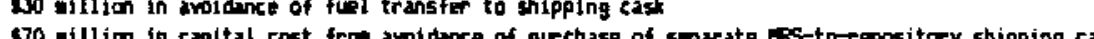

(Cant cost savings not included - treneportation syntel savings)

"s The higher costs and acreage requirewents for the Parsons dymeil design result fros:

- Hre advanced stage of conceptul design (Parsons is the mo facility Architect-Enginear)

- A corp conservative estieste of heat-disstpation dillities of the earth surrounding the drmalis

- Consictedile excavation requirements for leveling and preparing the storage site

- Pack naer the field gorfacer incressing dilling costs for the dprells

+ Starage wews for the tunnel rack and tumel dymell concepts are undergound

\# Est intes based on required times for procureant/cmstruction of storage

v5. five-year period askered for filling starage field 
TABLE A.10. MRS Storage Deployment Times

\begin{tabular}{|c|c|c|c|c|c|}
\hline \multirow[b]{3}{*}{ COCPPT } & \multicolumn{5}{|c|}{ 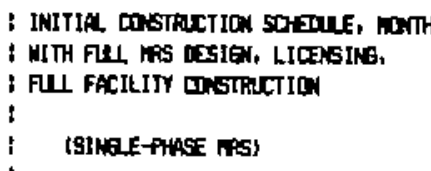 } \\
\hline & $i$ & \multirow[b]{2}{*}{ ESIEN } & $\begin{array}{l}\text { LIOES'G } \\
\text { TF FLL P P }\end{array}$ & \multirow{2}{*}{ 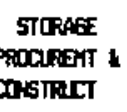 } & \multirow{3}{*}{ तास } \\
\hline & i & & $\mathrm{ms}$ & & \\
\hline COCFETE CASY & i & $2 b$ & $\mathbf{3 0}$ & $\mathbf{s 0}$ & \\
\hline COCFETE CAST-IN-THECH & i & 26 & 30 & 50 & 106 \\
\hline 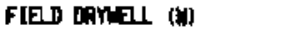 & $\mathbf{i}$ & 26 & 30 & 50 & 106 \\
\hline rWel oRnel & i & $2 b$ & 30 & 50 & 106 \\
\hline SETA, CAS1, STLDAEE & $i$ & 26 & 30 & 50 & 106 \\
\hline JETAL CASI, TRANGPRT & $\mathbf{i}$ & $\mathbf{2 6}$ & 30 & so & 106 \\
\hline OPE-CYDE VALT & I & $2 b$ & 30 & 50 & 106 \\
\hline ANSDD-Craf WLI & i & 26 & 48 & 50 & 124 \\
\hline TWE-RACX VAlLT & i & $2 b$ & 49 & 50 & 124 \\
\hline MHOTS HORIZOMT, WELT & i & $2 b$ & 30 & so & 106 \\
\hline 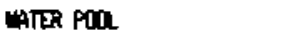 & 1 & $2 b$ & $\mathbf{3 0}$ & 50 & 100 \\
\hline
\end{tabular}

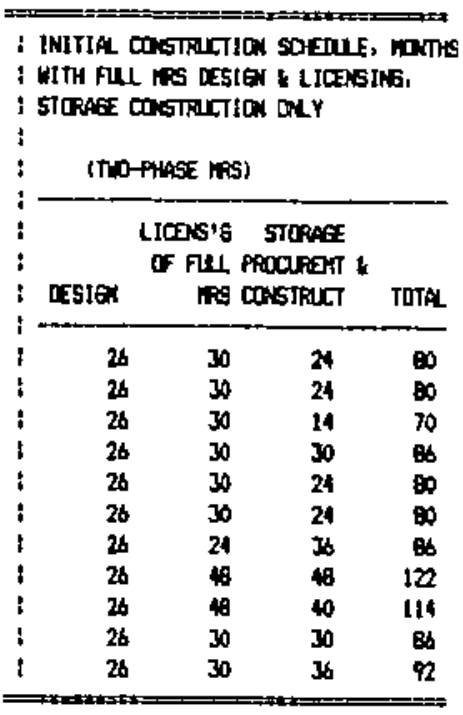

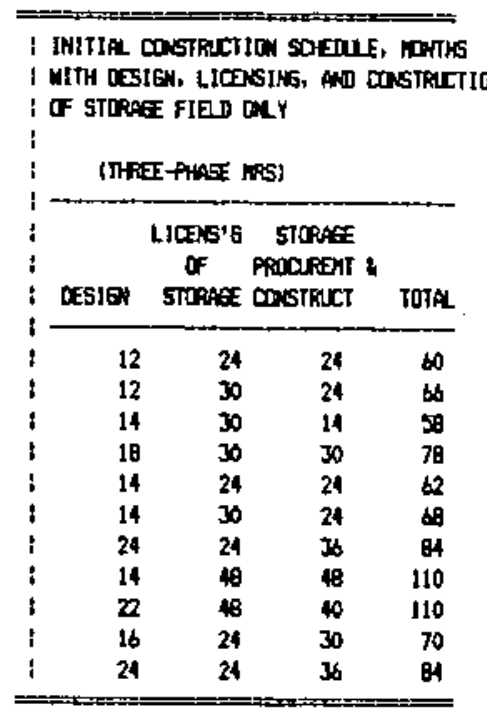


TABLE A.11. Cost/Area Estimate for Concrete Cask 0ption

conchute cesis

OONSTISCTIN CASTS (W000)

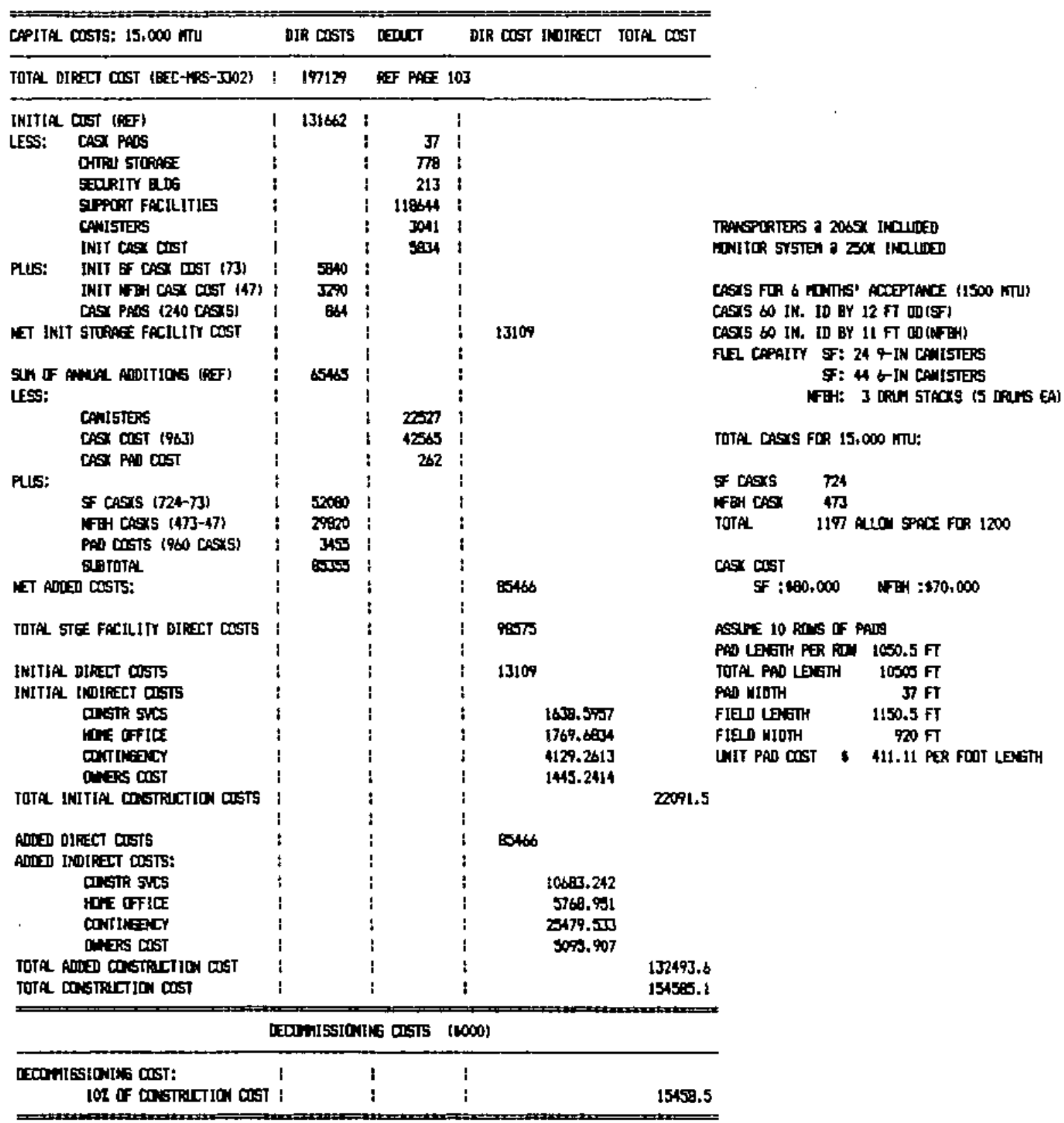


IABLE A.11. (contd)

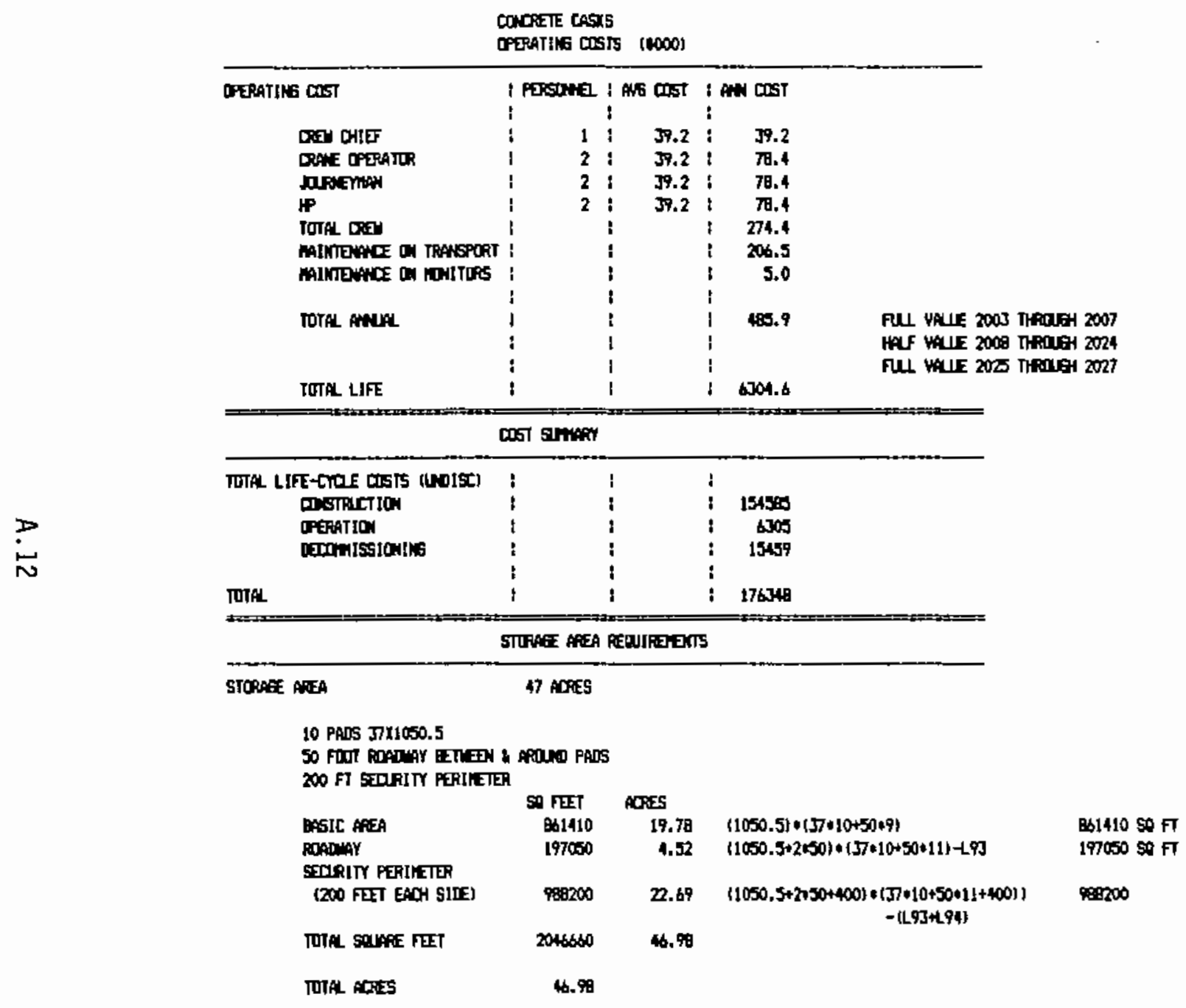


TABLE A.12. Cost/Area Estimate for Concrete Cask-In-Trench Option

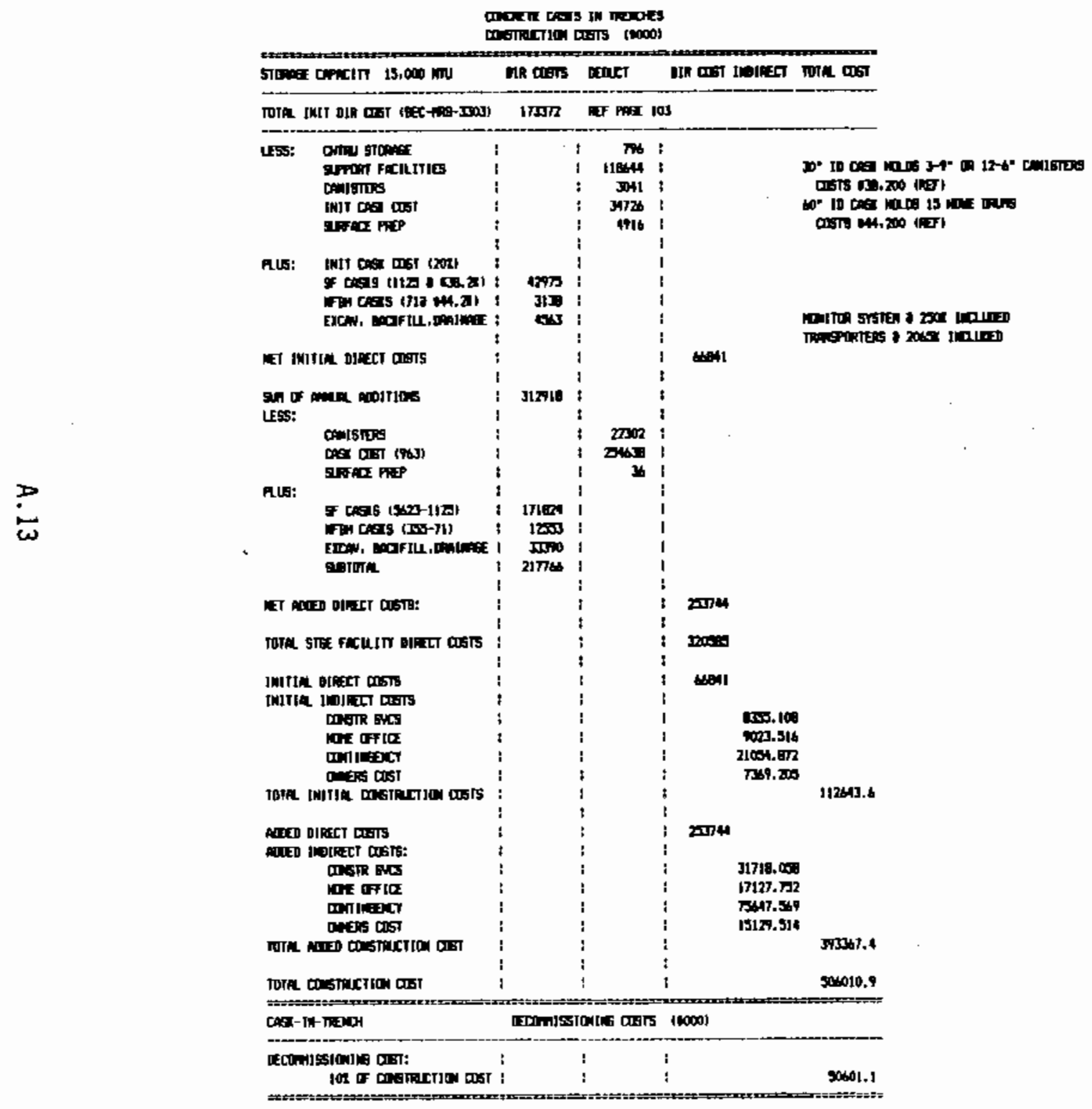


TABLE A.12. (contd)




TABLE A.13. Cost/Area Estimate for Field Drywell Option (Original Estimate)

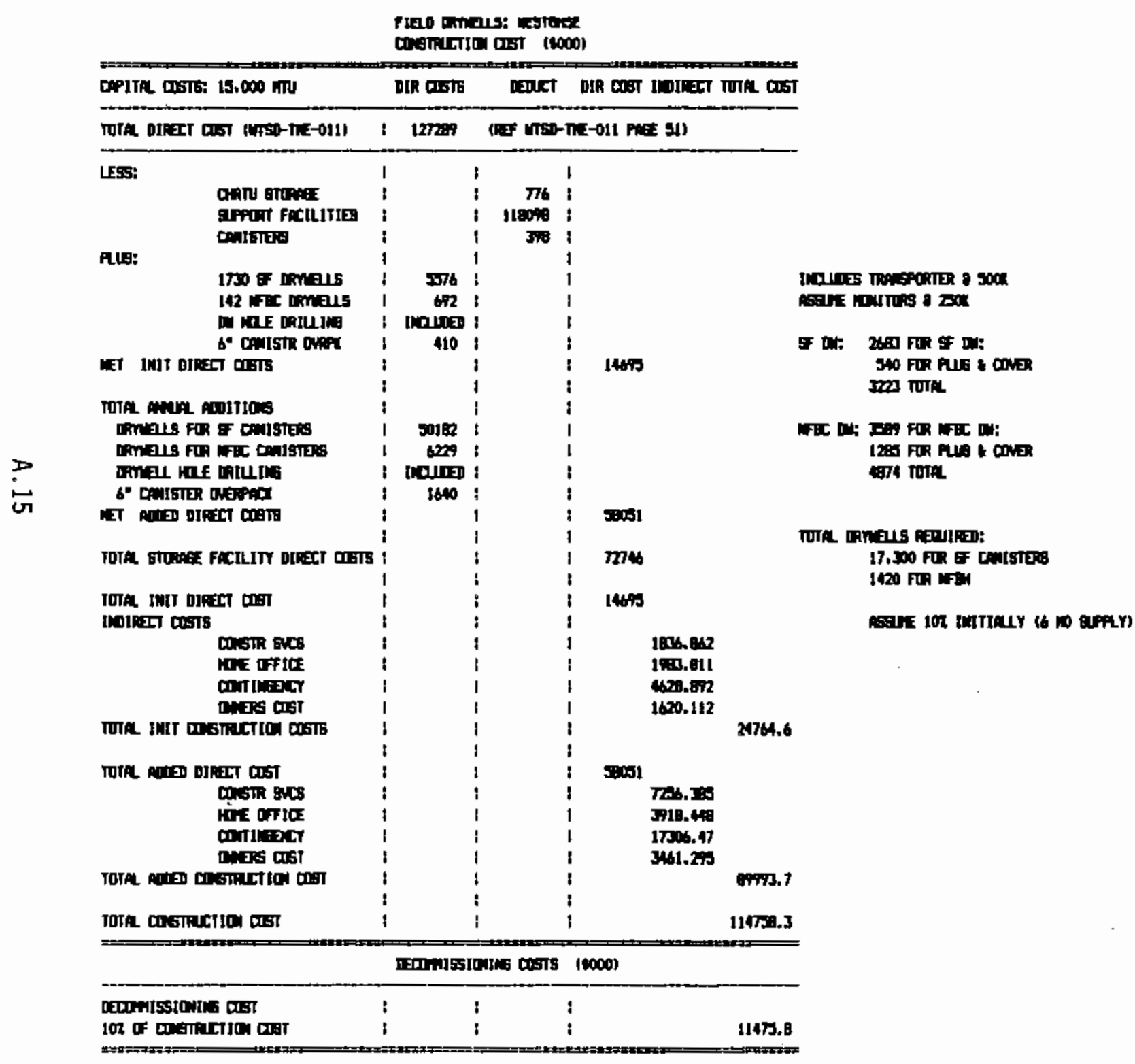


IABLE A.13. (contd)

\begin{tabular}{|c|c|c|c|c|c|}
\hline & & $\begin{array}{l}\text { Figo } \\
\text { aperme }\end{array}$ & IS 10000 & & \\
\hline & OPGATINA COSTS & 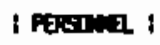 & $16 \cos 1$ & I AM CIST TUR (105) & \\
\hline & 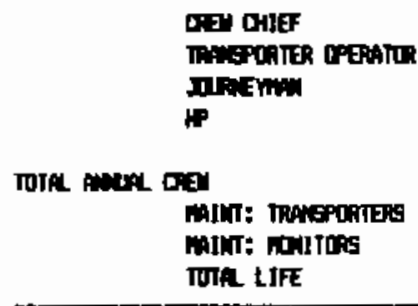 & 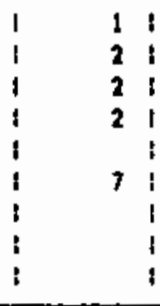 & $\begin{array}{l}37.2 \\
37.2 \\
3.2 \\
3.2\end{array}$ & $\begin{array}{r}37.2 \\
7.4 \\
70.4 \\
7.4 \\
774.4 \\
50.0 \\
2.0 \\
5047.6\end{array}$ & 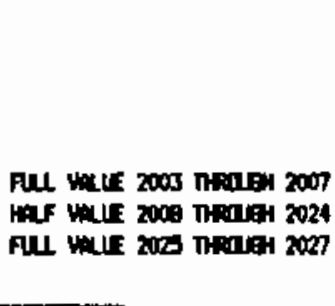 \\
\hline & FIGo onnas & COST SMmpr & & & \\
\hline & COST CATBERY & & & Wos (1000) & \\
\hline & 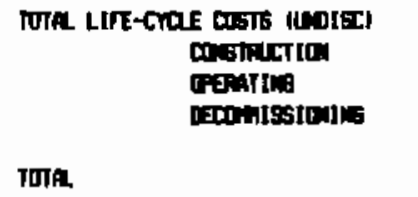 & $\begin{array}{l}1 \\
\vdots \\
\vdots\end{array}$ & & $\begin{array}{r}114701 \\
5009 \\
11476 \\
151208\end{array}$ & \\
\hline & 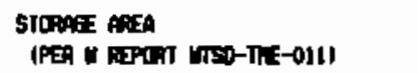 & $\ln 2009$ & & $!$ & \\
\hline
\end{tabular}


TABLE A.14. Cost/Area Estimate for Field Drywell Option (from MRS Conceptual Design)

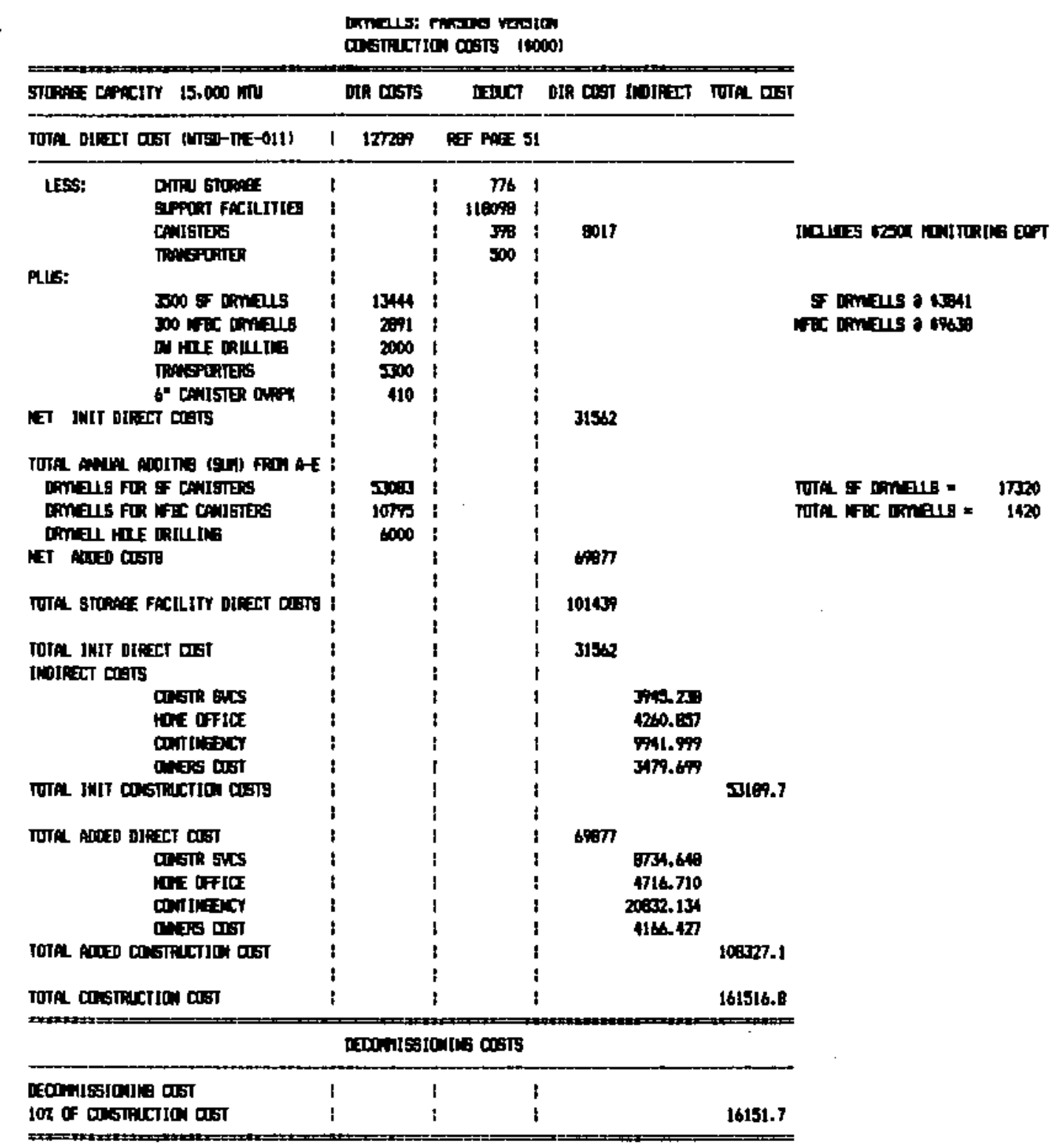




\section{TABLE A.14. (contd)}

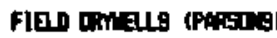

Crearita Dat9

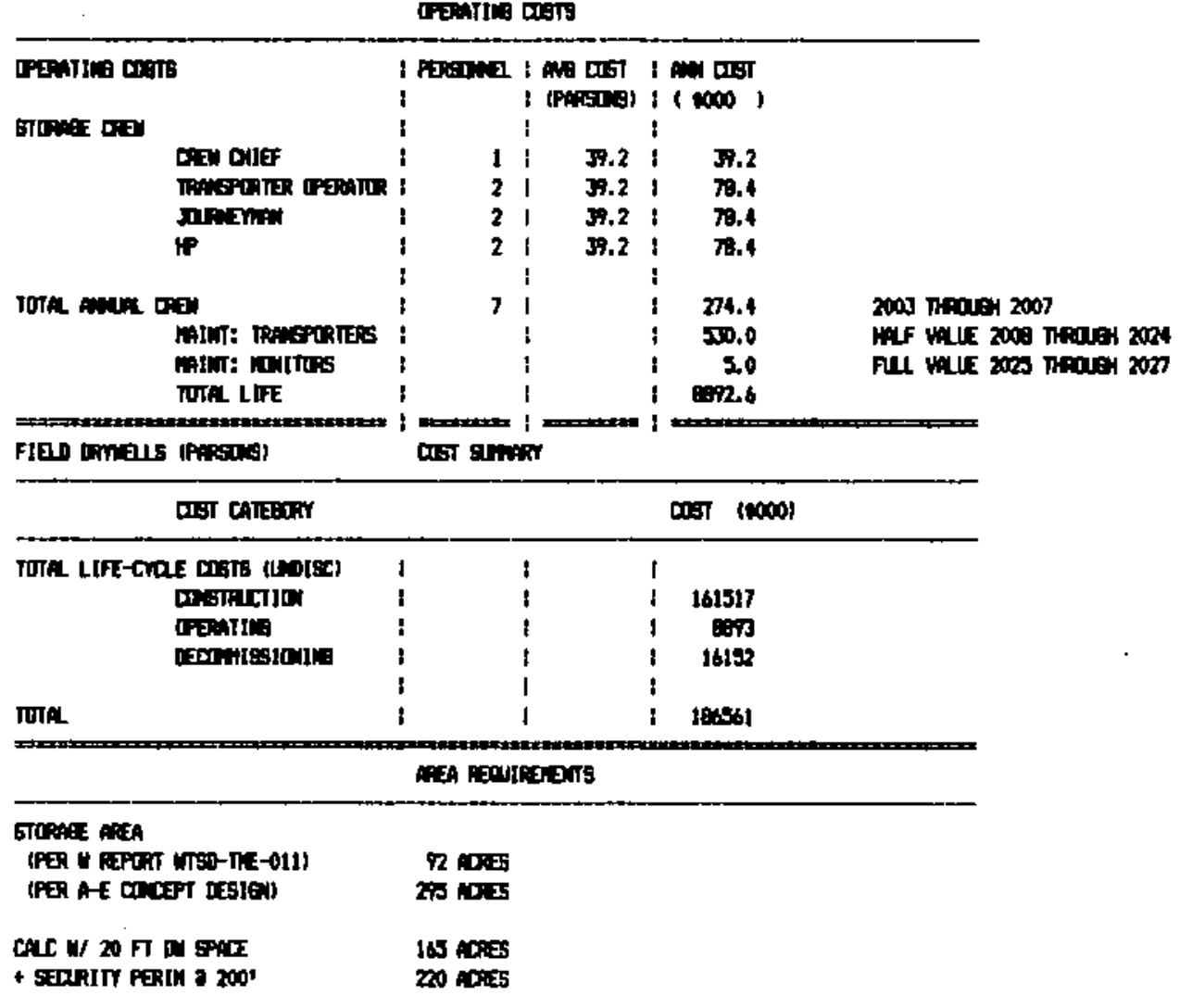


TABLE A.15. Cost/Area Estimate for Tunne1 Drywell option

roner tomants

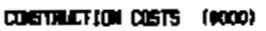

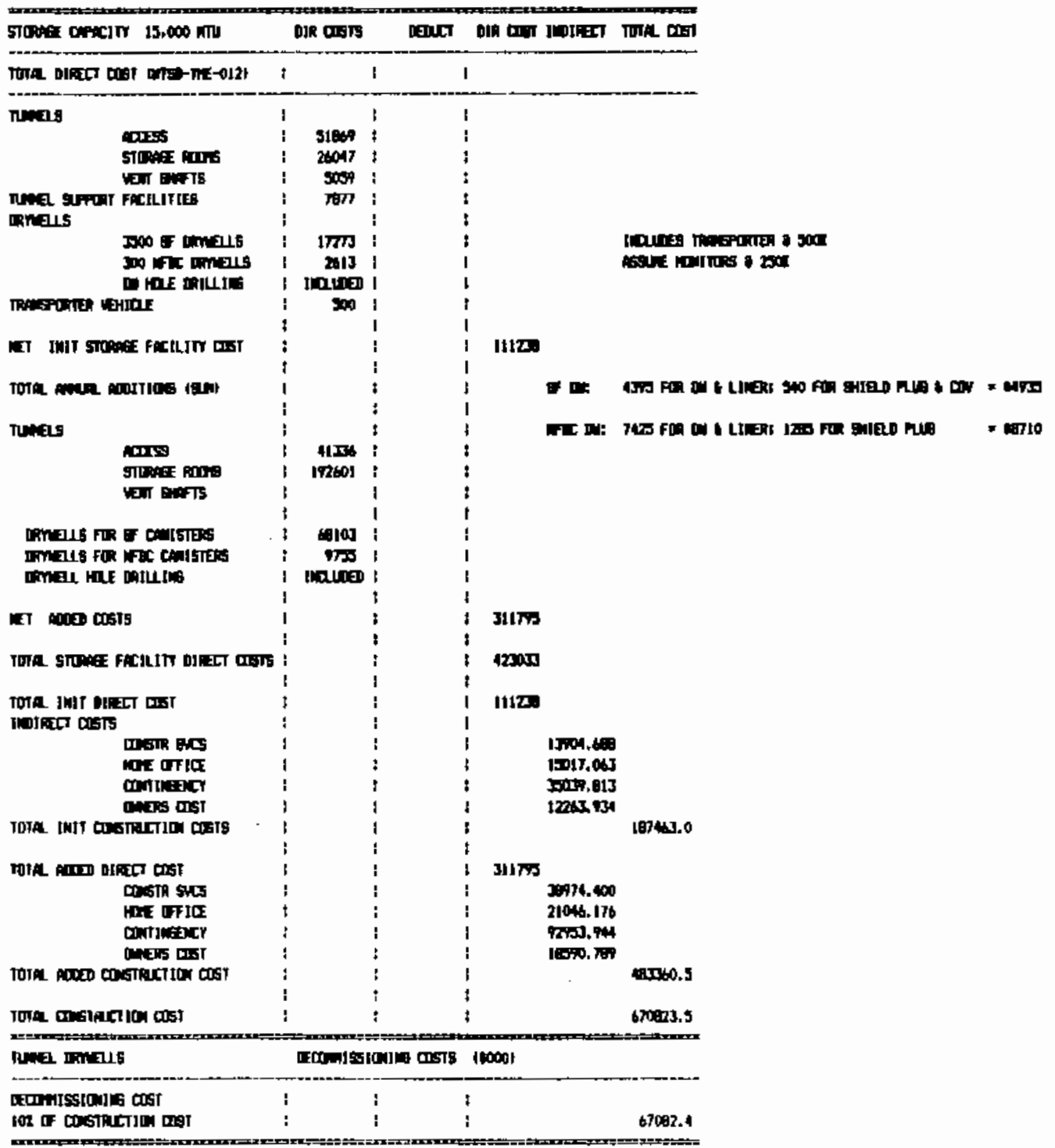




\section{TABLE A.15. (contd)}

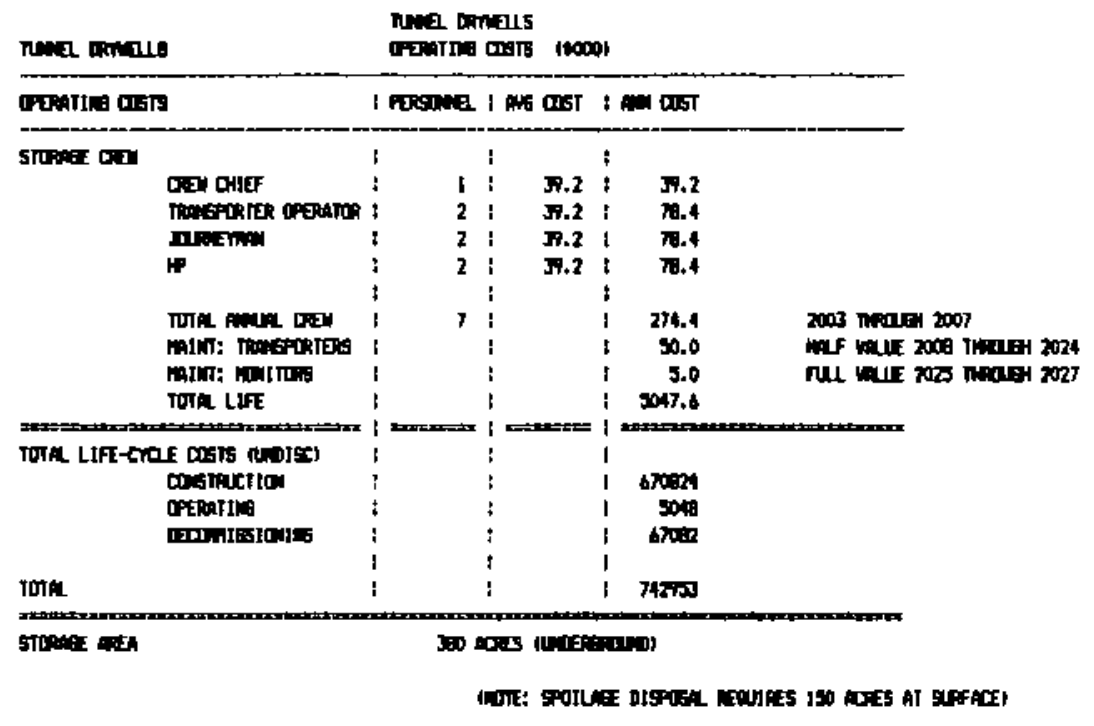


IABLE A.16. Cost/Area Estimate for Storage-Only Metal Cask Option

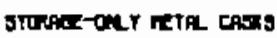

COSTRACTION COSTS

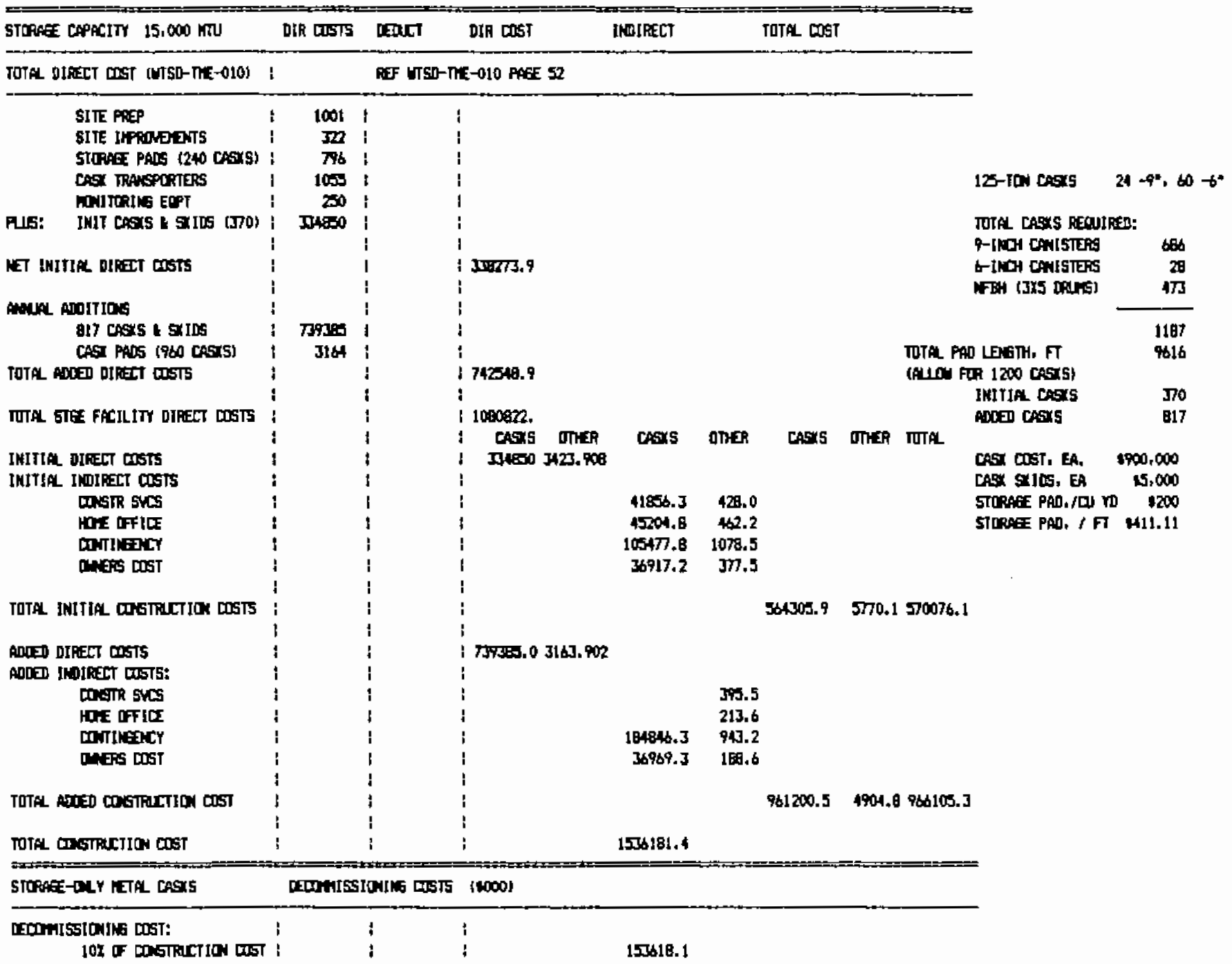


TABLE A.16. (contd)

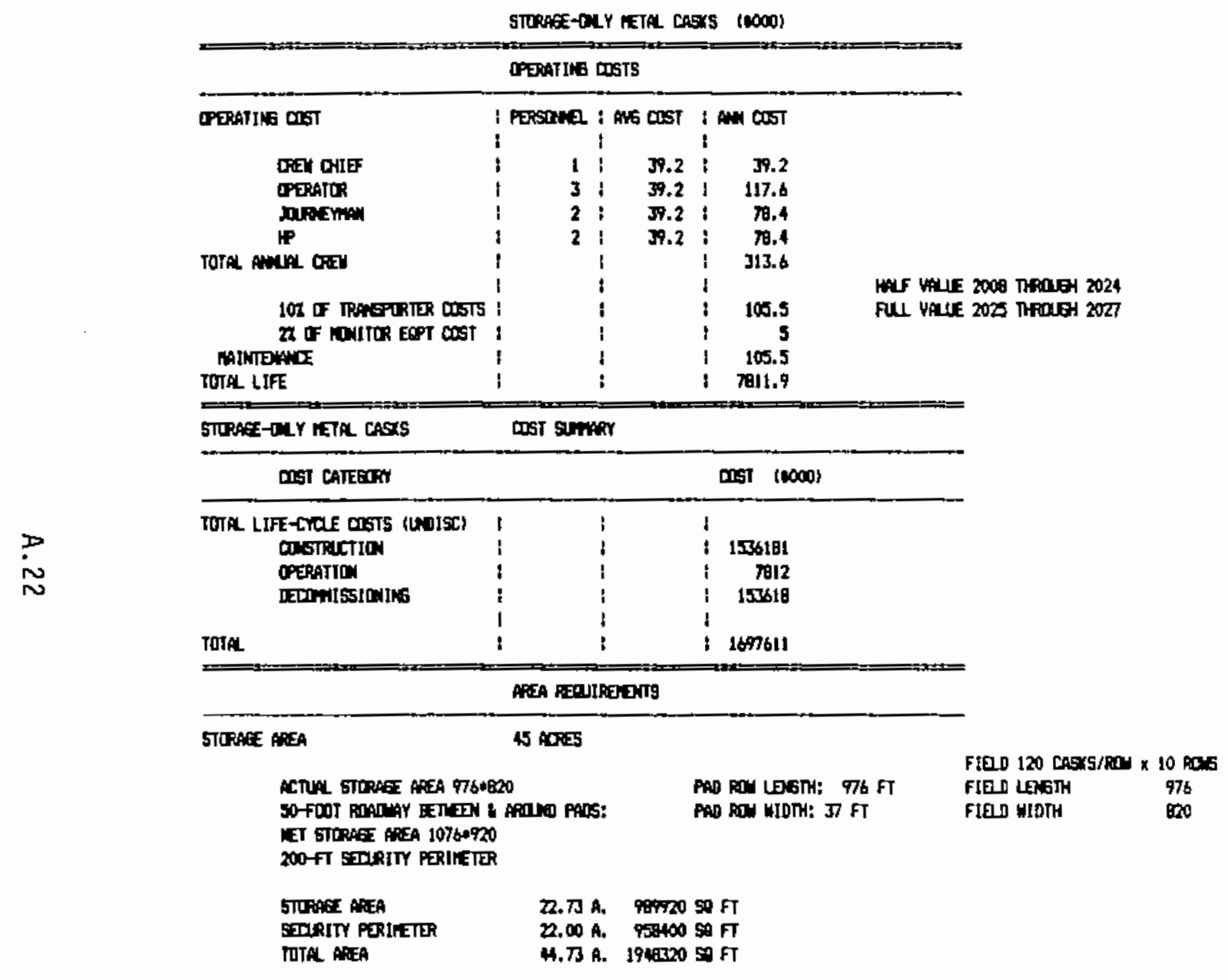


TABLE A.17. Cost/Area Estimate for Transportable Metal Cask Option

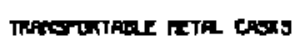

OONSTACTION COSTS (2000)

\begin{tabular}{|c|c|c|c|c|c|c|c|c|c|c|c|}
\hline \multirow{2}{*}{ 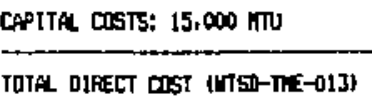 } & \multicolumn{2}{|r|}{ DIR COSTS } & IEXCT & \multicolumn{2}{|c|}{ BIR COST } & \multicolumn{2}{|r|}{ IHDIAECT } & \multicolumn{3}{|c|}{ TOTAL COST } & \\
\hline & i i & & REF MISD-T & -013 & PAEX 56 & & & & & & \\
\hline SITE PRPP & $1:$ & 1001 & i & $i$ & & & & & & & \\
\hline SIIE IPROMEATS & 11 & 320 & $!$ & $i$ & & & & & & & \\
\hline STOPAII PADS (240 CASXS) & i i & 401 & $i$ & i & & & & & & & \\
\hline CASA IRAKSPORTERS & $1:$ & 1050 & 1 & 1 & & & & & & & \\
\hline GNITOR EQPT ODST & 11 & 250 & $i$ & i & & & & & & & \\
\hline \multirow{2}{*}{ INIT CASKS \& 510S $(370)$} & i i & $44+350$ & i & $\mathrm{I}$ & & & & & & & \\
\hline & 11 & & $\mathbf{i}$ & i & & & & & & & \\
\hline \multirow[t]{2}{*}{ HET INIT STOPACE FACILITY COST } & 11 & & $i$ & i & 40757 & & & & & . & \\
\hline & 1 & & i & $!$ & & & & & & & \\
\hline \multirow[t]{2}{*}{ 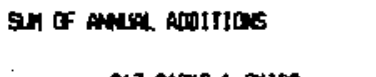 } & 1 & & i & $i$ & & & & & & & \\
\hline & 1 & & i & $:$ & & & & & & & \\
\hline $817 \cos x s+5105$ & $1:$ & 102555 & $i$ & $:$ & & & & & & & TOTA PAD \\
\hline IPPCT LIMIIERS & i: & 500 & 1 & $i$ & & & & & & & (AW FO \\
\hline \multirow{2}{*}{ CASX PADS } & i: & 1600 & 1 & $i$ & & & & & & & \\
\hline & 11 & & $:$ & 1 & & & & & & & \\
\hline \multirow[t]{2}{*}{ KET ADED COSTS: } & $1 i$ & & $:$ & i & 1027440 & & & & & & TUTA \\
\hline & 11 & & 1 & I & & & & & & & \\
\hline \multirow{3}{*}{ TOTAL STE FACILITT OIRECT COSTS } & i: & & i & $:$ & 1494819 & & & & & & \\
\hline & i i & & i & $i$ & & & & & & & \\
\hline & 1 & & i & 1 & $\cos x$ & OTER & cast & OTFER & $\cos x$ & OTHE & TOTR \\
\hline INITEAL DERECT COSTS & 11 & & $!$ & i & 44550 & 3029.24 & & & & & \\
\hline INITIAL INDIRETT CDSTS & i i & & t & i & & & & & & & \\
\hline CONSTR SVTS & 1 & & : & $\mathrm{t}$ & & & 58044 & 378.66 & & & \\
\hline H1E Gricr & i i & & 1 & : & & & 62687 & 400.55 & & & \\
\hline DOMIIEECY & 1 & & $i$ & : & & & 146770 & 954.21 & & & \\
\hline \multirow[t]{2}{*}{ ONEFS OAST } & $i:$ & & $i$ & i & & & 51195 & 30.97 & & & \\
\hline & i i & & $i$ & i & & & & & & & \\
\hline \multirow[t]{3}{*}{ TOTR IAITIAL COSTRACTION COSTS } & i & & i & i & & & & & 782546 & 5105.03 & 2801 \\
\hline & i & & : & i & & & & & & & \\
\hline & i & & i & $!$ & CASA & OTHER & & & & & \\
\hline ADOED DIFETT COSTS & $i$ & & $i$ & $:$ & 102015 & 1604.97 & & & & & \\
\hline ADUED INOIRECT CISTS: & : & & i & : & & & & & & & \\
\hline Costh SVCS & $i$ & & $\mathrm{i}$ & $i$ & & & & 200.62 & & & \\
\hline HUE OFFICE & i & & i & $\mathbf{i}$ & & & & 100.34 & & & \\
\hline CONIHATCY & i & & $i$ & i & & & 256459 & 478.4日 & & & \\
\hline \multirow[t]{2}{*}{ AUEST COST } & ! & & i & $!$ & & & 51292 & 95.70 & & & \\
\hline & $!$ & & i & i & & & & & & & \\
\hline \multirow[t]{2}{*}{ TOTAL AURED COSTIRCTIOA COST } & : & & $i$ & : & & & & & 155066 & 2489.11 & 1 15607. \\
\hline & $i$ & & ! & i & & & & & & & \\
\hline TOTAL COSTRACTION COST & i & i & $i$ & i & & & 2123724 & & & & \\
\hline TRANSPIRTAELE RETA CASAS & & EETMISS & SIaNing Cos & 51 & $00\}$ & & & & & & \\
\hline 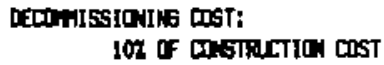 & $!$ & ; & $i$ & $\vdots$ & & & 21252.4 & & & & \\
\hline
\end{tabular}


TABLE A.17. (contd)

TASPPRTABEF FETA. CASMS

TOEFAIIH COSTS $(2000)$

\begin{tabular}{|c|c|c|c|c|c|c|}
\hline \multicolumn{6}{|c|}{ 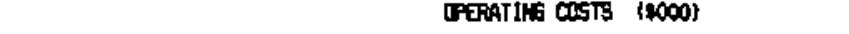 } & \\
\hline \multirow{2}{*}{ CPERATING COST } & $i$ & I PESONAZ & \multicolumn{2}{|c|}{ I AN OST } & : AN COST & \\
\hline & 1 & & 1 & & i & \\
\hline CQDI OHIF & 1 & 1 & i & 39.2 & 39.2 & \\
\hline OPEATTQ & i 1 & 3 & $i$ & 37.2 & 117.6 & \\
\hline DOFEnim & 1 & 2 & i & 39.2 & 8.4 & \\
\hline \multirow[t]{2}{*}{ ip } & ! & 2 & 1 & 37.2 & $\pi .4$ & \\
\hline & i & i & i & & i & \\
\hline \multirow[t]{2}{*}{ LABCM } & i & : & : & & 313.6 & 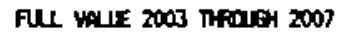 \\
\hline & $i$ & 1 & ; & & ; & HES WLIS 2008 TFOOOH 2024 \\
\hline IOT OF TRAGPOATE COSTS & : : & i & $:$ & & 105.5 & 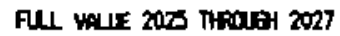 \\
\hline a OF NONIRR EPT COST & $i$ & i & $i$ & & 5.0 & \\
\hline MalKTEMANE & $i$ & i & $i$ & & 100.5 & LAMOUT CPERATIOS SANIMSS: \\
\hline LESS: SAVINES IN REH UNADOUT & $i$ & i & i & & -300000 & UTILITIES \\
\hline PORT TPERATIOS & i & : & 1 & & $\mathbf{i}$ & MAINT: \\
\hline \multirow[t]{2}{*}{ Cos Ramifification } & $i$ & आ15 & $i$ & & 5315 & PEPLACDERT \\
\hline & $i$ & ; & $:$ & & 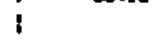 & TUIAL \\
\hline IUIAL LIFE & : & i & : & & 31226.9 & \\
\hline
\end{tabular}

Plunt electricity use in "londout mly" phass

is $\$ 3.8$ aillion per year. Assuse use in loadout operations is 22. 1 aillim per year.

2BOO PER VEAR

2000 PER TEAR

ANul LifE RaNO IF

$5100 \quad 30617 \quad 30000$

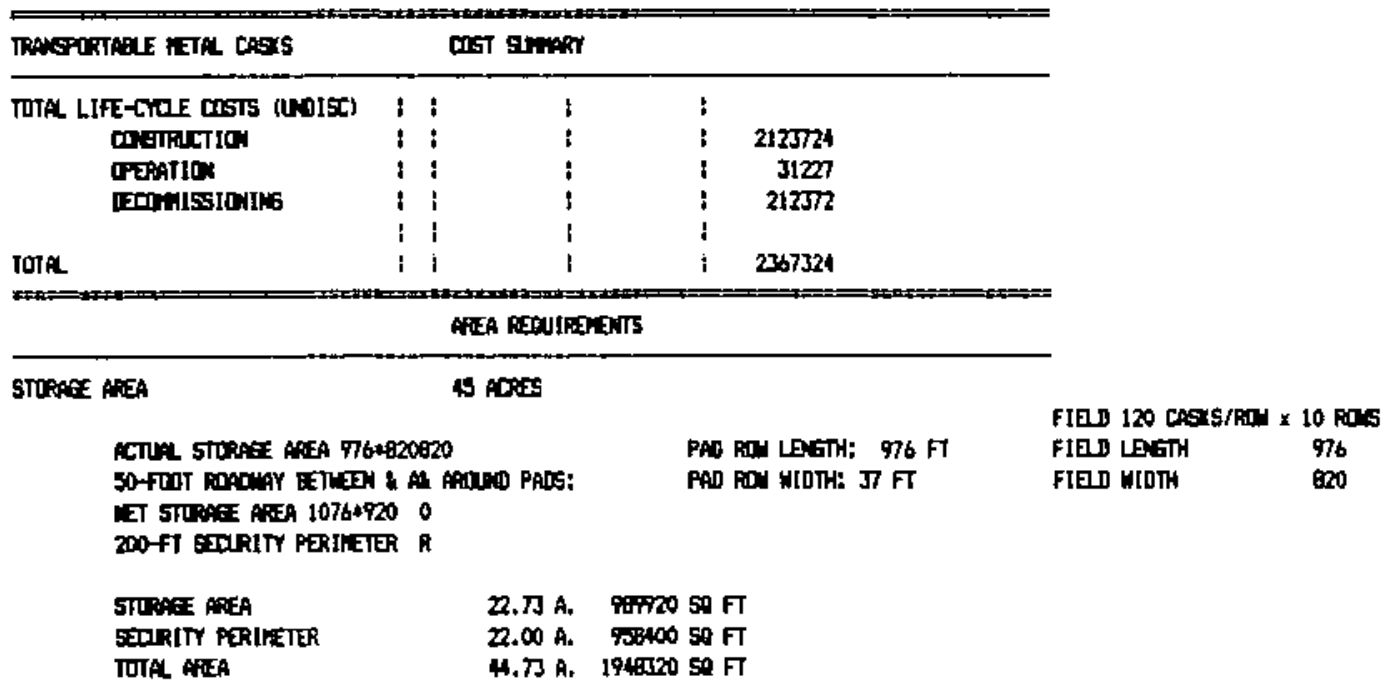


TABLE A.18. Cost/Area Estimate for Open-Cycle Vault Option

actar met

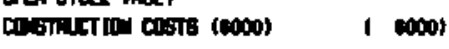

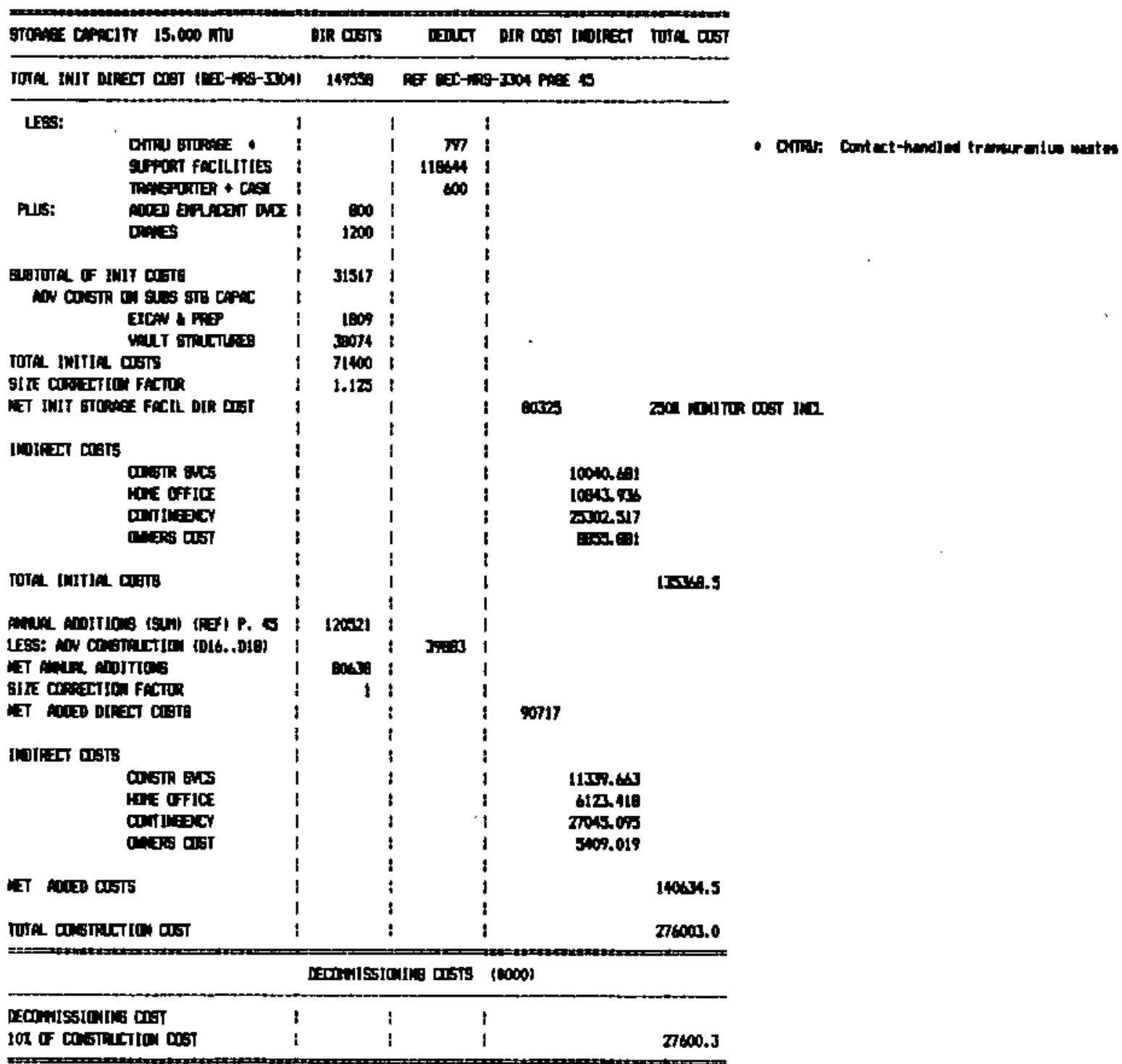


IABLE A.18. (contd)

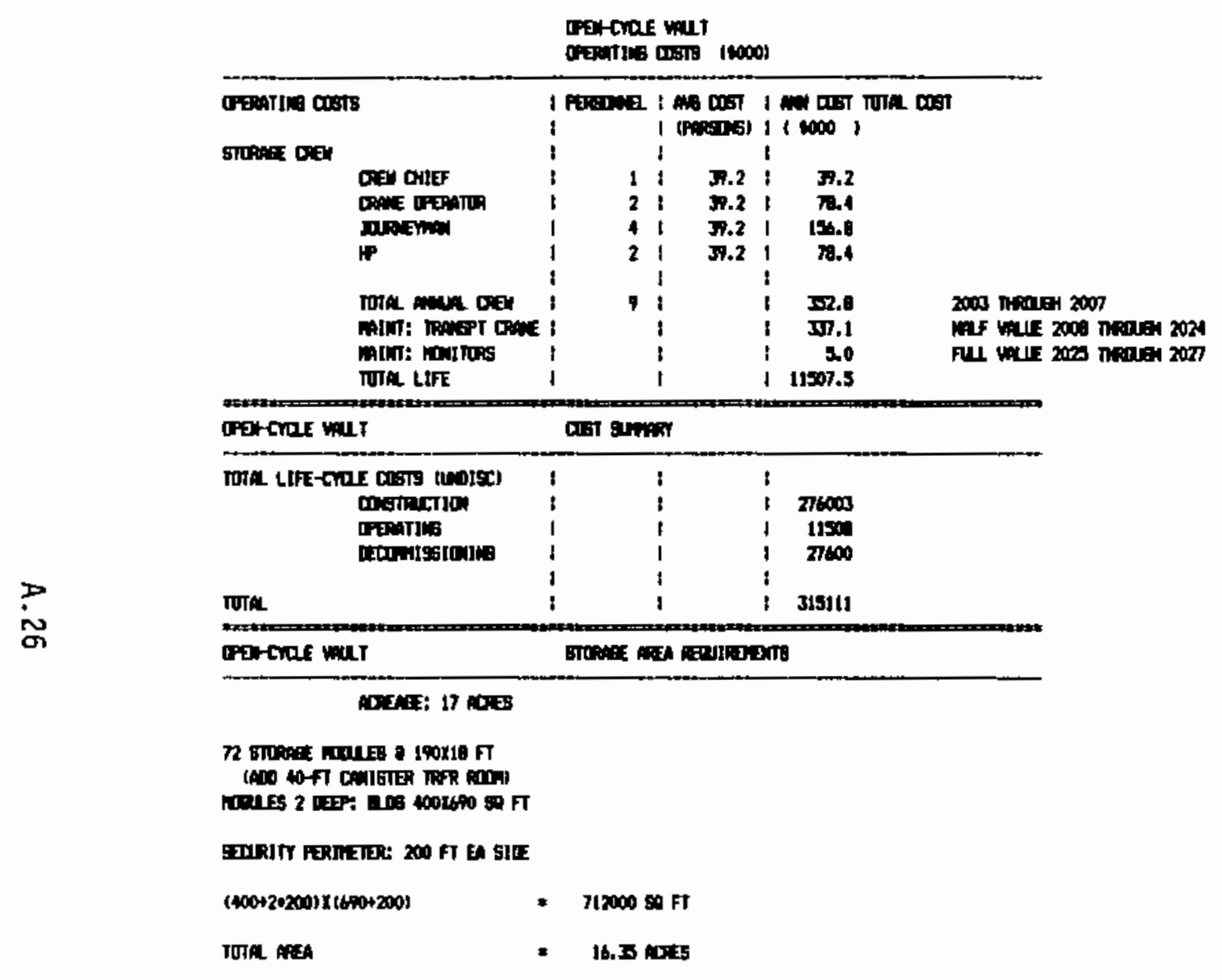


TABLE A.19. Cost/Area Estimate for Closed-Cycle Vault Option

dosid-6rol well

COSTICTION DOSTS (2000)

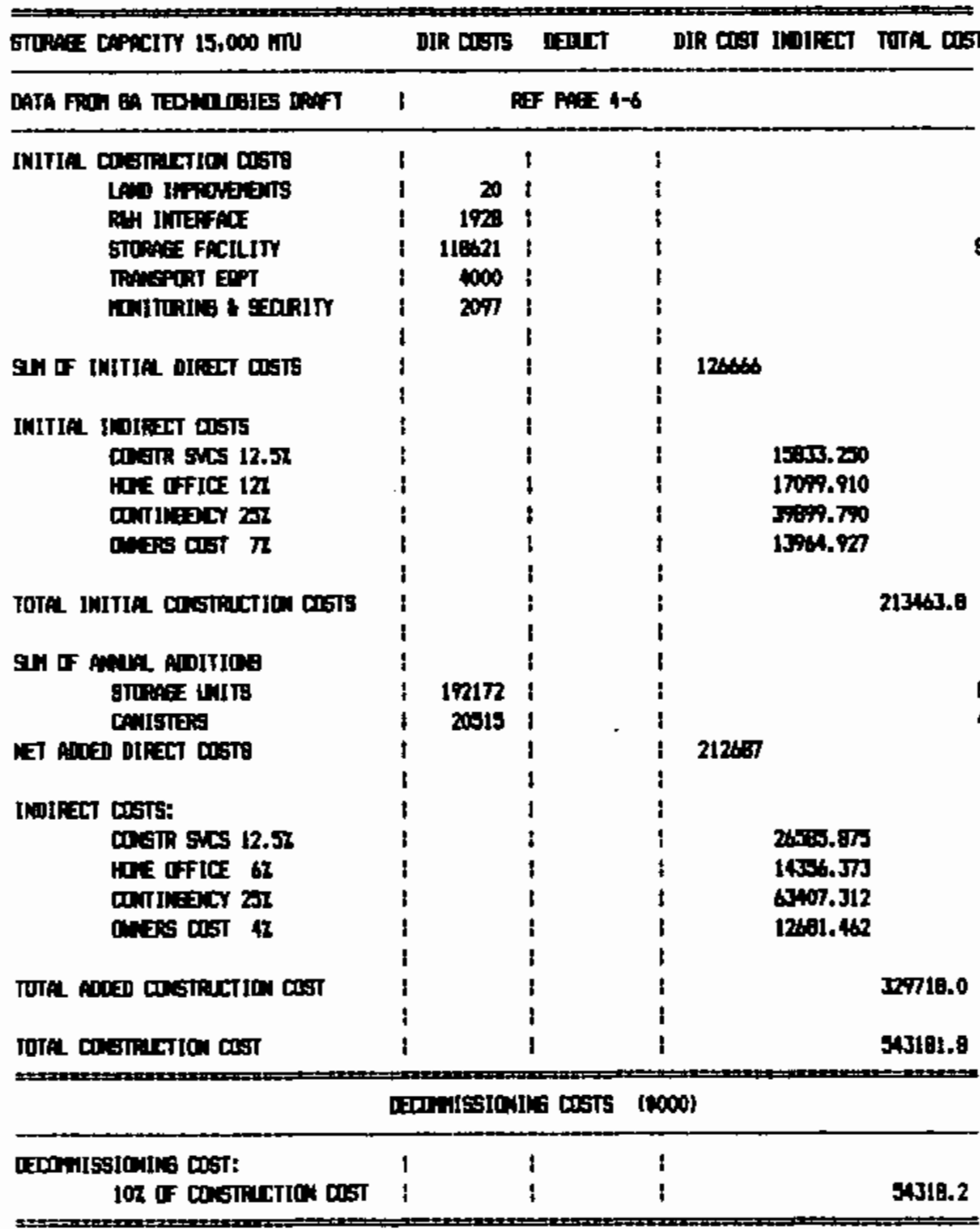


TABLE A.19. (contd)

arip-Crof Wilt

oreminim costs inool

\begin{tabular}{|c|c|c|c|c|c|}
\hline \multirow{6}{*}{ 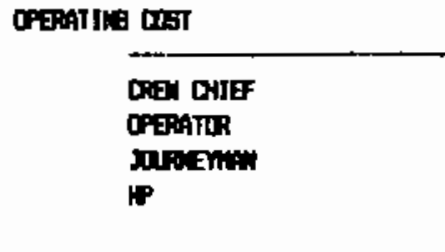 } & \multicolumn{3}{|c|}{ I FERSNAE : An COST } & \multicolumn{2}{|c|}{ I AN GST TUTAL COST } \\
\hline & $\mathbf{t}$ & : & 37.2 & ; & 39.2 \\
\hline & 2 & : & 37.2 & ; & 8.4 \\
\hline & $\downarrow$ & $\mathbf{i}$ & 37.2 & i & 39.2 \\
\hline & 1 & $\mathbf{i}$ & 3.2 & 1 & 3.2 \\
\hline & $\mathbf{i}$ & i & & i & \\
\hline \multirow[t]{2}{*}{ TOTA ANAM FOR CREN } & 5 & 1 & & i & $1 \% .0$ \\
\hline & 1 & 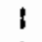 & & i & \\
\hline IOT OF TMANGTRTER COSTS & i & ; & & ; & $\mathbf{4 0 0 . 0}$ \\
\hline n o mortor ENT GST & $i$ & i & & 1 & 41.9 \\
\hline malMTEAHCE & 1 & : & & 1 & 41.9 \\
\hline TOIAL AHIA OPEATINA GETS & 1 & 1 & & ! & 637.9 \\
\hline LIFETIKE OPEAAIIA COSTS & 1 & 1 & & i & 14283 \\
\hline COESD-CMOE Vilt & \multicolumn{5}{|l|}{ Wot awn } \\
\hline \multicolumn{2}{|l|}{ COST CATEEOI } & \multicolumn{4}{|c|}{$\operatorname{cost}(2000)$} \\
\hline TUIAL LIFE-CMDE COSTS ILNIE) & i & ! & & ; & \\
\hline CostRctIO & 1 & i & & i & SAJ1gR \\
\hline OFEATIOI & $i$ & 1 & & ; & 14283 \\
\hline 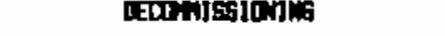 & $\mathbf{i}$ & 1 & & i & 5A318 \\
\hline & $\mathbf{i}$ & i & & 1 & \\
\hline TOTAL & 1 & 1 & & i & 61170 \\
\hline
\end{tabular}

GTOBAE AFEA REOIIREDTIS

GTQRAEE AREA

1) ADEB

CANISTESS O 9 PER MOIE

DOUES FoA 1103 CAHISTES

Rans a 16 molles/tei

BASE STLPAE ABEA

SEDRIT PEAILTIER

26.52 ADES
20.57 ADDES
4. BD ACOES

Ful hus 2003 nfouter 2007

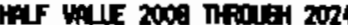

FUl Wule 2020 IFOA 202

TQTAL AREA

$8.89 \quad 29$

$1155000 \mathrm{SDFT}$ (PER RON 550x70 50 FT)

$8000008 \mathrm{FT}$

2010000 ED FT 
IABLE A.20. Cost/Area Estimate for Tunnel-Rack Vault option

ruset ward

COSTIRTIION COSTS (2000)

\begin{tabular}{|c|c|c|c|c|c|}
\hline \multirow{2}{*}{$\frac{\text { CAPITAL COSTS: 15,000 ITU }}{\text { TOTAL DIFECT COST (EA) }}$} & 1 DIR CESTS & \multirow{2}{*}{ RET PATE } & \multicolumn{2}{|r|}{ DIR COST INDIRECT } & \multirow[t]{2}{*}{ TDTAL COST } \\
\hline & 226167 & & $4-8$ & . & \\
\hline \multirow{3}{*}{ SPFDT FACILITIES } & 1 & $\mathbf{i}$ & : & & \\
\hline & $\mathbf{i}$ & $117 \% 60$ & 1 & & MONITAR SYSTEN a 250\% INLHED \\
\hline & i & : & ; & & 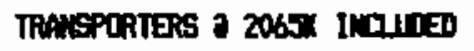 \\
\hline \multirow[t]{2}{*}{ KET INIT STOPAE FACILITY COST } & 1 & : & $\mathbf{I}$ & 103199 & \\
\hline & $\mathbf{I}$ & : & $\mathbf{I}$ & & \\
\hline \multirow[t]{2}{*}{ Su OF ANIA fDITIOS } & $!$ & $\mathbf{i}$ & ! & & \\
\hline & $:$ & i & : & & \\
\hline \multirow[t]{3}{*}{ STOPAEE RACXS } & i IIRHIIE) & AS TPEMTI & $\mathbf{s} \mathbf{c}$ & STS! & \\
\hline & i & ! & i & & \\
\hline & $\mathbf{i}$ & : & $\mathbf{i}$ & & \\
\hline \multirow[t]{2}{*}{ RET ADOED COSTR: } & 1 & ; & $\mathbf{i}$ & 0 & \\
\hline & i & $\mathbf{i}$ & $!$ & & \\
\hline \multirow[t]{2}{*}{ TOTAL STE FACILITY DIRECT COSTS } & : & ! & : & 109199 & \\
\hline & ; & $\mathbf{i}$ & $\mathbf{i}$ & & \\
\hline & ! & : & ! & & \\
\hline DOSTR SVS & $\mathbf{i}$ & $:$ & i & 13524.875 & \\
\hline hIE OFIa & $\mathbf{i}$ & 1 & 1 & 14606.865 & \\
\hline CorTIREgicy & $\mathbf{l}$ & $\mathbf{i}$ & ! & 34082.685 & \\
\hline \multirow[t]{2}{*}{ Ging COST } & : & $\mathbf{i}$ & : & 11920,940 & \\
\hline & $\mathbf{i}$ & $\mathbf{i}$ & : & & \\
\hline \multirow{2}{*}{ TOTAL COSTRICTION COSTS } & i & $\mathbf{i}$ & ! & & 182342.3 \\
\hline & $==\Rightarrow$ & $=$ & 吾 & 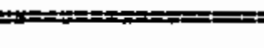 & $\Longrightarrow$ \\
\hline Trangax Gat & \multicolumn{3}{|c|}{ IECOnISSIRINA COSTS } & . & \\
\hline EECOHISSIONIMS COST: & ! & $\therefore$ & 1 & & $\cdot$ \\
\hline 10L a costruction cost & ! & 1 & $:$ & & 18234.2 \\
\hline
\end{tabular}


IABLE A.20. (contd)

THAZ-RACX WIIT

OPBATIM costs (2000)

\begin{tabular}{|c|c|c|c|c|c|}
\hline \multirow{2}{*}{$\frac{\text { CPEPATINA COST }}{\text { FRON GAT DORHENT }}$} & \multicolumn{2}{|c|}{ I PERShE : ARB COST } & \multicolumn{3}{|c|}{ : AN COST } \\
\hline & 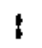 & i & $\mathbf{i}$ & & \\
\hline & ; & ; & $\mathbf{1}$ & & \\
\hline TOTAL ANAL, LOAD/CX & $:$ & $i$ & 1 & $\mathbf{5 4 6 4}$ & 3000 nTu/n \\
\hline TUTA ANGA, STRPAE & i & i & $\mathbf{i}$ & 2509 & STLAEE * ? \\
\hline & 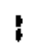 & ! & $\mathbf{i}$ & & $3000 \mathrm{n} u / n$ \\
\hline TOTAL LIFE & i & i & ! & 100475 & \\
\hline \multicolumn{6}{|c|}{ 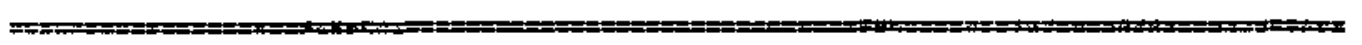 } \\
\hline TUNE-PACX VILts & \multicolumn{2}{|c|}{ COST SIMARY } & & & \\
\hline TOTAL LIFE-CYOE COSTS (INDISC) & : & ! & $\mathbf{i}$ & & \\
\hline COSTFICTIDN & ; & 1 & $\mathbf{i}$ & 182342 & \\
\hline OPBATION & : & 1 & $\mathbf{i}$ & 100475 & \\
\hline DECHMISSICNIKS & : & : & $\mathbf{i}$ & 18234 & \\
\hline & : & i & i & & \\
\hline TOTAL & i & 1 & 1 & 301052 & \\
\hline
\end{tabular}

STORAFE AREA

20 ACRES (RE)

STQRAGE AREA IS LNQEREROWO 
TABLE A.21. Cost/Area Estimate for Modular Horizontal Vault Option

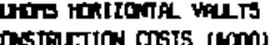

STRAE CAPACITY 15,000 nTU DIR COSTS DEUCT DIR COST INDIRECT VOTAL COST

\begin{tabular}{|c|c|c|c|c|}
\hline TOTAL DIRET CIST & 1 & & $\mathbf{i}$ & $\mathbf{i}$ \\
\hline INITIR COSTS & $\mathbf{i}$ & & : & i \\
\hline INITIAL hDOUES (Z BANS) & $i$ & 12110 & i & 1 \\
\hline IMITIA NHOTS CANISTERS $(400)$ & ! & 43600 & i & i \\
\hline TRANSPCRTER & ; & 1500 & i & : \\
\hline DEITORING (2500 PER RWOLE + \$1500) & i & 350 & i & ; \\
\hline SECURITY FECIX \& SWAEILAKE SYST & i & 119 & ! & $\mathbf{i}$ \\
\hline
\end{tabular}

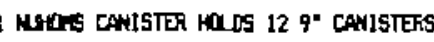

OA $306^{\circ}$ CANISTERS

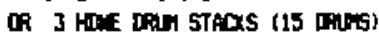

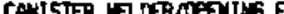

KET INIY DIPECT COSTS

Aruar aDolitions (SM)

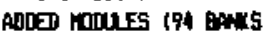

ADCED RAOTS CANISTERS (1500) tonituria

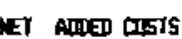

TOTAL STLRAE FACILITY DIRECT COSTS

INITIAL DIFIT COSTS

INDIRECT COSIS

MOSTR SVCS

HTE tFFICE

COMIMEDCT

ances Cost

TOTAL IMIT ONSTFLCIION OIST

ADOED DIRECT COSTS

NUIRET CISTS

COSTR SUCS

DWE OFICE

continowicr

AnePS COST

TOTAL ANISD CONGTRITIOR COST

TOTAL COSTRACIION COST

6117

16457 9" CANITEERS

$1640 b^{*}$ CANISIERS

2094 Hone DFints

(1419 DFin GTACTS)

DOUE BAHS PERD

$=\quad 1371.42=1372$ MhOTL

₹ $\quad 54.67=55 \mathrm{kHOS}$

TOTAL 1900

$148.75=119$ Barks

16-TOOUE BAN COSTS Ha4,400 (\$242,200 PER SIDE)

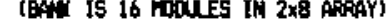

WhOTS hEDE (50" ID) COSTS 3109,000

205538

265717

61179

7617.425

8259.219

2462.471

98020

200

$25+92.160$

$138 \pi .791$

$612 \pi .867$

1205.17

31865

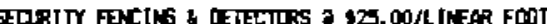

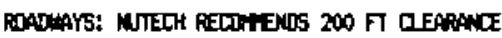

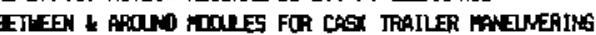

ASSPE AN INTEERAL TRANSPORTEB RATER THAW TRAILEF

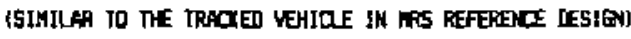

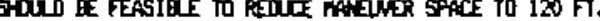

TOTAL CONTIRICITON COST $\quad: \quad t \quad t \quad 47455$

IEDNAISIININ COSTS (1000)

DECAmISSIONIn COST

10x of onsthiction cos

$i: \quad 41745$


TABLE A.21. (contd)

MHONS HERZTETAL VALTS

OPEMATING COSTS (8000)

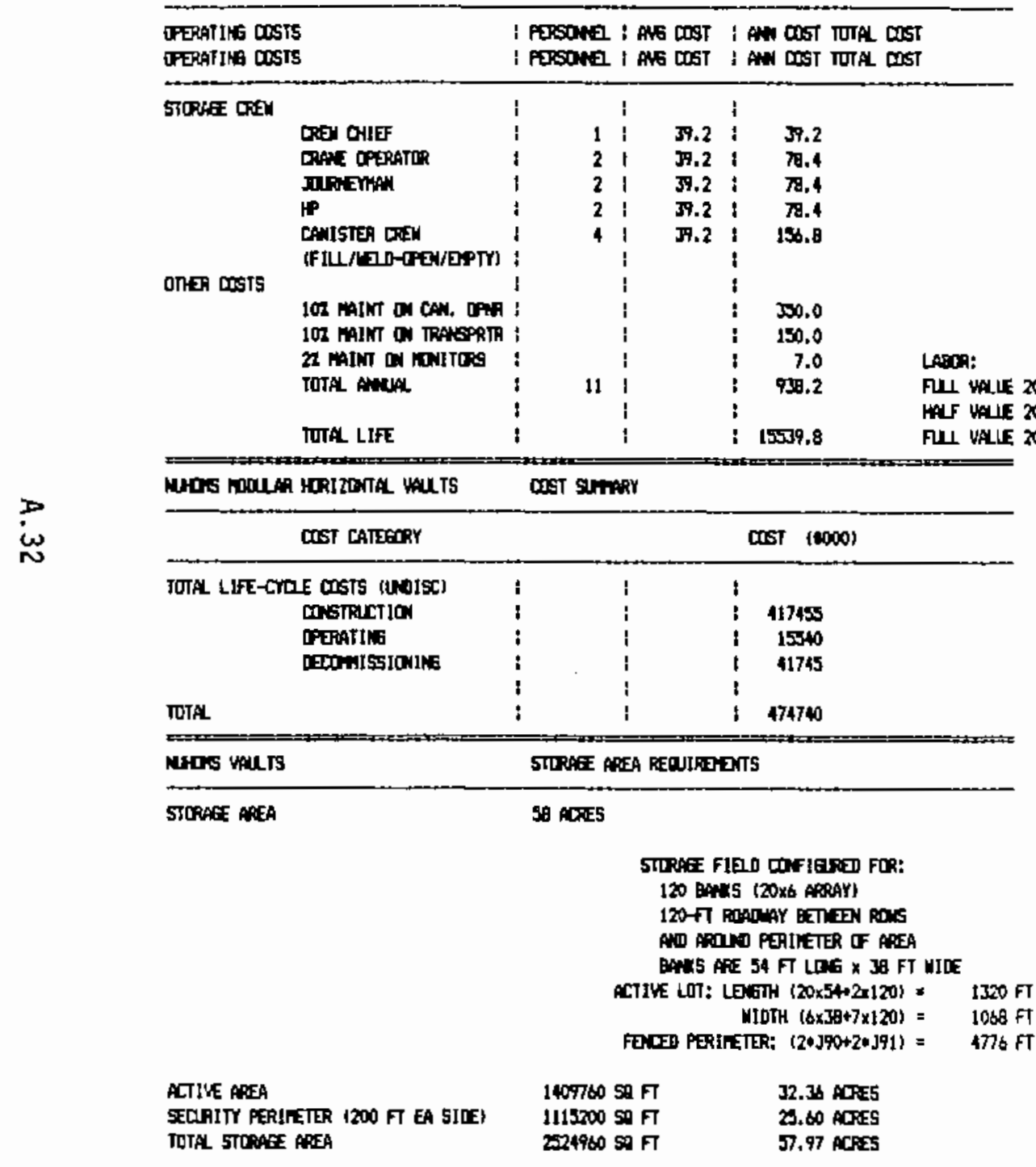


TABLE A.22. Cost/Area Estimate for Water Pool 0ption

\begin{tabular}{|c|c|c|c|c|c|c|c|c|}
\hline \multirow{3}{*}{$\frac{\text { STWAFE CPACIIY } 15,000 \mathrm{MTU}}{\text { TOTA DIFET UIST }}$} & \multicolumn{4}{|c|}{ 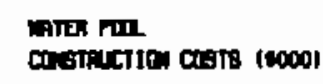 } & \multicolumn{3}{|c|}{$(-\infty \infty)$} & \\
\hline & \multicolumn{3}{|c|}{ DIR WLSTS } & \multirow{2}{*}{ 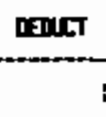 } & DtR MST 1 & \multirow[t]{2}{*}{ trofrat } & \multirow[t]{2}{*}{ TUTA Cost } & \\
\hline & 1 & & 1 & & : & & & \\
\hline Exconatias & 1 & 910 & 1 & & \multirow[t]{2}{*}{$!$} & & & 70,000 al M EITAMTIOO \\
\hline BACAFIL DISPESA & $i$ & 160 & $i$ & $i$ & & & & 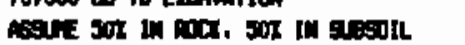 \\
\hline MUER CONARE & $i$ & & ; & $\mathrm{i}$ & & & & \\
\hline pm. & 1 & 10180 & i & i & & & & 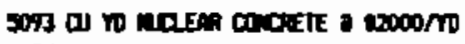 \\
\hline CAG PITB & i & 390 & $:$ & 1 & & & & 199. \\
\hline Dowe couns & $i$ & 100 & ; & i & & & & $50 \cdot \quad \cdot$ \\
\hline stapapo moxere & $i$ & 117 & ; & : & & & & ה \\
\hline ERIDEF CRAE, 75 TOW & $i$ & 700 & i & i & & & & \\
\hline POO CFowes (2) & $i$ & 1400 & $i$ & ; & & & & \\
\hline DREN BALS & i & 50 & i & $:$ & & & & \\
\hline MATER COL I PLAIF & $i$ & 1600 & $i$ & : & & & & \\
\hline HaC & i & 45 & i & i & & & & \\
\hline घE & $i$ & $\pi 0$ & $i$ & ; & & & & \\
\hline POA LINING & $i$ & 400 & $i$ & i & & & & \\
\hline 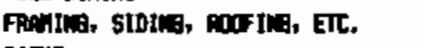 & $i$ & 1119 & $i$ & i & & & & \\
\hline Racrs & $i$ & & $i$ & ; & & & & \\
\hline Pen fa & $i$ & 18750 & i & $\mathrm{i}$ & & & & \\
\hline moe man gracas & $i$ & 750 & i & i & & & & \\
\hline IRASPQRTER \& CASX & $i$ & 1500 & $i$ & i & & & & \\
\hline 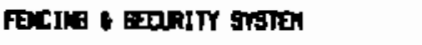 & $i$ & $\mathbf{x}$ & 1 & 1 & & & & FECDB : MTRITY SERINEAR FWOT \\
\hline & $i$ & & : & $\mathbf{i}$ & & & & \\
\hline 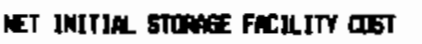 & $i$ & 51701 & $i$ & ; & $51 \pi$ & & & \\
\hline & $i$ & & i & i & & & & \\
\hline AWUR ADOHIOS (SON) & 1 & 0 & i & i & & & & \\
\hline & i & & ; & ; & & & 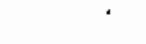 & \\
\hline TOTA STOAFE FACJLITY DIRET COOTS & $i$ & & i & ; & 51701 & & & \\
\hline & $i$ & & ; & ; & & & & \\
\hline 1NOIFET COFTS & 1 & & i & i & & & & \\
\hline COSETR ENO & $i$ & & $i$ & ; & & 642.600 & & \\
\hline WTE BFIX & $i$ & & $i$ & 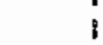 & & 6900,462 & & \\
\hline Gomilatery & $i$ & & $i$ & i & & 16311,079 & & \\
\hline Dent tost & 1 & & i & i & & 5700.87 & & \\
\hline & i & & 1 & ; & & & & \\
\hline 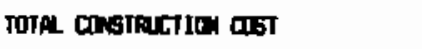 & i & & $i$ & i & & & 8rat & \\
\hline & & comiss & [ON] & costs & $(20000)$ & & & \\
\hline DECOMISSIOUIN DST & 1 & & : & : & 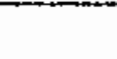 & & & \\
\hline 102 of castraction cost & $i$ & & $:$ & : & & & 8726 & \\
\hline
\end{tabular}




\section{IABLE A.22. (contd)}

MATER POM

OTJOATS COETS (1000)

\begin{tabular}{|c|c|c|c|c|c|}
\hline \multirow{2}{*}{ 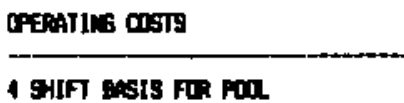 } & \multicolumn{5}{|c|}{ 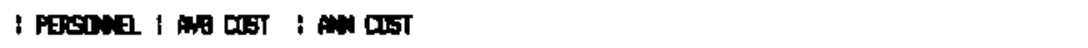 } \\
\hline & $i$ & i & ! & & \\
\hline Cis CHIE & 4 & 39 & 157 & & \\
\hline PH OFERTOA & {$[3$} & 39 & 510 & & \\
\hline Duremen & 9 & 37 & : & & \\
\hline mathigunce & $\mathbf{3}$ & 39 & 118 & & \\
\hline$\varphi$ & 5 & 39 & 19 & & \\
\hline & 1 & $\mathbf{1}$ & $:$ & & \\
\hline TUTA Coil & $\mathbf{H}$ & i & 1300 & & \\
\hline matM & $i$ & ; & 2017 & 10020 TUTA DRST & 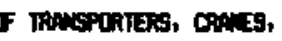 \\
\hline UTLITIES & 1 & $i$ & $2=0$ & consis & PLPIFICATION STIESS \\
\hline consumpes & 1 & ; & 650 & MINT: IOT G AEOTE, & II G OTH MSTR OSTI \\
\hline TOTR Anix & 1 & $:$ & 450 & & \\
\hline & $i$ & : & i & & \\
\hline TOTA LIFE & 1 & 1 & i 11500 & Ful Wue, 2003-202 & \\
\hline \multicolumn{6}{|c|}{ 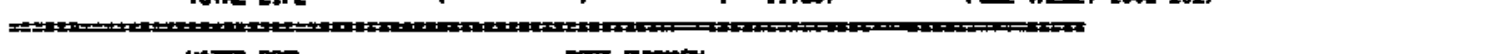 } \\
\hline mIER pon & & 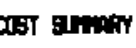 & & & \\
\hline COST CATEER: & & & Cust $(1000)$ & & \\
\hline \multirow{5}{*}{ 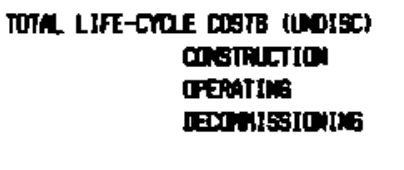 } & I & 1 & 1 & & \\
\hline & $\mathbf{I}$ & $i$ & | 8724 & & \\
\hline & 1 & 1 & 1119007 & & \\
\hline & $i$ & 1 & : $\quad 672$ & & \\
\hline & $i$ & i & & & \\
\hline TUTA & 1 & $:$ & 12159 & & \\
\hline \multicolumn{6}{|c|}{ BTOPEE APEA REWIRETIS } \\
\hline STLBAE AREA & 9 & ACPSS & & & \\
\hline DILD:G & 1 & PORE & & & \\
\hline ACTESO APEA & 0.2 & 9 ACEE & & & \\
\hline PEIIETER RAONAY & 1 & MOE & & & \\
\hline GERIT FERIKETR & 7 & acress & & FERIHETER & 2X24 LINEA FET \\
\hline TUIA AREA & 9 & ACRAS & & & \\
\hline
\end{tabular}


APPENDIX B

DESCRIPTIONS OF CANDIDATE CONCEPTS FOR MRS 
APPENDIX B

\section{DESCRIPTIONS OF CANDIDATE CONCEPTS FOR MRS}

This appendix provides summary information on and descriptions of the candidate storage concepts included in the body of this report. Much of this information, in an earlier form, appeared in the original concept evaluation report (Triplett and Smith 1984). (a) The information has been updated to represent current status, and two storage concepts--the water pool and the NUHOMS modular horizontal vault system--have been added.

The storage concepts in general are suitable for use with either integral spent fuel assemblies or consolidated fuel (with provision for separate storage of assembly hardware removed during fuel disassembly prior to consolidation). Consolidated spent fuel is assumed to be packaged in sealed canisters prior to storage. Similar canisters may be required for intact fuel assemblies; the canisters aid in radioactivity containment and in limiting the spread of contamination and resultant requirements for decontamination of equipment.

In most storage concepts the fuel is held in larger packaging arrangements: a cask, storage canister, drywell liner, or similar device. If bare, intact assemblies are stored in these devices, the interior of the storage device must be filled with an appropriate inert gas, adequately sealed, and monitored for atmospheric composition as well as for radioactive content. In some concepts, storage of bare assemblies may be questioned by NRC on the basis of requirements for multiple barriers against radioactivity release. If the fue 1 is contained in sealed and inerted canisters, inerting of the enclosing storage device may be optional, although monitoring for radioactive content of the contained atmosphere is required. The only exception is the water pool; storage of bare fuel assemblies is permitted under terms of the NRC Waste Confidence Agreement, again with adequate monitoring of the pool and surroundings and encapsulation of leaking assemblies when needed.

(a) References in this appendix are listed in Section 7 of the main report. 


\section{B.1 CONCRETE CASḰ}

The use of concrete casks placed in an open field provides a highly modular, quickly deployable and easily expandable storage system. A typical concrete storage cask is depicted in Figure B.1. These casks are approximately 10 to 12 feet ( 3 to 3.7 meters) in diameter and 22 feet (6.7 meters) high. A loaded cask may weigh over 200 tons (91 metric tonnes); it would probably be fabricated at the storage site. The casks selected for the

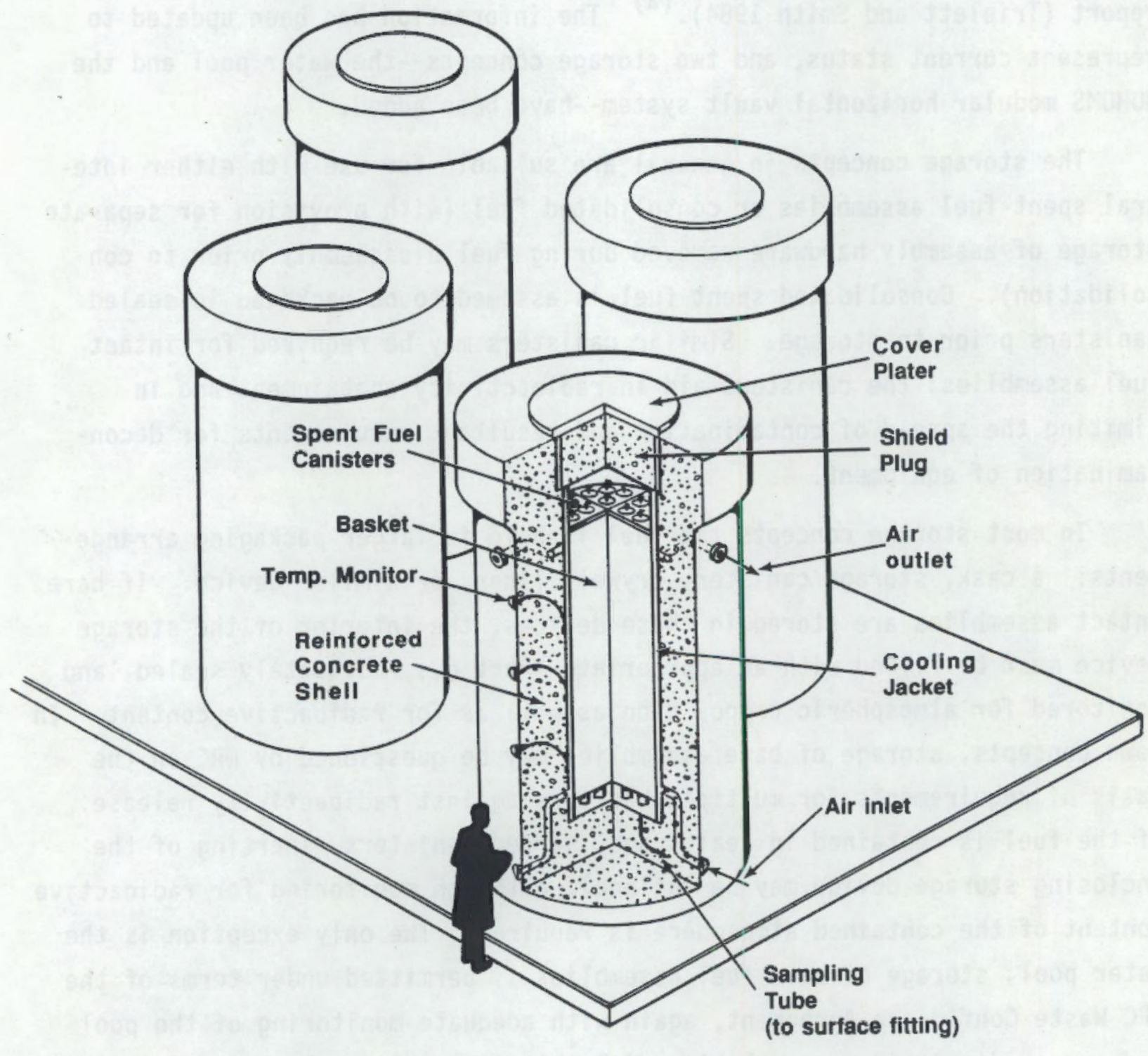

FIGURE B.1. Concrete Storage Cask 
evaluation were of 5 feet ( 1.52 meters) internal diameter (with an outer diameter of 12 feet [ 3.66 meters]), with a capacity of 249 -inch $(23 \mathrm{~cm})$ or 446 -inch $(15 \mathrm{~cm})$ spent fuel canisters, or three stacks of 5 waste drums each.

The concrete casks initially designed for use with the MRS facility (Parsons 1985) depended on heat conduction through the cask walls for c001ing; their capacity was limited by restrictions on concrete temperatures. The MRS architect-engineer has since conceptually designed a modified cask, with an air jacket surrounding the cask liner to provide heat removal by natural-draft air circulation. This cask was used in the concept re-evaluation. The thermal capacity of casks similar in design has been established by tests performed in prior years (Davis 1977; Anderson and Meyer 1980). The conceptual new cask of Parsons was assumed for this study.

At the center of the cask structure is a steel 1 iner extending the length of the cask cavity. The liner is surrounded by an air jacket used to remove heat from the stored fuel or waste. Reinforced concrete is cast around the liner and jacket, forming the bulk of the cask structure and providing both strength and radiation shielding. A basket within the cask liner holds the waste canisters within the cask. For this evaluation, three types of baskets were assumed: one for each size of spent fuel canisters, and another to hold the stacks of drums containing the volume-reduced assembly hardware resulting from fuel consolidation. Thermocouple tubes extend through the concrete shielding to the liner, and sample tubes communicating with the interior of the liner permit sampling the atmosphere within the cask. Air ducts extend through the concrete near the base of the cask, connecting to the air jacket of the liner. A similar set of ducts is provided near the top of the cask. In service, air is drawn through the bottom ducts by natural convection, rises through the air jacket where it removes heat from the cask liner, and exhausts through the upper ducts. This system provides efficient cooling of the cask, while maintaining the concrete shield within its allowable temperature range.

A concrete-filled steel shield plug fits into the top of the cask cavity. Steel welding flanges extending from the cask liner allow welding of 
a steel plate, covering the plug; to the liner; this provides leak-proof closure of the interior of the cask.

Heavy-duty transporters are provided to move the cask from its point of manufacture to the receiving and handling (R\&H) building, where the fuel or hardware waste canisters are loaded into the cask, and thence out to the storage yard.

At the R\&H building the cask is mated to an outloading port and is then filled with spent fuel canisters or stacks of hardware drums. The shield plug is then fit into the cask, and closure is made by welding a steel cover

plate to the welding flange extending from the liner. After testing the weld for integrity and leak-tightness, the cask is evacuated and filled with inert gas if appropriate; it is then moved by the transporter to the storage field.

The casks are stored on heavy concrete pads which provide a steady, level base for stability. In the reference concept included in the MRS Proposal to Congress, each pad is 37 feet (11.3 meters) in width and 18 inches (46 centimeters) thick, extending the width of the storage field. The casks are $\mathrm{placed}$ in two staggered rows on each pad, forming a triangular lattice with 5 feet ( 1.5 meters) minimum clearance between casks in any direction. Roadways are provided between the pads for use by the cask transporters.

\section{B.2 CONCRETE CASK-IN-TRENCH}

This concept uses concrete casks similar to those described above, except that the cask pads are constructed in trenches excavated into the storage field, the casks are placed on the pads, and the trench is then backfilled until only the top surfaces of the casks are above ground. This arrangement provides added protection for the casks, and reduces their visibility from offsite. These casks and their emplacement are described by Boeing (BEC 1983C).

In the cask-in-trench concept, cooling of the casks is mainly by conduction through the cask body and thence through the surrounding soil (air cooling could be provided as above, but would require complex ducting arrangements). Therefore, smaller concrete casks which hold less fuel are used in this concept, to reduce the heat dissipation requirements for the 
cask; also, the air jackets for the liners are dispensed with. Because the smaller size of the casks requires that more casks be used, storage area requirements are considerably larger than for the surface-mounted casks.

Retrieval of casks from the field is more difficult than with surfacemounted casks. Each cask must be excavated before it can be removed from the field. Excavation problems may limit random retrieval of casks, requiring instead the sequential removal of rows of casks.

A conceptual cask-in-trench arrangement is depicted in Figure B.2.

\section{B.3 METAL STORAGE CASK}

Metal casks have been used for the transportation and temporary storage of radioactive materials since the earliest days of nuclear operations in the 1940s. Currently metal casks designed for storage of spent fuel and HLW are available from several vendors; a list of typical storage casks is shown in Table B.1. Several of these casks have been used in DOE demonstration programs; some are in various stages of the NRC certification process, or are certified for, storage at licensed sites. One site, the Virginia Power Surry site, has been licensed for at-reactor storage using metal casks; the GNS Castor V-2l cask is currently being used for storage at this site.

Handling and storage of spent fuel and associated assembly hardware in metal casks is similar to that described earlier for concrete casks. A new cask, upon arrival at the MRS site, is held in the new cask storage area until required. It is then moved by transporter to a designated outloading port of the R\&H building and loaded with fuel. The dual lids to the cask are then attached and the cask is welded closed, inerted if appropriate, and the welds and internal seals are tested for integrity and leak-tightness. The cask is then returned to the transporter, moved to the storage field, and placed on a storage pad similarly to the concrete cask.

The metal casks can be stored in the vertical position, similar to concrete casks. Alternatively, if mounting skids or permanently installed cradles are provided, the casks can be mounted on the skids and placed in a horizontal position, or placed horizontally on the cradles, for storage. 


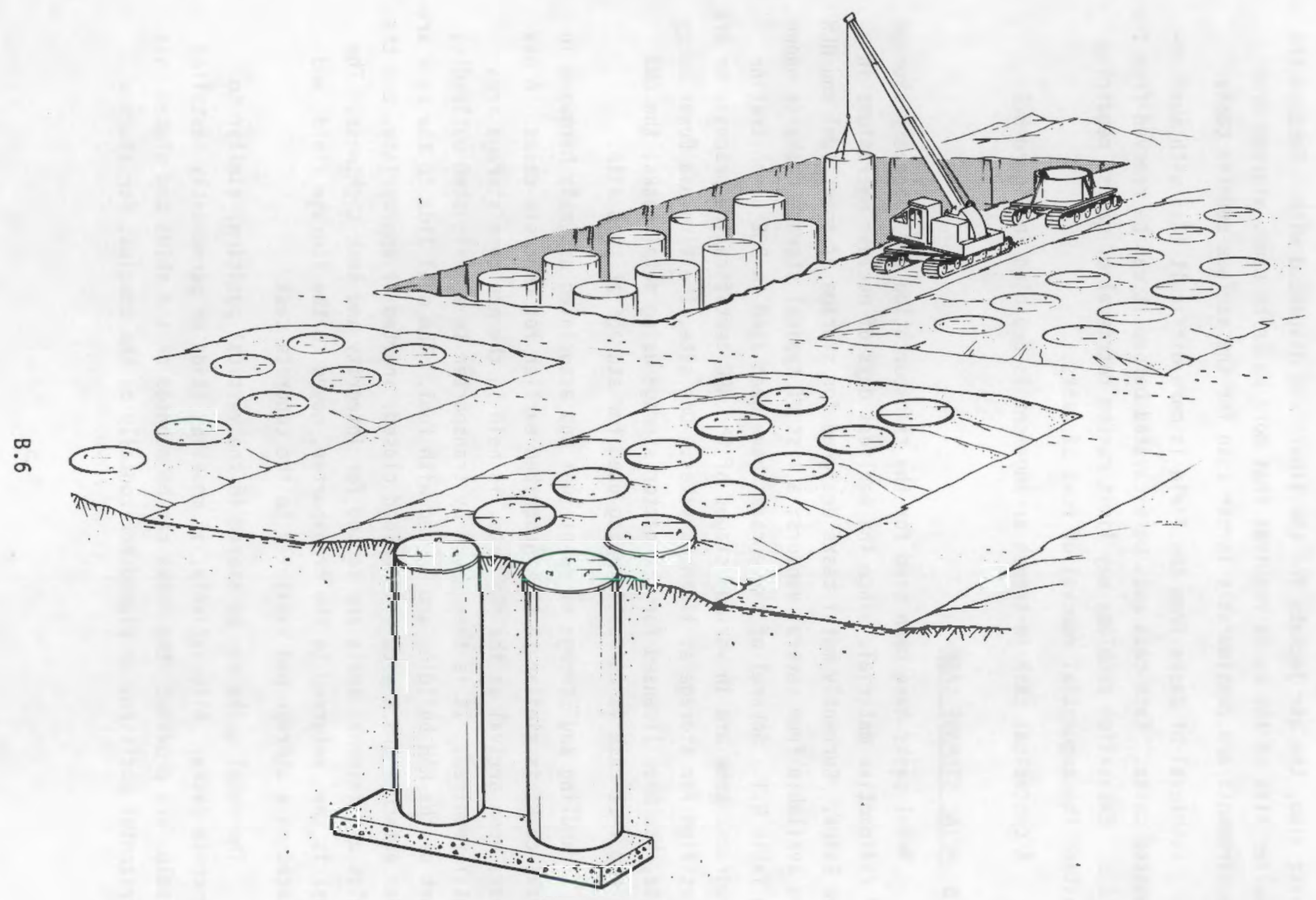

FIGURE B.2. Concrete Cask-In-Trench 
IABLE B.1. Characteristics of Typical Metal Storage Casks for Spent Fuel

\begin{tabular}{|c|c|c|c|c|c|c|}
\hline Manufacturer & Designation & $\begin{array}{l}\text { Capacity } \\
\text { Number of (a) } \\
\text { Assemblies }\end{array}$ & Body Structure & $\begin{array}{c}\text { Gamma } \\
\text { Shielding } \\
\end{array}$ & Neutron shielding & $\begin{array}{l}\text { Loaded } \\
\text { Weight } \\
\text { (Metric } \\
\text { Tons) } \\
\end{array}$ \\
\hline GNS & $\begin{array}{l}\text { CASTOR-1C } \\
\text { CASTOR-V/21 }\end{array}$ & $\begin{array}{ll}16 & \text { BWR } \\
21 & \text { PWR }\end{array}$ & Nodular Iron & Nodular Iron & Solid & $\begin{array}{r}80 \\
113\end{array}$ \\
\hline Transnuclear & $\mathrm{TN}-24$ & $\begin{array}{l}24 \text { PWR } \\
52 \text { BWR }\end{array}$ & Forged steel & Forged steel & Solid resin & 91 \\
\hline Mitsubishi & MSF-IV & $\begin{array}{l}24 \text { PWR } \\
52 \text { BWR }\end{array}$ & Stainless steel & SS/Lead & Liquid & 91 \\
\hline Westinghouse & $M C-10$ & 24 PWR & Forged steel & Forged steel & Solid & 91 \\
\hline Nuclear Assurance & $\mathrm{S} / \mathrm{T}$ & $26 \mathrm{PWR}(\mathrm{b})$ & Stainless steel & SS/Lead & Solid & 93 \\
\hline $\begin{array}{l}\text { Combustion } \\
\text { Engineering }\end{array}$ & $\begin{array}{l}\text { Dry-Cap-P24 } \\
\text { Dry-Cap-B60 }\end{array}$ & $\begin{array}{ll}24 & \text { PWR } \\
60 & \text { BWR }\end{array}$ & Forged Steel & Forged Steel & Solid external & $\begin{array}{l}91 \\
91\end{array}$ \\
\hline
\end{tabular}

(a) Capacity for integral assemblies. If fuel is consolidated, up to twice this number of equivalent assemblies may be accommodated.

(b) Larger baskets for the NAC S/T cask are undergoing licensing proceedings. The larger baskets, respectively, are designed for 28 consolidated fuel canisters (56 assemblies) and for 31 integral assemblies. Licensing of the 31 -assembly basket would require acceptance of burnup credit. 
Horizontal placement provides greater dynamic stability (against severe seismic stress, for example), at the expense of less efficient heat transfer to the surrounding air.

A typical metal storage cask is shown in Figure B.3.

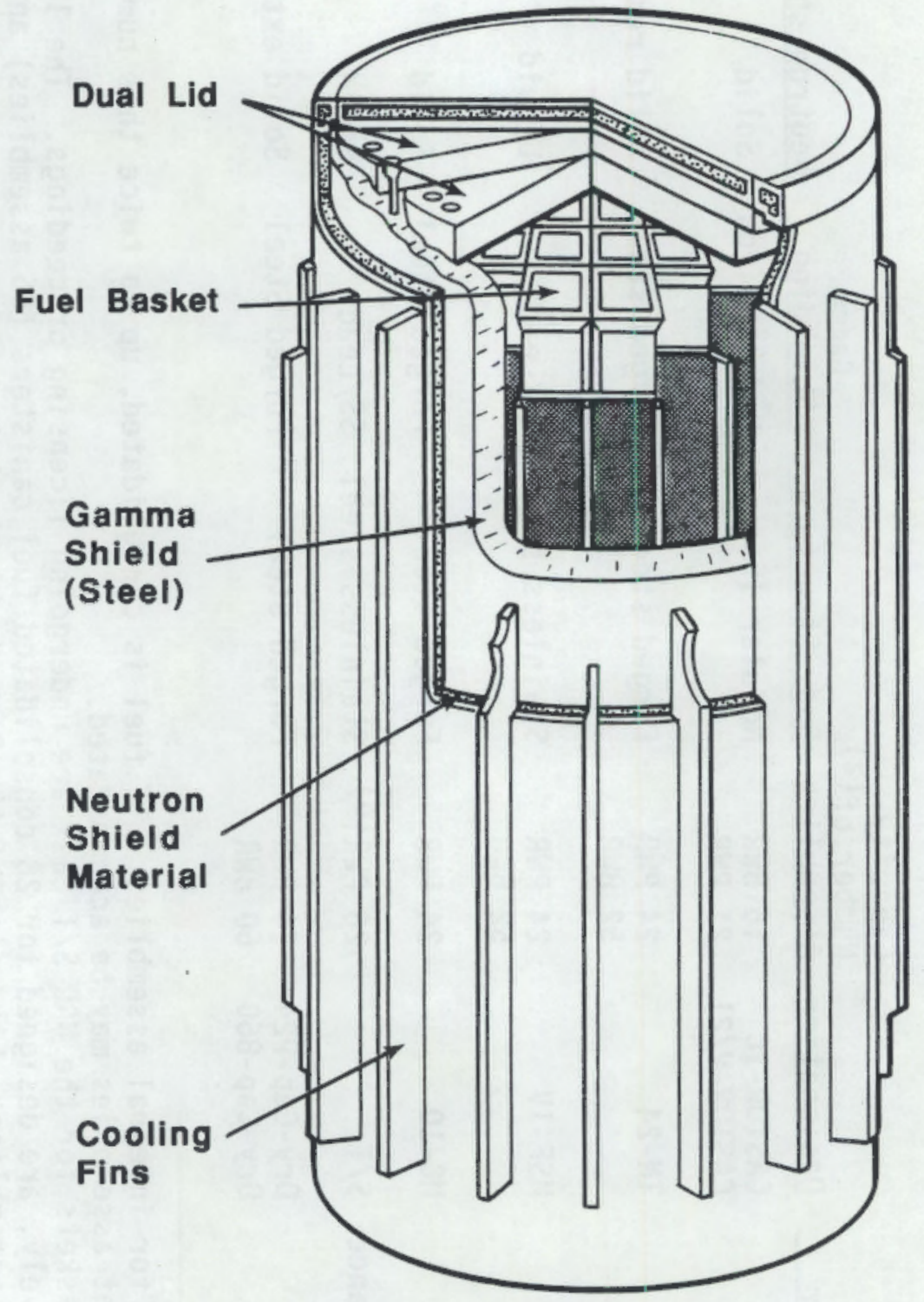

FIGURE B.3. Typical Metal Storage Cask 


\section{B.4 IRANSPORTABLE METAL STORAGE CASK}

The transportable metal storage cask concept is identical to that of the metal storage cask, except that the cask is assumed to be certified by NRC for both transportation and storage uses. Physically, the only difference in the concepts is the addition of impact limiters, personnel barriers (if needed) and other gear required for transport service In storage, it would appear as in Figure B.3. The cask designs must undergo generic testing as described in NRC Regulation 10 CFR 71, and must maintain certification for both services. As was mentioned in the body of this report, there is currently some question as to the feasibility of recertifying a cask for transport, under current regulations and assumptions, after extended periods of storage.

\section{B.5 FIELD DRYWELL}

The field drywell is one of the simplest, individually least costly, and rapidly deployable of the concepts evaluated for MRS storage. Storage in a drywell is totally underground, with only the lids of the individual wells at the ground surface. Dissipation of heat from the stored fuel is by conduction through the surrounding soil or rock.

Field drywells were the backup storage concept for the MRS design proposed in the DOE MRS Submittal to Congress (DOE 1987b). This design was the basis for the evaluation reported herein. Two basic drywell sizes were assumed; in each case, the drywell body is a steel 1 iner, about 21 feet (6.4 meters) in length, fabricated from carbon steel pipe with a wall thickness of 0.5 inches $(1.3 \mathrm{~cm})$. The pipe is close at the bottom with an end cap, at about 30 inches from the top the liner tapers to an increased diameter 4 inches $(10.2 \mathrm{~cm})$ larger than that of the main body. The tapered section holds a mating radiation shield plug inserted after the fuel/waste canister.

Drywells for spent fuel utilize liners 16 inches $(40.6 \mathrm{~cm})$ in outside diameter. Such a drywell will hold one 9 -inch $(23 \mathrm{~cm})$ square canister, containing a single PWR intact assembly or the consolidated fuel rods from two PWR or 5 BWR assemblies. Alternatively, it will hold two canisters 
six inches $(15 \mathrm{~cm})$ square (one BWR intact assembly per canister), held within a close-fitting stainless steel overpack nominally six by twelve inches (15 by $30 \mathrm{~cm}$ ) in size. The drywells containing assembly hardware drums are 30 inches $(76.2 \mathrm{~cm})$ in diameter, and are sized to hold a stack of five 55-gallon drums of waste held within a "skeleton" carrier.

Installation of the drywells is quick and simple. It has been estimated that, using two drilling crews, up to 10 drywells liners may be emplaced per day (WEC 1983C). The basic steps are:

- An oversize hole is drilled to the depth required for the 1 iner;

- A reinforced concrete collar is poured around the hole, to serve as a base for mounting the liner;

- The liner is installed and temporarily held in place by a clamping gauge;

- The empty space around the liner is filled with cement grout;

- Monitoring connections are made, and a temporary cover is placed on the drywell and $\mathrm{clamped}$ or welded in place.

A typical field drywell installation is shown in Figure B.4.

Emplacement and retrieval of fuel is accomplished using a rubber-tired, wheeled vehicle carrying a vertically mounted shielded transfer cask, bottomloading and bottom-discharging, for carrying the canisters to and from the storage field. A shielded apron beneath the cask provides radiation shielding for the gap beneath the cask; a "pocket" in this apron, beside the cask opening, holds a drywell shield plug. In operation, the transfer cask is loaded with a canister or drum stack and a shield plug at an outloading port of the R\&H building, the loaded cask is taken to the designated drywell, the drywell temporary cover is removed, and the bottom-opening cask port is aligned with the drywell. An annular shield is lowered to the drywell mounting ring. The canister is then lowered into the drywell, the transport vehicle is repositioned, and the shield plug is lowered into place. The emplacement crew then welds'a permanent cover on the drywell and connects the monitoring instrumentation. Unloading is essentially the reverse of these operations. 


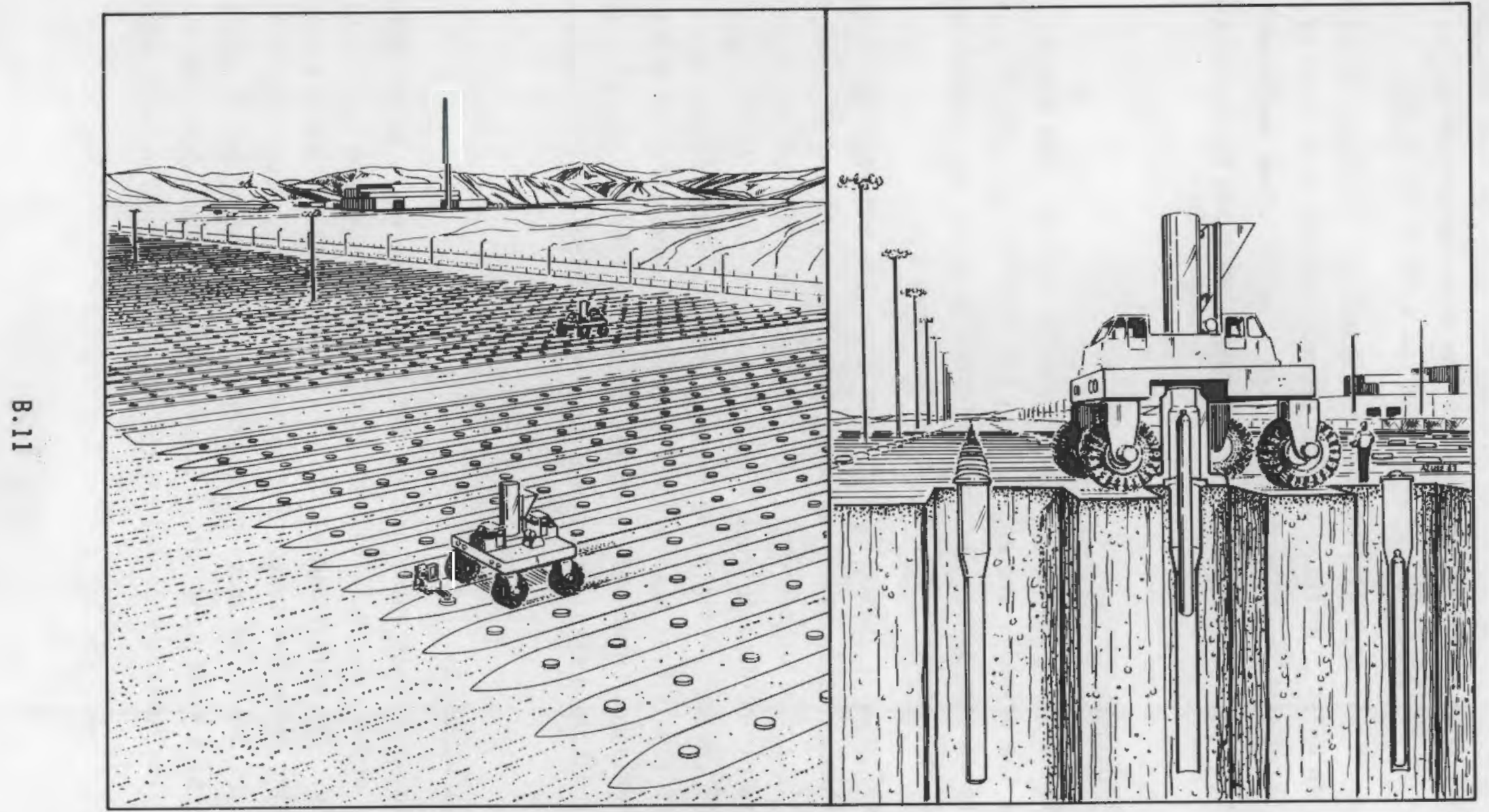

FIGURE B.4. Field Drywell Installation 
Spacing of the drywells is determined mainly by the heat-dissipation abilities of soils at the storage site. For this reason a drywell storage field may vary considerably inn area from one site to the next.

The grouted-in drywell liner may be subject to long-term corrosion, especially in moist climates. At some sites, cathodic protection of each liner may be advisable. Alternatively, construction of an earth berm to raise the drywell field above the extant water table may be feasible at some sites.

\section{B.6 TUNNEL DRYWELL}

A tunnel drywell storage system is similar to the field drywell system, except that the drywells are emplaced in the floor of a system of tunnels mined at the storage site. The entire installation is thus underground. A tunnel drywell conceptual site is shown in Figure B.5.

A tunnel drywell system is much more expensive and requires longer to construct than a field drywell system. Tunneling costs and disposal of mining spoils are major concerns. In addition, drilling of the drywells will almost certainly be done in rock formations, again adding to the cost. $\mathrm{Placement}$ of the waste within the tunnels provides added safety which may be important at some sites; however, the perceived "permanence" of the site may also be heightened. Maneuvering of the transport vehicles may slow emplacement speed; multiple openings may be required at high rates of emplacement or retrieval.

\section{B.7 OPEN-CYCLE VAULT}

In both appearance and function, the open-cycle vault is essentially an "air-cooled drywell field." Figure B.6 6 illustrates an open-cycle vault storage facility. The main floor of the vault building is a concrete shielding and supporting structure supporting an array of storage tubes similar to the drywell liners described above. The storage tubes extend into a vault beneath the main floor, and into a support plate mounted above the floor of the vault. The tubes are cooled by air which is drawn by natural convection 


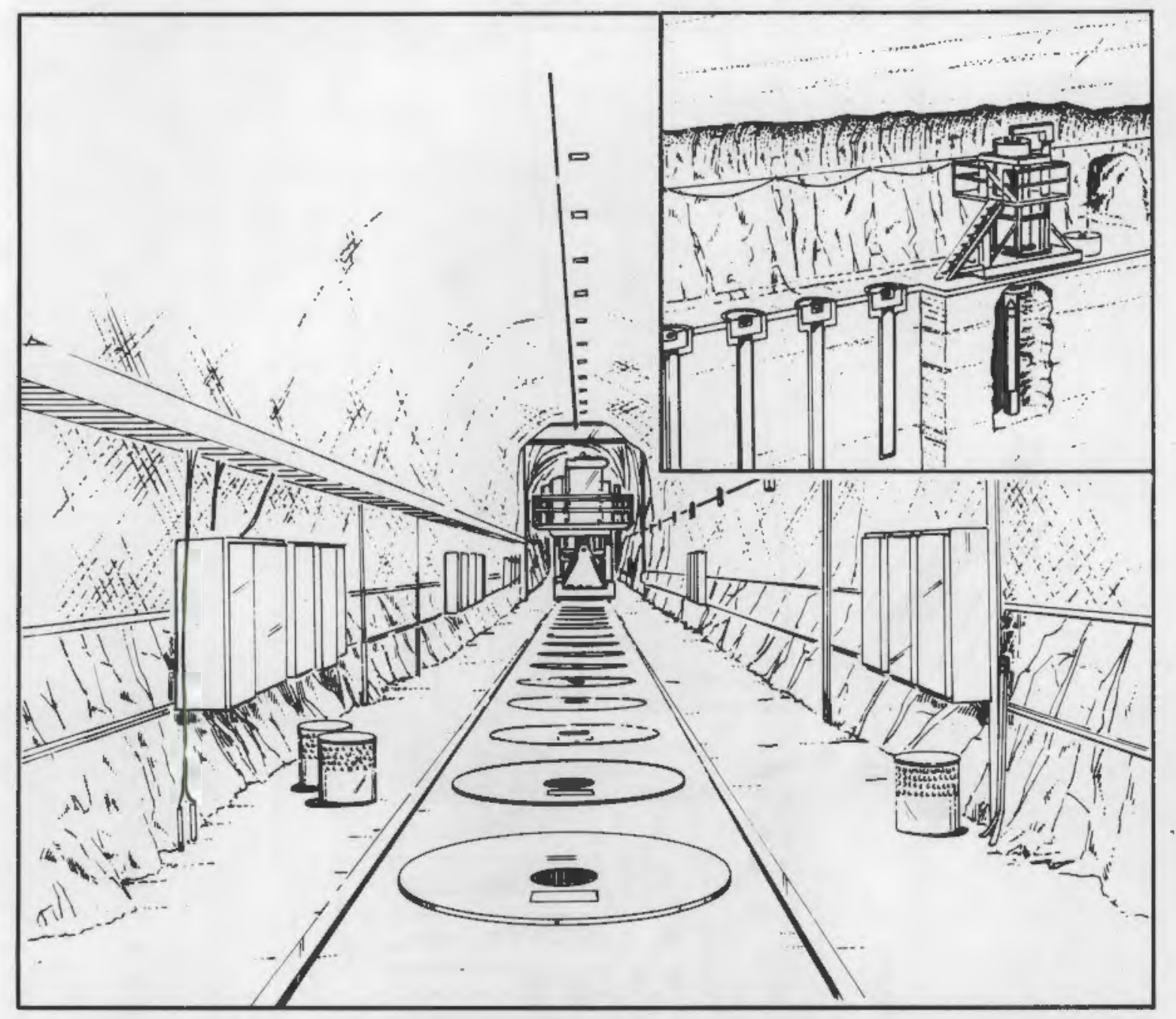

FIGURE B.5. Tunne1 Drywe11

into distributing ducts on the outside wall of the building, through the vault and around the storage tubes, and then exits up a stack abutting the centerline of the building. The figure indicates two mirror-image structures forming the vault building. This arrangement may be preferable for large installations (e.g., for reducing the likelihood of recirculation of cooling air in multi-building installations), but is amenable to several variations.

The re-evaluation of concepts based analyses for the open-cycle vault on the Boeing reference design (BEC 1983b), as did the initial evaluation. The Foster-Wheeler Corporation offers a commercially available vault design (F-W 1987) which, like the Boeing design, is based on a concept by the 


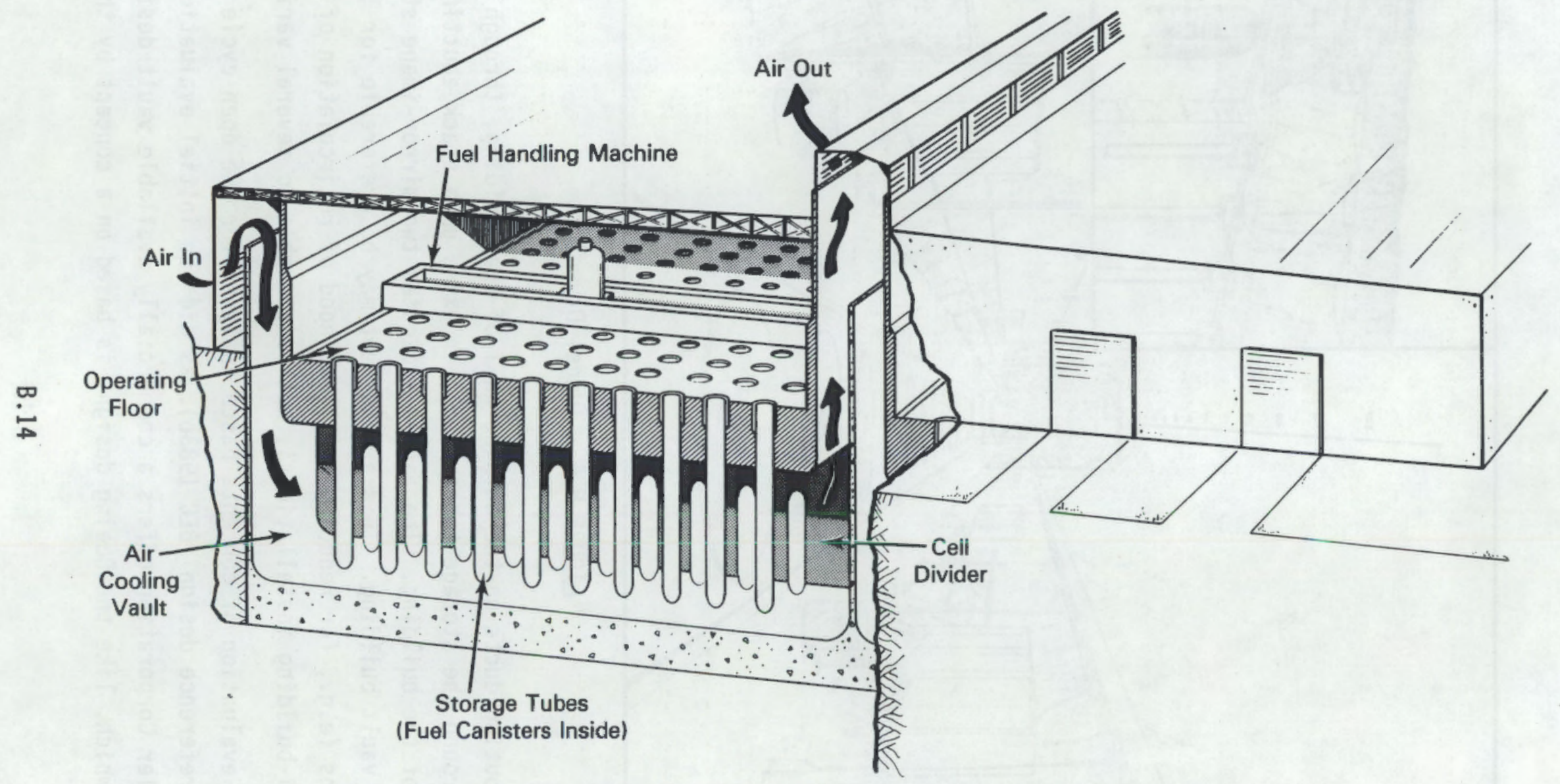

FIGURE B.6. Open-Cycle Storage Vault 
British General Electric Company. The Boeing and Foster-Wheeler designs are considered equivalent in their application to MRS.

The vault structure is modular in its design. Although the operating gallery above the main floor extends the length of each side of the building, the building structure and the subterranean vaults are constructed in segments which may contain storage for several hundred MTU of fuel each; the reference design (BEC 1983b) assumed 310 MTU per building segment, or 155 MTU per side. The transverse walls defining the segments strengthen the building, support the operating floor, and confine the air flow pattern through each vault. They also provide radiation shielding to construction crews while the facility is being expanded.

Each half of the operating floor is equipped with a fuel handling machine--essentially a transverse beam crane mounted a short distance above the floor on rails at the sides of the operating galley. The beam crane embodies a transversely-moveable carrier which in turn supports a shielded loading cask, functionally similar to the transfer cask described for field drywell use.

In loading of the vault, fuel or waste canisters are delivered from the MRS outloading port to a pickup area within the vault structure. In one possible arrangement, a cask car moves a multi-canister supply cask from the port into a cask well provided within and near the entrance to the vault structure; the transport mode may well vary depending on the degree of closecoupling between the R\&H building and the vault. From the supply cask a canister is loaded into the fuel handling machine, moved to and positioned over a storage tube, and the canister is lowered into the tube. A shielding plug is then positioned in the tube, and the tube cover is placed over the tube and welded in place.

The vault illustrated in Figure B.6 could also be constructed with the entire structure above the surface of the surrounding terrain, if the local water table is too near the surface to permit emplacing the vault in the ground. 


\section{B.8 CLOSED-CYCLE VAULT}

The closed-cycle vault concept, as evaluated herein, is described by the GA Technologies, Inc., report (Washington and Ganley 1984) and is shown in Figure B.7. The basic vault structure consists of a series of chevron-shaped (in plan view) concrete modules which are fitted together in rows and mounted on storage pads. Each module contains silos, or vertical holes, which serve as storage positions. Each of the silos is fitted with a carbon steel liner. Air jackets around each liner link with a plenum cast into the base of the module and with "hot air" return ducts to provide an enclosed, natural-draft air cooling system servicing all the silos in the module. Heat pipes, installed in the open sides of each module, connect with the hot-air return ducts and transfer their heat to the outside air, thus cooling the module in a completely closed system.

In loading a storage module, canisters of spent fuel or waste drums are placed into large storage canisters within the R\&H building; internal baskets in these canisters hold the contained fuel/waste canisters. The canisters are then moved in a silo loading machine, a shielded enclosure carrying both a storage canister and shield plug, to the vault complex (the GA report suggests a rail-cart transport system similar to that proposed for R\&H building operations). Positioning the loading machine over a designated silo, the machine then lowers the canister, rotates, and lowers a shield plug over the canister. Seal gaskets on the shield plugs close the silo openings, isolating the interior of the module from the outside air.

The storage canisters are sized to hold either spent fuel canisters or waste drums, by interchanging the internal baskets. A single canister, approximately 40 inches ( 1.22 meters) in diameter in the reference GA design, may be fitted with baskets holding 129 -inch $(23-\mathrm{cm})$ spent fuel canisters, 306 -inch $(15-\mathrm{cm})$ fuel canisters, or one waste drum stack. The storage canisters are closed with dual covers, and sealed using a combination of 0 -ring seals and seal welding. They may be inerted before storage, allowing their use with uncanistered fuel, if desired.

Retrieval of the storage canisters from the storage modules is essentially the reverse of the storage sequence described above. Following 

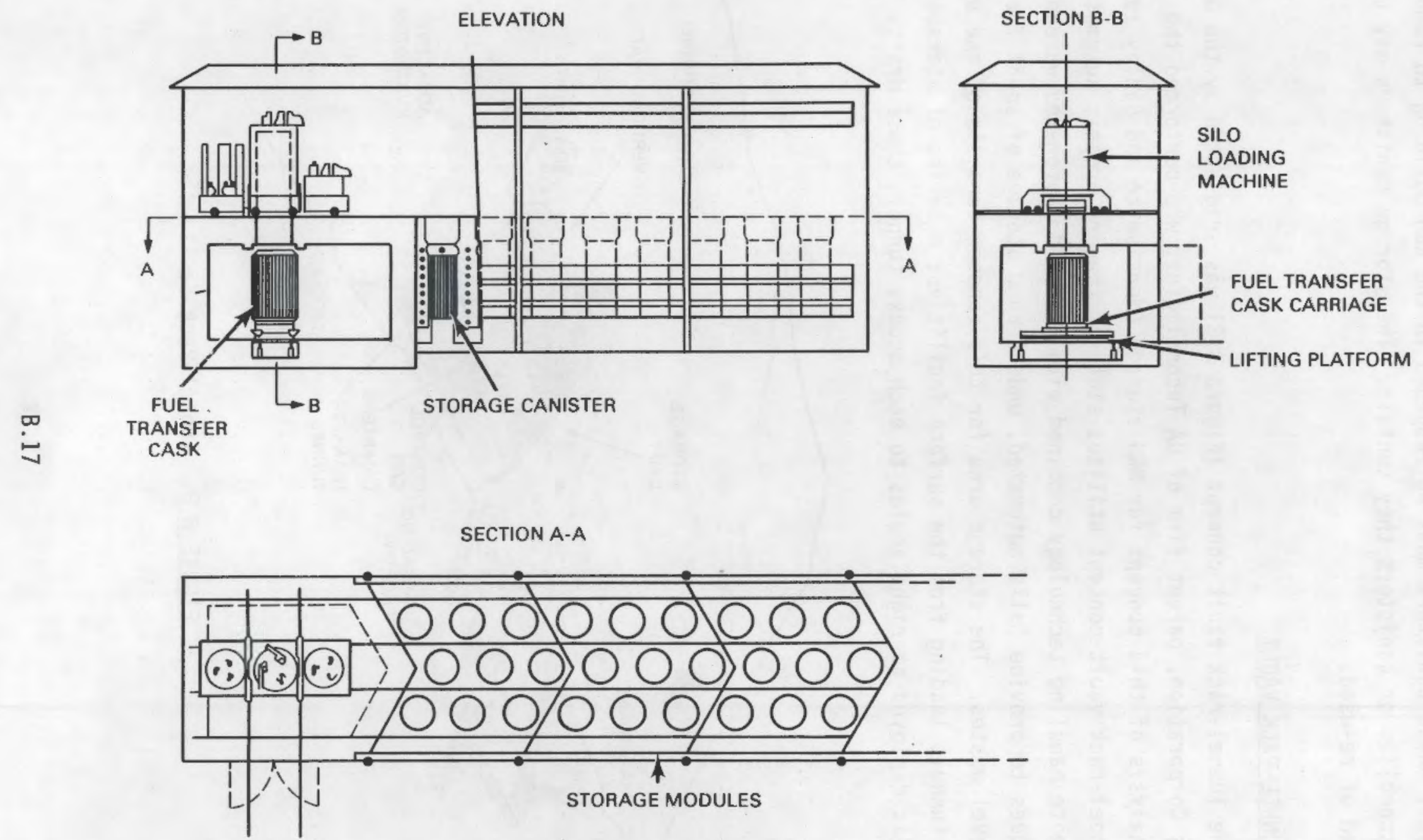

FIGURE B.7. Closed-Cycle Storage Vault 
retrieval, these canisters must be reopened in the $\mathrm{R} \& \mathrm{H}$ building to remove the fuel assemblies or canisters they contain. The storage canisters may then be scrapped of re-used.

\section{B.9 TUNNEL-RACK VAULT}

The Tunnel-rack vault concept (Figure B.8) was originated by the General Atomics Corporation, parent firm of GA Technologies, who performed the initial analysis of this concept for MRS storage (Morrisette and Ganley 1984). The tunnel-rack vault concept utilizes state-of-the-art process automation and remote handling technology combined with advanced, automated warehousing techniques to provide fully automated, underground storage of spent fuel and high-level wastes. The storage area for this concept consists of one or more access tunnels leading from the surface facilities; a series of storage drifts is deployed at right angles to each access tunne1; these drifts serve

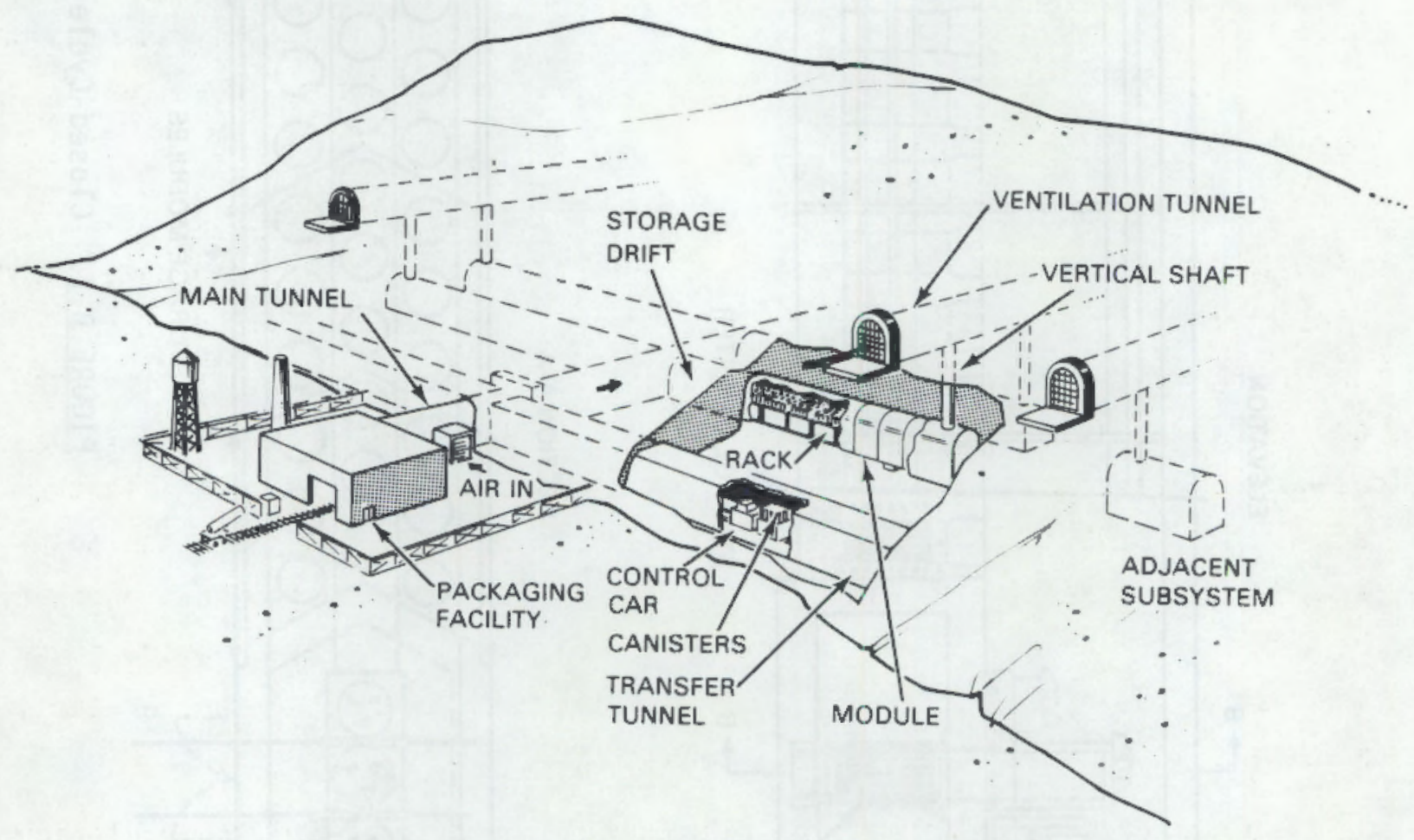

FIGURE B.8. Tunnel-Rack Vault 
as the storage rooms for the wastes. The access tunnels, if more than one is used, are connected to the interface facility by a transverse transfer tunnel.

The primary surface facility, connected to the tunnel system entrance by an airlock, is a building serving as an interface facility to the MRS Receiving and Handling building. The interface facility contains equipment for preparing the fuel and waste canisters for storage; it also contains a central control room for monitoring and control of the automated system operations, and a maintenance and repair area. This facility, designed for close coupling to the R\&H facility's loadout port, receives canistered fuel and assembly hardware directly from the R\&H port via a carrier mounted on an MRS rail cart, traveling through a shielded passageway (the facility can also function at a more remote location from the R\&H building, using transfer casks or equivalent). Within the interface facility, the incoming canisters are loaded into storage racks--open, rectangular stainless steel grid structures designed to hold the canisters while in storage. A typical rack design may hold up to 569 -inch $(23-\mathrm{cm})$ or 6 -inch $(15-\mathrm{cm})$ canisters, or somewhat fewer waste drum canisters.

After loading, a storage rack is placed on a rail-mounted carrier, which in turn is mounted on a transfer car. The transfer car then enters the access tunnel through the air lock, and travels, on rails provided on the tunnel floor, to the mouth of a designated storage drift. At this point the rack carrier leaves the transfer car and moves down the storage drift to a designated position. At this point lifting devices on the carrier lift the rack upward, move it laterally to the side wall of the drift, and then downward; a lip on the side of the rack engages a side-rail running the length of the drift wall, and the rack is suspended from the rail in its storage position, above the drift floor. The carrier then returns to the transfer cart, and to the interface facility, for another rack.

Cooling of the fuel in storage is provided by natural-draft circulation of air. Atmospheric air enters each access tunnel through an intake duct; it then flows through the access tunnels and the storage drifts, cooling the 
fuel. The heated air is returned to the surface through air-return shafts and drifts leading to the surface.

\section{B.10 WATER POOL STORAGE}

The storage of spent fuel in water pools is a we11-known technology; for over 45 years underwater storage of LWR spent fuel, at reactors and elsewhere, has been a near-universal practice. The NRC Waste Confidence Decision (49 FR 171) emphasizes the safety and reliability of pool storage. The storage pool at Morris, Illinois, has been licensed for commercial fuel storage under 10 CFR 72 (NRC 1981; NRC 1982).

For the present re-evaluation of MRS storage concepts, a single pool of 15,000 MTU capacity was chosen as a model, with a scenario calling for filling of the pool to capacity within a five-year period. Alternative concepts could include sequential building of segments of the pool, or the construction of several, smaller independent pools. Neither of the alternatives appeared appropriate for this analysis.

To date, no storage pool has been enlarged by the addition of pool segments. However, the pool at the Morris, Illinois, storage facility was designed to accommodate later additions if needed. A transfer gate was built into the end wall of the pool to allow pass-though of fuel assemblies to future pool segments, and the foundation area for a complete new pool segment was excavated, then backfilled, at the time the original pool was built. The pre-excavation was judged to be required to prevent possible rupturing of the initial pool wall, under its load of water, if heavy excavation work were performed adjacent to it. Presumably the same precautions would be needed at other sites where pool additions were contemplated. For the model pool evaluated in this report, the projected filling to 15,000 MTU fuel within five years appeared to preclude the opportunity for sequential additions due to insufficient construction time; at best only a two-segment pool could be completed, and this would require essentially continuous construction, with little saving relative to the cost for a single pool.

A series of smaller pools, rather than a single pool, could have some advantages in rapidity of loading and unloading fuel. However, each pool 
would need to be self-sufficient, with separate cask handling facilities, cooling and purification equipment, and added staff. Considerable cost additions would result.

The pool selected for evaluation has capacity for 15,000 MTU of consolidated and canistered spent fuel, plus assembled stacks of sealed drums containing assembly hardware. The pool is approximately 200 feet (61 meters) in length and 130 feet ( 40 meters) wide. It is equipped with poisoned highdensity racks; three rack sizes are required (for 9-inch and 6-inch canisters, and drum stacks). The pool is designed for operation as a dual facility, with "right" and "left" operating areas. Two fuel-handling cranes are employed; at the center the rails are mounted on a beam running the length of the pool superstructure and supported by columns extending down into the foundation beneath the pool floor. At the front end of the pool, two cask wells are provided to accommodate canister transfers to and from the R\&H building. Each well is provided with its own cask crane. A single equipment room is provided in a building adjunct adjacent to the pool; here the water cooling and purification equipment is located.

Spent fuel canisters and drum stacks from the R\&H building are loaded into a transfer cask (essentially a shipping cask for on-site use), moved to the pool, and immersed in the cask well. The canisters and/or drum stacks are unloaded and placed in temporary storage positions along the front wall of the pool; the cask is removed and returned. Subsequently the fuel handling cranes on each side move the packages to permanent storage positions further back in the pool.

Operations involved in unloading the pool are essentially the reverse of those for loading.

\section{B.11 MODULAR HORIZONTAL VAULT}

The modular horizontal vault concept is a relatively recently developed storage concept being marketed as the NUHOMS system by the NUTECH Corporation (NUTECH 1985). This concept has been licensed for use at the H. B. Robinson site of Carolina Power and Light Company and at the Duke Power Company's Oconee site. In October 1988, the Baltimore Gas and Electric Company 
announced its intent to utilize NUHOMS modules for spent fuel storage at its Calvert $\mathrm{C} 1$ iffs reactor site.

The NUHOMS concept employs a large, multi-assembly canister for containment of the fuel being stored. The at-reactor licenses are for storage of bare assemblies--seven PWR assemblies per canister for Robinson, and 24 per canister for Oconee. These canisters are stored in modular, concreteshielded horizontal vaults equipped with air passages for direct cooling by natural-draft circulation of air. Figure B.9 depicts a typical NUHOMS installation.

Each NUHOMS canister is constructed of a stainless steel cylinder, equipped with lead-shielded end pieces. One end piece welded to the canister body during fabrication; the other is welded on after filling the canister with fuel. The end shields reduce occupational exposure during filling and handling of the canisters, and reduce end-streaming radiation during subsequent storage in the horizontal modules. Baskets within the canisters hold the fuel assemblies or fuel canisters during storage; poison may be added to the basket if needed. The horizontal concrete modules are built in banks of several connected units, as shown in the figure. Thick concrete shields cover each face of the module structure, and concrete dividers between the modules provide both structural stability and additional shielding. Within each module a steel pipe sized to accommodate one canister is held horizontally, closed at one end and opening to the front face of the module. Space between this pipe and the concrete structure forms an air jacket for cooling the canister; air ducts draw air, by natural-draft circulation, in from the front face of the module, into the internal air space and around the support tube, and out through a duct on the top face.

Handling of the NUHOMS shielded canister requires use of a transfer cask sized to fit the canister, equipped to accommodate a hydraulic ram entering through the bottom end shield; the entrance hole is sealed by a shield plug when not in use.

In use at MRS, two sizes of shielded storage canisters are assumed: a canister of 48.5-inch $(123 \mathrm{~cm})$ diameter, capable of holding 12 9-inch or 30 6-inch spent fuel canisters, and a 50-inch canister sized for three stacks of 


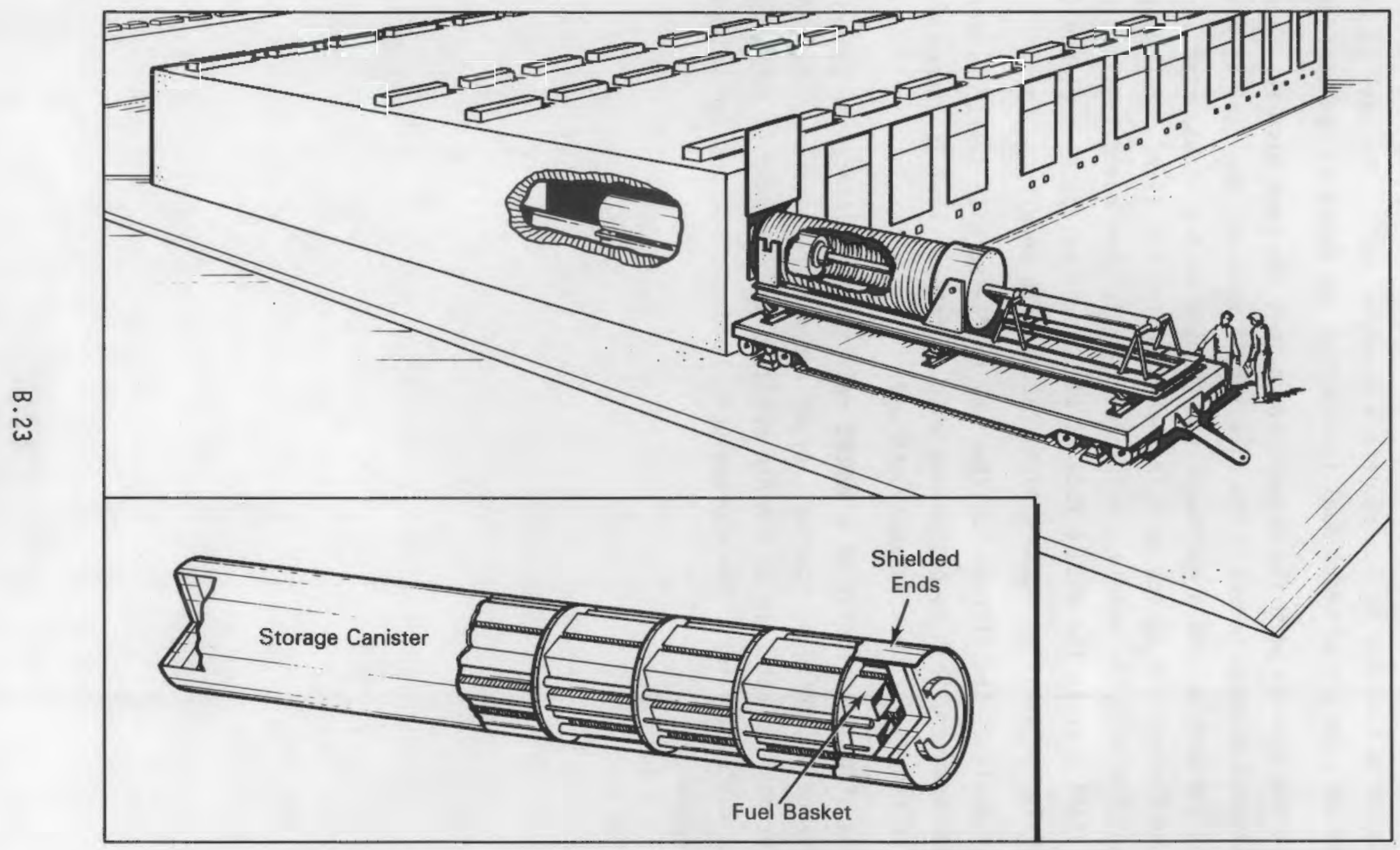

FIGURE B.9. Modular Horizontal Vault 
five waste drums each. Each canister is loaded within the R\&H building outloading ce11, the top shielded end piece is welded in place and tested, and the completed canister is loaded into a transfer cask. The cask is closed, mounted on a dedicated heavy-haul transporter and moved to the storage yard.

In the storage yard the transporter aligns the cask with the opening in a horizontal storage module. The cask lid is removed, the cask is moved against the module, and a hydraulic ram mounted on the transporter is inserted through the access hole in the bottom of the cask. The ram pushes the canister into the module cavity. The cask is then moved away and closed, and a steel door on the module face is closed and welded to a flange connecting to the canister support pipe, closing the module cavity.

If desired, the storage canister may be filled with inert gas before storage; however, this is not needed when canistered fuel is stored. It would be needed for bare assembly storage.

The steps for removal of a NUHOMS canister for storage are essentially the reverse of those for storing. After removal from storage, the storage canister must be returned to the R\&H building and reopened to retrieve the fuel or waste canisters; the storage unit is then discarded for salvage or LLW disposal. 


\section{DISTRIBUTION}

No. of

Copies

\section{OFFSITE}

2 DOE/Office of Scientific and Technical Information

14 Office of Civilian Radioactive Waste Management

U.S. Department of Energy

1000 Independence Ave., SW

Washington, DC 20545

ATTN: J. Carlson

R. Blaney

W. Danker

M. Frei

H. Hale

C. Head

T. Isaacs

S. Kale

K. Klein

C. Kouts

N. Moon

G. Riling

J. Saltzman

R. Stein

G. Rodriguez

Yucca Mountain Project Office

U.S. Department of Energy

P.0. Box 98518

Las Vegas, NV 89183-8518

G. Beeman

Battelle, Pacific Northwest

Laboratories

370 L'Enfant Promenade,

Suite 900

Washington, DC 20024-2115
No. of

Copies
A. Dennis
Sandia Nationa] Laboratory
Division 6311
A1buquerque, NM 87105
2 Roy F. Weston, Inc.
955 L'Enfant Plaza, SW
Washington, DC 20024
ATTN: J. Richardson
A. Papadopoutos

\section{ONSITE}

2 DOE Richland Operations Office

C. E. Collantes

E. C. Norman

32 Pacific Northwest Laboratory

J. F. Fletcher (22)

R. E. Heineman

R. W. McKee

D. R. Payson

R. I. Smith

Publishing Coordination

Technical Report Files (5) 
